\title{
A SOLUÇÃO dE PLANCK PARA O PROBLEMA DA RADIAÇÃO DO CORPO NEGRO (PRCN) E O ENSINO DA FÍSICA QUÂNTICA
}

\author{
ERIKA REGINA MOZENA
}

COMISSÃO EXAMINADORA:

PROF. DR. JOÃO ZANETIC - IF/USP (orientador)

PROF. DR. CÁSSIO COSTA LARANJEIRAS - IF/UnB

PROF. DR. LUIS CARLOS DE MENEZES - IF/USP

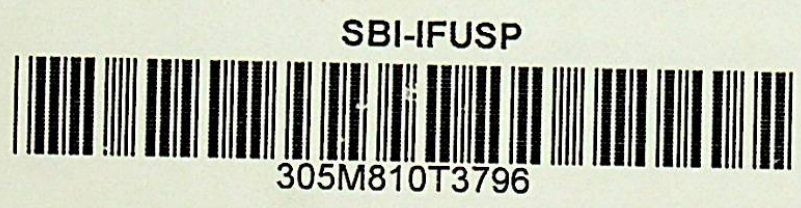

Dissertação apresentada ao Instituto de Física e à Faculdade de Educação da Universidade de São Paulo como parte dos requisitos necessários à obtenção do título de Mestre em Ensino de Ciências - modalidade Física.

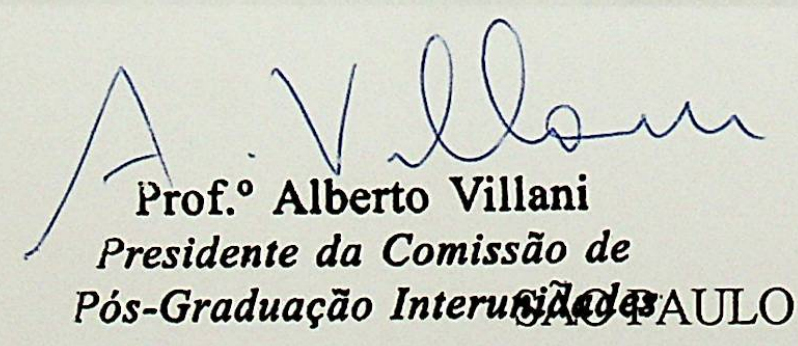

INSTITUTO DE FÍSICA Serviço de Biblioteca e Informação Tombo: $\frac{3796}{e x \cdot 1}$ 
FICHA CATALOGRÁFICA

Preparada pelo Serviço de Biblioteca e Informação do Instituto de Física da Universidade de São Paulo

Mozena, Erika Regina

A Solução de Planck para o Problema da Radiação do Corpo Negro (PRCN) e o Ensino de Física Quântica.

São Paulo, 2003

Dissertação (Mestrado) Universidade de São Paulo Instituto de Física. Departamento de Física Experimental

Orientador: Prof. Dr. João Zanetic

Área de Concentração: Ensino de Ciências

Modalidade Física

Unitermos: 1. Ensino de Física Quântica;

2. História da Ciência;

3. Radiação do Corpo Negro;

4. Planck. 
A história da fisica não é somente a seqüência de descobertas experimentais e observações, seguidas pelas suas descrições matemáticas: é também uma história dos conceitos. Para um entendimento do fenômeno a primeira condição é a introdução de conceitos adequados.

Werner Heisenberg

Os jovens deveriam ler História da Ciência porque freqüentemente o ensino universitário é extremamente dogmático, não mostrando como ela nasceu. Por exemplo, um estudante pode facilmente imaginar que o conceito de massa seja simples e intuitivo, o que não corresponde à verdade histórica.

Mário Schenberg 
Ao André, o grande e verdadeiro amor da minha vida. 


\section{MEUS MAIS SINCEROS AGRADECIMENTOS}

Ao André, que além de compartilhar todos os aspetos da minha vida, também auxiliou de maneira ímpar na redação deste, principalmente na elaboração e redação dos apêndices.

À minha querida familia: pais Angelo e Izabel; irmãos Áurea, Michele, Helen, Djo e Bel; os cunhados Heitor, Rogério e João e meu querido sobrinho Ícaro. Agradeço a eles simplesmente por tudo e por me compreenderem nesse período complicado do mestrado. Também gostaria imensamente de agradecer à minha querida prima Marisa que corrigiu tão gentilmente $o$ abstract para mim.

À minha segunda familia: Beatriz, João, Odete e Nelson, pelo apoio, incentivo e pelo carinho com que fui recebida, propiciando-me um fecundo pouso para reflexão e trabalho.

Ao meu querido orientador João Zanetic, pela opção e predileção original pelo tema, pela sua força, entusiasmo, pelas longas conversas realmente agradáveis e sua liberdade de trabalho.

À CAPES, pelo imprescindível e importante apoio financeiro.

A todos os professores do nosso programa, com especial carinho para o Menezes, meu primeiro contato na pós-graduação e com o qual aprendi muito sobre o que é ser um educador.

Aos colegas do grupo de estudos do João Zanetic e aos amigos do corredor de ensino, especialmente à querida amiga Cristina, Luciana, Zé, Alexandre, Bete, Armando, Lilian, Graziela, Walkíria, Marcos, Bete Gaúcha, Cristian e Marcelo.

À cara Lola, que durante a minha estada em São Paulo, ofereceu-me o conforto, a dedicação e o carinho de um verdadeiro lar.

Ainda não posso deixar de expressar minha gratidão, carinho e reconhecimento à minha orientadora de iniciação científica na graduação Maria José $\mathrm{P}$. Monteiro de Almeida e aos amigos do grupo de Estudos em Ciência e Ensino (gepCE-Unicamp). Eles proporcionaram de uma maneira muito agradável e importante a minha iniciação no mundo da pesquisa em ensino de física. 


\section{SUMÁRIO}

CONSIDERAÇÕES INICIAIS.

APRESENTAÇÃO.

I - BREVE HISTÓRIA INTERNALISTA

1. A RAdiaÇão térmica e o Problema da RAdiaÇão do CoRPo NEGRo (PRNC) ................................. 12

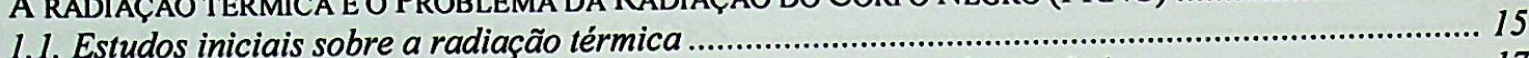

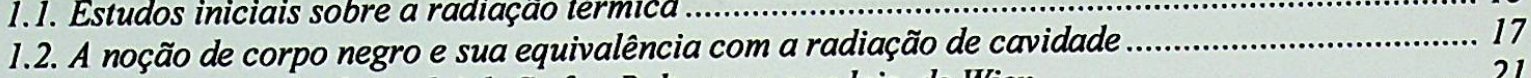

1.3. Primeiros resultados: a lei de Stefan-Boltzmann e as leis de Wien ............................................. 21

1.4. Alguns desenvolvimentos experimentais envolvendo os primeiros resultados do estudo da radiação

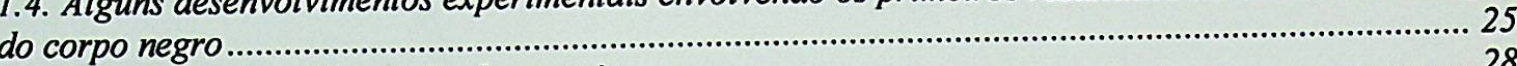

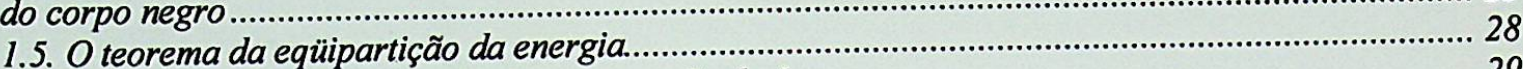

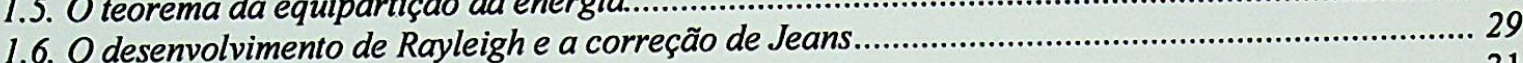

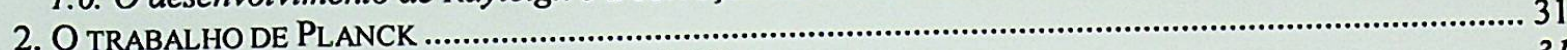

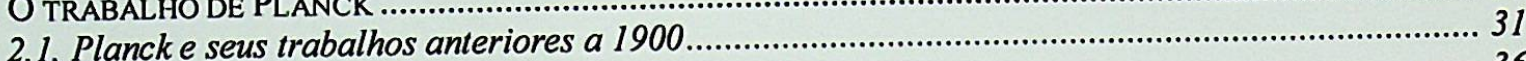

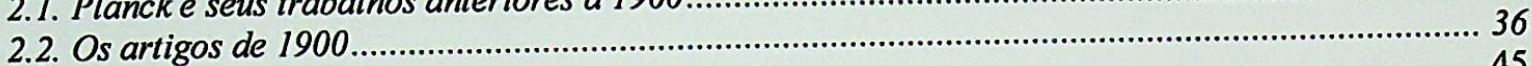

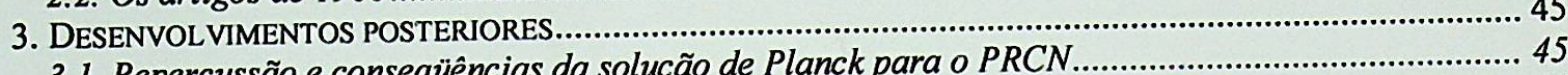

3.1. Repercussão e conseqüências da solução de Planck para o PRCN ……………............................ 45

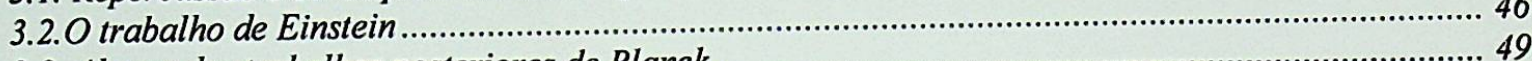

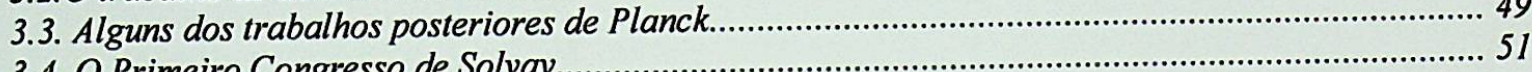

3.4. O Primeiro Congresso de Solvay.

II - O FUNCIONAMENTO DA CIÊNCIA, A EDUCAÇÃO CIENTÍFICA E OS MANUAIS

DIDÁTICOS: DISTORÇÕES PARA A FISICA E O SEU ENSINO.................................................. 53

1. O REFERENCIAL TEÓRICO: A EPISTEMOLOGIA DE THOMAS S. KUHN …................................................. 53

1.1. A origem de um novo paradigma: a fisica quântica ……............................................................ 57

2. A CONCEPÇÃO SOBRE A CIÊNCIA PROMULGADA PELA EDUCAÇño CIENTÍFICA E OS MANUAIS DIDÁTICOS 59

3. A HISTÓRIA E A FILOSOFIA DA CIÊNCIA NOS MANUAIS DIDÁTICOS: ADULTERANDO A FISICA E O SEU ENSINO

4. PREPARANDO OS FUTUROS CIENTISTAS E PROFESSORES DE FISICA TAMBÉM PARA EVENTUAIS

REVOLUÇÕES: DIMINUIÇÃO E FLEXIBILIZAÇÃO DOS CONTEÚDOS, HISTÓRIA E FILOSOFIA DA CIÊNCIA. ......... 68

III - O ENSINO DO PROBLEMA DA RADIAÇÃO DO CORPO NEGRO E OS TEXTOS ACADÊMICOS.

1. DifiCULdADES DE ABORDAGEM DO PROBLEMA DA RADIAÇÃo DO CORPO NEGRO (PRCN) .................... 74

DO PROBLEMADARADACAOD DORPONEGRO(PRCN)

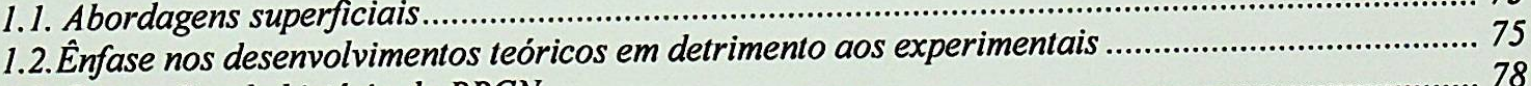

1.3. Distorções da história do PRCN

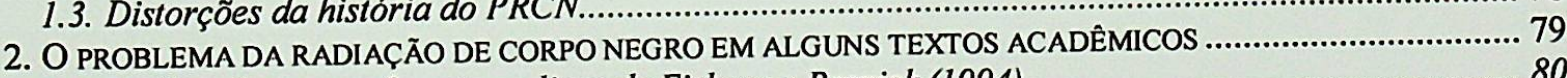

2.1. Análise do texto referente ao livro de Eisberg e Resnick (1994) .................................................8 80

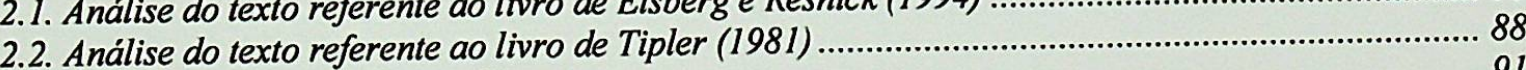

IV - UM EXEMPLO DE INOVAÇÃO: A DISCIPLINA EVOLUÇÃO DOS CONCEITOS DA FÍSICA

1. A DISCIPLINA E SUA DINÂMICA ……...............

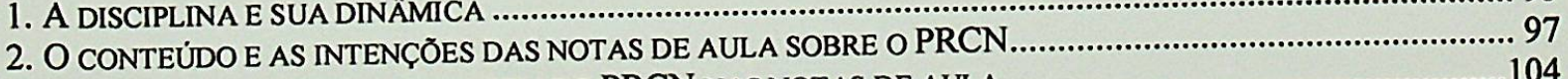

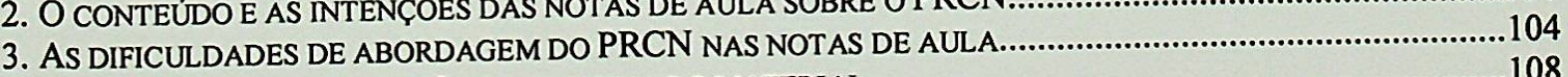

4. SUGESTÕES PARA AMPLIAÇÃO E MELHORIA DO MATERIAL ....

5. APROFUNDANDO MELHOR O SIGNIFICADO E OS OBJETIVOS DA DISCIPLINA …....................................110

V - DISCUSSÕES FINAIS: APONTANDO ALGUNS DOS PROBLEMAS DO ENSINO DO PRCN E AMPLIANDO SEU POTENCIAL PEDAGÓGICO

VI - BIBLIOGRAFIA 
APÊNDICE I - DERIVAÇÃO DA LEI DE KIRCHHOFF

APÊNDICE II - O DESENVOLVIMENTO DE BOLTZMANN

APÊNDICE III - ESTUDO DE UM OSCILADOR HARMÔNICO NAS PAREDES DE UM CORPO NEGRO

APÊNDICE IV - ANÁLISE COMBINATÓRIA 139

APÊNDICE V - ATIVIDADE DE ESTUDO E APLICAÇÃO. 141

APÊNDICE VI - TRABALHOS E AVALIAÇÕES 


\section{RESUMO}

Este trabalho tem por objetivo estudar e propor alternativas para o ensino do Problema da Radiação do Corpo Negro (PRCN) e sua solução estabelecida por Planck. Para alcançar esse empreendimento, nosso estudo foi dividido em quatro partes:

- Compilamos, a partir da literatura e da leitura de alguns originais, um breve histórico com várias deduções fisicas da radiação térmica, do PRCN e sua solução por Planck. Com isso, além de ganharmos embasamento para as análises subseqüentes, também disponibilizamos um texto para o aprendizado do PRCN por estudantes de fisica, que procura conjugar aspectos conceituais, matemáticos, históricos e metodológicos.

- Traçamos, baseados na epistemologia de Thomas Kuhn, um panorama da educação científica, cujo principal instrumento é o manual didático. Observamos que na busca por síntese e para manter e propagar a visão cumulativa, linear, objetiva e racional da ciência, os manuais didáticos distorcem a própria fisica e o seu ensino.

- Analisamos a abordagem de dois textos sobre o PRCN de manuais didáticos de Física Moderna, tendo como pano de fundo algumas das dificuldades de abordagem do PRCN apontadas pela literatura.

- Contrapomos os problemas das abordagens dominantes a outra que consideramos inovadora: aquela utilizada em parte da disciplina "Evolução dos Conceitos da Física" do Instituto de Física da USP - São Paulo, quando ministrada pelo orientador desta dissertação.

Com relação ao ensino do PRCN e sua solução por Planck, a análise de alguns textos pretensamente didáticos sobre $o$ assunto nos mostrou que a utilização desse conteúdo para ensinar a quantização de energia não está atingindo seus objetivos. Ao utilizar abordagens superficiais e sintéticas, esses textos promovem distorções para a fisica, o fazer científico e a sua história.

A análise da abordagem do PRCN bastante detalhada na disciplina "Evolução dos Conceitos da Física", cuja estrutura se aproxima mais aos nossos anseios pedagógicos em contraposição às abordagens dominantes que analisamos, nos mostrou que os problemas apontados podem ser minimizados.

A partir desses resultados e da nossa pretensão em formar pesquisadores e professores autônomos, críticos, reflexivos e que possam realmente dominar e aplicar o conhecimento fisico, sugerimos, então, a ampliação da discussão sobre a radiação térmica e o PRCN para outras disciplinas e áreas do ensino de física. 


\section{ABSTRACT}

The purpose of this work is to study and propose alternatives to the Black Body Radiation Problem (PRCN in Portuguese) and its solution established by Planck. In order to reach this undertaking, our study has been divided in four parts:

- We have compiled a brief historic with a lot of physical deductions of the thermal radiation, the PRCN and its Planck's solution, using the literature and some original papers. This way, we gained structure for the subsequent analysis, and we disposed a text for the physics students learn the PRCN, which intend to conjugate the conceptual, mathematical, historical and methodological aspects.

- By using Thomas Kuhn epistemology, we have traced a scientific education panorama, whose main instrument is the didactic manual. We observed that, on its search for synthesis and to maintain and to propagate the cumulative, linear, objective and rational science view, these manuals distort the proper physics and its learning.

- We have analyzed the PRCN approach present in two Modern Physics didactic manuals, resting this analysis on the difficulties of the PRCN approach pointed by the literature.

- We compared the problems in the dominant approach to another which we consider an innovation: the approach present in part of the Physics Institute (at USP-São Paulo) class "Physics Concepts Evolution", when it is ministered by this thesis adviser.

The analysis of some didactic texts showed us that their objectives (to teach the energy quantization) haven't been reached. When superficial and synthetic approaches are used, these texts distort Physics, the scientific doing and its history.

The analysis of the detailed PRCN approach present in the class "Physics Concepts Evolution", whose structure is closer to our pedagogic wishes compared to the analyzed dominant approach showed us that the pointed problems could be minimized.

From these results and our pretension to graduate autonomous, critic and reflexive researchers and teachers, which could actually dominate and apply the physics knowledge, we suggest the increase of the thermal radiation and the PRCN discussions to others class and areas of physics teaching. 


\section{CONSIDERAÇÕES INICIAIS}

Almejamos fornecer algumas explicações sobre os objetivos deste trabalho. Em primeiro lugar, gostaríamos de deixar muito claro que este não é um trabalho histórico, de maneira que não estamos mostrando nada de novo sobre o PRCN e justamente por essa razão não recorremos à leitura de textos originais da ciência (embora efetuamos a leitura de alguns), mas sim a historiadores que desenvolveram trabalho sério sobre $o$ assunto. Nosso principal intento em delinear neste um breve histórico sobre o PRCN é fornecer subsídios para se entender e pensar a história e a própria Física envolvida no problema, mostrando assim a produção científica dos historiadores de uma maneira didática para um público específico e não leigo, visando atingir principalmente estudantes de Física.

Também é importante o leitor estar atento ao fato de que os desenvolvimentos matemáticos e a própria denominação de constantes que utilizamos neste trabalho foram muitas vezes simplificados para a construção de um texto didático e coerente em si. Por exemplo, muitos cientistas ao trabalharem com um mesmo fenômeno, ou grandeza fisica, podem designá-lo de maneira diferente a outros; procuramos, assim, em cada desenvolvimento deste trabalho, utilizar as grandezas fisicas que julgamos mais apropriadas para a compreensão dos fenômenos, mesmo que estas não tenham sido as utilizadas historicamente em textos originais.

Também este não pretende ser apenas um trabalho em defesa do uso da história da ciência no ensino. Sobre esse assunto existem muitos outros trabalhos, não nos cabendo nem mesmo aqui citá-los. Nosso objetivo é diverso. Queremos criticar as abordagens utilizadas no ensino do PRCN, pautadas nos manuais didáticos, e mostrar, com o exemplo da disciplina "Evolução dos Conceitos da Física", uma abordagem histórico-filosófica que segue a nossa proposta pedagógica para o ensino de fisica. 


\section{APRESENTAÇÃO}

Neste trabalho procuramos analisar, avaliar e propor alternativas para o ensino do Problema da Radiação de Corpo Negro (PRCN) e sua solução por Planck, assunto normalmente introdutório nas disciplinas de Física Moderna.

A solução do PRCN por Planck é considerada por muitos como o início da Física Quântica, pois seu trabalho, nessa abordagem, é aquele no qual pela primeira vez foi estabelecida a quantização da energia. Seguindo essa linha de raciocínio, uma gama de manuais didáticos, com conteúdo pouco variado, apresenta o PRCN com o objetivo explícito de ensinar e exemplificar a quantização da energia. No entanto, uma análise mesmo superficial destes relatos, mostrando excessivas distorções da história da ciência, além da deturpação e omissão da termodinâmica do trabalho de Planck, coloca o assunto como importante tema de estudo e reflexão para a pesquisa em ensino de fisica.

Certos da necessidade e importância deste trabalho, como um mergulho inicial no tema e na sua complexidade, desenvolvemos um estudo sério, mas ainda superficial, da história e da física da questão. Como resultado, apresentamos no capítulo I um breve histórico do PRCN, tendo como referencial a epistemologia de Thomas Kuhn, pensada principalmente a partir da leitura de "A Estrutura das Revoluções Científicas".

Baseados nessa maneira de interpretar o funcionamento da ciência, discutida brevemente no capítulo II, passamos a analisar a educação científica, a qual procura divulgar e consolidar os paradigmas vigentes, além de manter e propagar idéias arraigadas sobre o fazer científico. Como o treino científico é realizado principalmente através da resolução de exercícios semelhantes e modelados da mesma forma, este é principalmente pautado nos manuais didáticos. Ainda no capítulo II discutimos a maneira como esses textos sintetizam e simplificam o conhecimento fisico, além de distorcerem a história mantendo uma concepção de ciência objetiva, cumulativa, racional e livre de conflitos internos.

Apresentamos, também no capítulo II, nossa visão ideal de educação científica, cujo objetivo se baseia na formação de profissionais em ciência (pesquisadores e professores) autônomos, críticos e reflexivos. Almejamos, de certa maneira, prepará-los para eventuais futuras crises e revoluções científicas. Acreditamos que isso seja possível se o ensino da ciência selecionar, flexibilizar e problematizar melhor seus conteúdos, diminuindo a importância dos manuais didáticos e minimizando seus efeitos que julgamos e apontamos como nocivos. 
Tendo como referencial nossa discussão sobre o funcionamento da educação científica, seus problemas intrínsecos e as principais dificuldades de abordagem do PRCN apontadas pela literatura, procuramos analisar no capítulo III como esse tema é tratado nas disciplinas de Física Moderna. Como a educação científica é pautada nos manuais didáticos, a avaliação das abordagens sobre o PRCN em dois livros nos forneceu um bom diagnóstico desse ensino. Verificamos que este, normalmente, é pautado em abordagens superficiais e sintéticas, as quais ocasionam distorções para a ciência, o fazer científico e sua história.

No capítulo IV contrapomos as abordagens dominantes a outra inovadora, que se aproxima mais da nossa proposta pedagógica discutida no capítulo II. Trata-se da abordagem histórico-filosófica empreendida para o PRCN como conteúdo de parte da disciplina "Evolução dos Conceitos da Física" do Instituto de Física da USP - São Paulo, quando ministrada pelo orientador deste trabalho. Procuramos mostrar, através da exposição da disciplina e análise das notas de aula, os objetivos específicos e as estratégias através das quais esta procura enriquecer o ensino da ciência.

Retomando e encerrando as análises desenvolvidas ao longo deste trabalho, empreendemos no capítulo $\mathrm{V}$ as discussões finais, delineando os principais problemas que detectamos nos manuais didáticos sobre o PRCN e sugerindo, baseados na proposta da disciplina "Evolução dos Conceitos da Física", a modificação e ampliação da utilização desse tema, que é rico demais para se restringir à introdução do estudo da física moderna. 


\section{I - BREVE HISTÓRIA INTERNALISTA}

Gostaríamos de iniciar este trabalho com algumas considerações sobre a história da física que nós estamos pensando. Existem diversas concepções de história e não é nosso objetivo discuti-las aqui ${ }^{1}$. Embora julgamos que os aspectos sociais não devam se separar dos aspectos internos na (re)construção da história da ciência, considerar os aspectos sociais envolvidos em nosso tema histórico de estudo consistiria sozinho em um objeto de pesquisa, dada a escassa literatura sobre o assunto.

Dessa forma, optamos por discutir de maneira breve, porém com maior profundidade em relação ao material que há disponível em língua portuguesa, uma breve história epistemológica interna ${ }^{2}$ do Problema da Radiação do Corpo Negro (PRCN), através da qual almejamos exemplificar o nosso ideal por uma história da ciência "que procura descobrir, analisar e avaliar como os problemas surgiram, foram investigados, tiveram solução ou desapareceram de cena". 3

Embora saibamos que não atingimos plenamente os objetivos citados acima, acreditamos que cada uma das nossas tentativas contribui para isso.

\section{A radiação térmica e o Problema da Radiação do Corpo Negro (PRNC)}

Por volta da metade do século XIX, houve um grande desenvolvimento industrial e bélico, de maneira que a indústria siderúrgica expandiu-se de forma acelerada. Contudo esse desenvolvimento esbarrava num fator de dificil controle, porém necessário para melhorar a qualidade da produção de aço: precisar a temperatura dos altos fornos siderúrgicos ${ }^{4}$. Um termômetro comum, e mesmo os termopares pouco fariam face às elevadas temperaturas dessas fornalhas ${ }^{5}$.

Uma possível solução para esse problema seria utilizar a radiação eletromagnética (luz) proveniente do forno para a determinação da temperatura. Já era observado o fato de que com o aumento da temperatura, a cor do forno se modificava, passando desde o

\footnotetext{
${ }_{2}^{1}$ Esse assunto está discutido com bastante profundidade em Zanetic (1989), p. 104.

${ }^{2}$ Podemos dizer simplificadamente que a história epistemológica é aquela pautada em alguma concepção filosófica, ou seja, pautada em uma visão sobre o funcionamento da ciência. Entendemos também por história interna da ciência aquela na qual só são levados em consideração os aspectos internos e intrínsecos dos desenvolvimentos científicos, sem a análise das condições sócio-econômicas.

${ }^{3}$ Zanetic (1989), p.129.

${ }^{4}$ Osada (1972), p. 48.

${ }^{5} \mathrm{~A}$ temperatura necessária à produção de aço é da ordem de $1500{ }^{\circ} \mathrm{C}$, que pode variar conforme a liga.
} 
vermelho, depois para uma tonalidade alaranjada, amarelo, até atingir uma coloração branco-azulada.

Hoje sabemos que um forno ou qualquer objeto aquecido emite um amplo espectro contínuo de radiação eletromagnética (luzes de diversas cores, inclusive não visíveis) e a esse fenômeno damos o nome de "radiação térmica". Conforme a temperatura desse corpo aumenta, a emissão mais intensa ocorre para comprimentos de onda diferentes, daí a mudança da cor que vemos.

Quando o objeto tiver atingido a temperatura do corpo humano, o pico de radiação estará no infravermelho longo [não visível]. O corpo humano irradia também ondas de rádio, mas os comprimentos de onda mais curtos e mais energéticos são sempre mais fáceis de serem detectados e, portanto, tornam-se os mais acentuados.

Assim que o objeto atingir a temperatura de aproximadamente $600^{\circ} \mathrm{C}$, o pico de radiação se deslocará para o infravermelho curto. Nesse ponto, entretanto, a pequena quantidade de radiação do lado mais energético do pico torna-se particularmente significativa, pois ela atinge a região da luz vermelha visivel. A cor do objeto torna-se, então, vermelho-escura.

Este vermelho constitui apenas uma pequena porcentagem da radiação total emitida, mas como somos capazes de vê-lo, damos-lhe toda a atenção e dizemos que o corpo está "aquecido ao rubro".

À medida que a temperatura subir ainda mais, o pico de radiação continua a deslocar-se para comprimentos de onda mais curtos e cada vez mais luz visível de comprimentos de onda mais e mais curtos é emitida. Embora a luz vermelha seja a mais irradiada, luzes de coloração alaranjada e amarela são acrescentadas em quantidades menores, mas significativas. À temperatura de $1.000^{\circ} \mathrm{C}$, a mistura de cores se nos apresenta de cor alaranjada, e lá pelos $2.000^{\circ} \mathrm{C}$, de cor amarela. Isso não significa que apenas a luz alaranjada seja irradiada a $1.000^{\circ} \mathrm{C}$ e apenas amarela a $2.000^{\circ} \mathrm{C}$. Se esse fosse o caso, seria realmente de esperar que a seguir o objeto se apresentasse como "aquecido ao verde". Mas não podemos esquecer que o que vemos são misturas de luzes.

No momento em que $6.000^{\circ} \mathrm{C}$ for atingido (a temperatura da superfície do Sol), o pico de radiação estará no amarelo visível e estaremos recebendo grande quantidade de luz visível, desde o violeta até o vermelho. Toda a gama de luz visível do espectro se nos apresenta com cor branca, de sorte que o Sol está "aquecido ao branco".

Para objetos ainda mais quentes do que o Sol, todos os comprimentos de onda de luz visível continuam a ser irradiadas e em quantidades ainda mais apreciáveis. $\mathrm{O}$ pico de radiação desloca-se, porém, para o azul, de modo que a mistura não é perfeitamente balanceada a nossos olhos e o branco tem um matiz azulado.

Tudo isso acontece para os objetos que quando aquecidos emitem o "espectro contínuo", irradiando luz numa ampla faixa de comprimentos de onda. Certas substâncias, em condições apropriadas, irradiarão luz de apenas determinados comprimentos de onda. $\mathrm{O}$ nitrato de bário irradia luz verde quando aquecido e é por isso usado em fogos de artificio. 
Podemos então dizer que está "aquecido ao verde". (Asimov, 1990, p.83-

84)

Não necessariamente a cor que vemos é aquela com emissão mais intensa, pois esta última pode ocorrer para um comprimento de onda que não enxergamos, já que nossos olhos são adaptados para ver apenas uma pequena faixa do espectro ${ }^{6}$.

Esse fenômeno não ocorre apenas em altos fornos de siderúrgicas. Todos os corpos emitem radiação térmica (radiação emitida devido a sua temperatura). Para os corpos "frios" (à temperatura ambiente, por exemplo) a maior parte da sua radiação térmica está na região do infravermelho, cuja percepção não é possivel aos nossos olhos. Por essa razão não vemos esses corpos no escuro. Só podemos vê-los devido à luz visível (proveniente do sol ou lâmpadas, por exemplo) que é refletida por eles; embora seja importante salientar que existem alguns materiais que absorvem luz de comprimentos de onda fora da região do visível, emitindo em seguida luz visível, como o pó que reveste as paredes das lâmpadas fluorescentes.

Chamamos a vasta gama de comprimentos de onda que um corpo emite de espectro. Podemos representar graficamente, para determinada temperatura, a intensidade da emissão de um corpo em função do seu espectro. Isso é que o chamaremos de curvas de distribuição de emissão.

Os fenômenos descritos, além de envolverem o eletromagnetismo devido à emissão de radiação eletromagnética, também são objeto de estudo da termodinâmica. Todo corpo absorve e emite radiação do meio que o cerca. Absorvendo a radiação que sobre ele incide, o corpo está absorvendo energia. Para que a energia interna do corpo não aumente progressivamente até o infinito, o corpo necessita doar energia, o que é feito na forma de energia eletromagnética também. Quando um corpo está mais frio que o meio que o cerca, ele irá se aquecer, pois a taxa de absorção de radiação do corpo é maior que a taxa de emissão (ou seja, o corpo absorve mais energia por unidade de tempo do que emite). No equilibrio térmico (ambiente e corpo na mesma temperatura) as taxas de absorção e emissão são as mesmas para o corpo.

$\mathrm{O}$ equilibrio de temperaturas entre os corpos se dá pela condução e também pela radiação de calor. A condução de calor é determinada pelo gradiente de temperatura em cada ponto enquanto a radiação de calor num ponto é caracterizada por vários fatores: pela direção, intensidade,

\footnotetext{
${ }^{6}$ Podemos situar os limites do espectro visível entre 430 e $690 \mathrm{~nm}$. Contudo é possível enxergar comprimentos de onda ligeiramente fora desses limites, caso a luz seja suficientemente intensa.
} 
freqüência e polarização de todos os raios que passam pelo ponto, sendo que estes raios são independentes entre si. ${ }^{7}$

\subsection{Estudos iniciais sobre a radiação térmica}

Historicamente o estudo da radiação térmica desenvolveu-se mais profundamente com a análise da luz solar e o surgimento da espectroscopia. Podemos afirmar que essa última nasceu no momento em que Newton decodificou a decomposição da luz branca através do prisma.

Durante o século XIX a espectroscopia ganhou força especialmente depois que Joseph von Fraunhofer (1787-1826) inventou o espectroscópio, que produzia espectros por um acoplamento entre luneta ocular e prismas. Esse dispositivo experimental foi melhorado por Gustav Robert Kirchhoff (1824-1887) e Robert Bunsen (1811-1899), na segunda metade do século XIX. Em 1859, os dois chegaram a uma importante lei empírica: todo elemento químico é caracterizado por um espectro que lhe é próprio. A partir daí ampliou-se o estudo da radiação emitida pelo sol: o espectro solar e sua composição.

No mesmo ano, Kirchhoff procurou estudar a relação entre a radiação térmica e a temperatura, através do estudo das linhas de Fraunhofer do espectro solar. Ele verificou ser o sódio um dos constituintes básicos da atmosfera solar. Chegou a esse resultado através da comparação do espectro solar com o produzido pelo sódio incandescente. Esse estudo o levou a outro trabalho lido na Academia de Ciências de Berlim em dezembro de 1859, o qual tratava sobre o problema da emissão e absorção de radiação pela matéria. Neste ele mostrava que

(...) para raios de mesmo comprimento de onda, à mesma temperatura, a razão do poder de emissão para a capacidade de absorção é a mesma para todos os corpos. ${ }^{8}$

Essa proposição ficou conhecida como a Lei de Kirchhoff. À primeira vista pode parecer uma proposição sem muita importância, mas ela é fundamental e provavelmente instigou as pesquisas sobre o assunto, pois surgia aí um absoluto na natureza.

Simplificando, poderíamos dizer que este enunciado revela que a relação entre a emissão e absorção de radiação por um corpo para uma dada temperatura é sempre a mesma, independentemente da natureza e constituição do corpo 9 .

\footnotetext{
${ }^{7}$ Planck, Theory of Heat, citado por Albuquerque (1988).

8 Jammer (1966), p.2. Citado por Zanetic (1999b), p. 102.

${ }^{9}$ Fleming $(2001$, p.4) acredita que a aplicação da lei de Kirchhoff que mais teria interessado a ele mesmo seria o fato de comprovar um resultado anterior seu: um corpo não emite uma freqüência que não absorva.
} 
Para chegar a essa conclusão enunciada acima, Kirchhoff calculou as condições de equilíbrio para a troca de radiação entre duas placas paralelas infinitas, revestidas por superficies refletoras ideais do lado de fora. Kirchhoff assumiu que a primeira placa (1) absorveria e emitiria radiação somente de comprimento de onda $\lambda$, restrição não imposta à segunda (2). Com esse artificio o problema se restringia apenas à troca de radiação com comprimento de onda $\lambda$ entre as duas placas, já que outros comprimentos de onda seriam reabsorvidos pela segunda placa após repetidas reflexões.

Como no equilibrio a energia absorvida é igual à energia emitida, o que pressupõe uma temperatura constante e igual para ambas as placas, Kirchhoff chegou ao seguinte resultado, que exprime matematicamente sua lei $^{10}$ :

$$
\frac{P_{1 \lambda}}{a_{1 \lambda}}=\frac{P_{2 \lambda}}{a_{2 \lambda}}
$$

Em que $P_{1 \lambda}$ é o poder emissivo (a energia irradiada no comprimento de onda $\lambda$ por unidade de tempo ${ }^{11}$ ) para a primeira placa, e $a_{1 \lambda}$ é o poder absorvente ${ }^{12}$ (a fração da energia absorvida da radiação incidente com comprimento de onda $\lambda$ ). Os símbolos $P_{2 \lambda}$ e $a_{2 \lambda}$ correspondem às mesmas grandezas para a segunda placa.

Essa lei expressa a característica dos corpos de que quanto maior a fração de energia que ele absorve, mais ele emite, já que a razão (1) tem um valor constante. ${ }^{13}$

Simultaneamente às publicações de Kirchhoff, Balfour Stewart (1828-1887) estabeleceu independentemente a validade dessa lei baseado em medidas experimentais ${ }^{14}$.

Como ressalta Fleming (2001, p.4-5), é importante, ao se estudar a história do estudo da radiação térmica, estar atento ao fato de que Kirchhoff descreveu a radiação sempre sob a forma de raios, o que não fazemos atualmente. Há também o aspecto de que o problema do equilibrio da radiação com a matéria envolve calor radiante e luz, na época coisas distintas. Os trabalhos de Maxwell, que propuseram a luz como radiação eletromagnética dentro de um certo intervalo de freqüências, apareceram gradualmente entre os anos de 1860 e 1865, enquanto que o grande trabalho de Kirchhoff foi publicado

\footnotetext{
${ }^{10} \mathrm{O}$ desenvolvimento completo dessa lei está no apêndice I.

${ }_{11}^{11}$ Note que o poder emissivo é uma medida de potência (energia por tempo).

12 A nomenclatura em português para as grandezas fisicas descritas foi extraída de Gibert (1982). Em Segrè (1987) a grandeza nomeada em nosso texto como poder absorvente é descrita como poder de absorção.

${ }^{13}$ Para o estudo do corpo negro isso é importante, pois com uma absorção total $\left(a_{\lambda}=1\right)$, sua emissão é máxima. Portanto o corpo negro seria um emissor ideal.
} 
em 1860. Nada se sabia então da natureza eletromagnética da luz e era corrente o pensamento de que a luz só existia no intervalo visível, sendo a radiação térmica outro fenômeno físico.

Também é importante ter em mente que o processo e a resolução do problema da radiação do corpo negro, foram desenvolvidos sob a crença (ou dúvida) da existência do éter, o qual era parte integrante dos desenvolvimentos teóricos, principalmente porque a radiação se propagava pelo éter e no interior da cavidade também existia esse "fluido etéreo". No entanto, em nenhum dos desenvolvimentos históricos que estudamos os autores discutiram essa questão. A ausência da noção de éter, por exemplo, na solução de Planck do PRCN foi motivo de críticas na época.

\subsection{A noção de corpo negro e sua equivalência com a radiação de cavidade}

Em 1860, Kirchhoff introduziu a noção idealizada de corpo perfeitamente negro, ou corpo negro.

Para facilitar a compreensão desta idéia, vamos recapitular alguns conceitos básicos da física. Podemos dizer (numa análise macroscópica) que quando a luz incide sobre qualquer superficie três fenômenos podem ocorrer (mesmo simultaneamente): parte da luz é refletida pelo objeto, outra parte é absorvida e ainda há a possibilidade de outra parte ser transmitida pela superficie. Quando vemos um objeto que não é uma fonte primária de luz, nossos olhos captam a luz visivel que foi refletida por este. Assim, quanto mais luz o objeto absorver ou transmitir, menos ele irá refletir e menos luz chegará aos nossos olhos oriunda do objeto. Dessa maneira, veremos o objeto cada vez mais escuro. Se toda luz visível que incidisse num corpo fosse absorvida pelo mesmo e nada fosse refletido, esse objeto seria perfeitamente preto.

A noção de corpo negro, no entanto, é um pouco mais sofisticada, pois um corpo negro é aquele que absorve toda a radiação que sobre ele incide, visível ou não, sem reflexão ou transmissão; ou seja, a taxa de absorção de radiação é igual a 1 (100\%), por isso a analogia com um objeto preto, que absorve toda a luz visível, sendo o preto a ausência de cor. A diferença está no fato de que o corpo perfeitamente negro não absorve apenas a radiação na região do visível, mas todo o espectro ${ }^{15}$.

\footnotetext{
${ }^{14}$ Jammer (1966), p.4.

${ }^{15}$ Newton já havia falado em corpo negro em seu livro Óptica: "os corpos negros conservariam o calor mais facilmente da luz que aqueles de outras cores". Citado por Jammer (1966), p. 4, nota 10.
} 
É importante notar que essa noção é uma idealização, pois corpos perfeitamente negros não existem ${ }^{16}$. Como Trigg (1971) afirma: "este tipo de idealização é bastante comum na ciência, e é especialmente válida quando, como será visto ser verdadeiro no presente caso, a situação ideal pode ser aproximada na realidade" (p.5).

No caso do corpo negro, sua idealização provavelmente ${ }^{17}$ foi baseada no fato de que, independentemente da sua constituição, a sua emissão (ou seja, o seu espectro) seria sempre a mesma. Também há o aspecto de que como o corpo negro absorve toda a radiação que sobre ele incide (poder de absorção $a_{\lambda}=1$ ), pela lei de Kirchhoff a sua emissão é máxima, sendo assim um emissor ideal.

Portanto, a noção de corpo negro se mostrava como um absoluto na física, fato que levou muitos cientistas a estudar o assunto com afinco, principalmente Planck ${ }^{18}$.

Com relação à aproximação com a realidade na pesquisa da radiação de corpo negro, encontrá-la-emos no Sol. Podemos aproximá-lo para um corpo negro pois a radiação que sobre ele incide passa por reflexões sucessivas sendo quase que completamente absorvida. No entanto, com relação à emissão, o Sol não possui um espectro contínuo como o de um corpo negro, pois apresenta algumas linhas escuras, conhecidas como linhas de Fraunhofer, que representam os comprimentos de onda absorvidos pelos átomos presentes nas camadas mais exteriores do Sol. O primeiro a observar tais linhas foi William Hyde Wollaston (1766-1828) em 1802. Em 1814, Fraunhofer contou cerca de 574 dessas linhas no espectro solar e identificou várias delas por letras.

Planck sugeria que um corpo negro deveria satisfazer três condições independentes, reforçando o caráter sofisticado dessa noção:

Primeira, o corpo deve ter uma superfície negra a fim de permitir que os raios incidentes entrem sem reflexão. Desde que, em geral, as propriedades de uma superfície dependem dos dois corpos que estão em contato, esta condição mostra que a propriedade de negrume aplicada a um corpo depende não somente da natureza do corpo, mas também daquela do meio contíguo. Um corpo que é negro relativamente ao ar

\footnotetext{
${ }^{16}$ Por definição poderíamos considerar um buraco negro como um corpo negro. No entanto, uma discussão mais aprofundada sobre o assunto deveria analisar se a emissão de um buraco negro fornece um espectro de corpo negro, discussão que foge ao escopo deste trabalho.

17 Dizemos provavelmente, pois essa afirmação não se encontra explicitamente em nenhuma literatura que consultamos. Essa é uma inferência que fizemos a partir do estudo que realizamos.

${ }^{18}$ Conforme o próprio Planck narra em sua autobigrafia sobre a radiação do corpo negro: “....a radiação, em todas suas propriedades incluindo sua distribuição espectral de energia, não depende da narureza dos corpos, mas somente e exclusivamente da temperatura. Portanto, esta assim chamada distribuição normal de energia espectral representa algo absoluto, e uma vez que eu sempre considerei a procura por absoluto como o principal objetivo de toda a atividade científica, eu ansiosamente me pus a trabalhar" (p. 34-35).
} 
pode não sê-lo relativamente ao vidro, e vice versa. Segunda, o corpo negro deve ter uma certa espessura mínima dependente do seu poder absorvente, a fim de assegurar que os raios após passarem para o corpo não serão capazes de deixá-lo de novo num diferente ponto da superfície. Quanto mais absorvente um corpo é, menor o valor dessa espessura mínima, enquanto que no caso de corpos com poder absorvente excessivamente pequeno somente uma camada de espessura infinita pode ser considerada negra. Terceira, um corpo negro deve ter um coeficiente de espalhamento excessivamente pequeno. Caso contrário os raios recebidos por ele seriam parcialmente espalhados no interior e podem deixá-lo de novo através da superfície. (Planck, 1959, p.10)

Como um corpo negro tem superficie negra, caso ele existisse e estivesse "frio" (pico de emissão no infravermelho) não o veríamos, já que nenhuma radiação é refletida por ele. No entanto, quando aquecido, seu pico de emissão poderia chegar próximo à faixa do visível, de maneira que o veríamos como uma fonte de luz.

Kirchhoff também mostrou que a emissão de radiação para um corpo negro é da mesma "qualidade e intensidade"19 que a radiação dentro de uma cavidade de paredes adiatérmicas $^{20}$ e temperatura $T$. Ou seja, ele mostrou que o estudo de um corpo negro poderia se restringir ao da emissão de tal cavidade ${ }^{21}$. Dessa maneira o estudo da radiação de corpo negro aproximava-se ainda mais da realidade.

A radiação no interior dessa cavidade tem origem nas paredes da mesma, e segundo TRIGG (1971, p.7) Kirchhoff mostrou que esta radiação é isotrópica (a mesma em qualquer direção) e homogênea (a mesma em todos os pontos da cavidade). Se a radiação fosse mais intensa em alguns pontos que em outros, absorvedores idênticos em pontos distintos teriam temperaturas diferentes e poderiam ser utilizados um como fonte e outro como depósito de uma máquina térmica que produziria trabalho indefinidamente, visto que a radiação na cavidade manteria a temperatura dos reservatórios térmicos.

Para entendermos melhor a equivalência de emissão entre o corpo negro e a radiação no interior da cavidade, vamos supor que um corpo não negro a temperatura $T$ seja colocado no interior de uma cavidade em equilíbrio térmico a mesma temperatura. A energia emitida pelas paredes da cavidade em forma de radiação com comprimento de

\footnotetext{
${ }^{19}$ Citado por Jammer (1966), p.5.

${ }^{20}$ Adiatérmica é uma superficie que não permite a passagem de radiação térmica.

${ }^{21}$ Acreditamos que o objetivo da equivalência proposta por Kirchhoff entre corpo negro e a radiação de cavidade tenha sido feita com o intuito de facilitar o tratamento matemático do estudo do corpo negro, assim como também talvez facilitar a experimentação ou mesmo fazer a analogia com os fornos. Essa equivalência é importante. Ela facilita o cálculo, pois no interior da cavidade é possível obter os modos estacionários da
} 
onda entre $\lambda$ e $\lambda+d \lambda$, por unidade de tempo e área a temperatura $T$, é $R_{\lambda}$ (radiância espectral). Como essa radiação é homogênea, a energia por unidade de tempo e área que incide sobre o corpo também é $R_{\lambda}$.

Essa radiação, então, é parcialmente absorvida pelo corpo. A fração de energia absorvida com comprimento de onda $\lambda$ pelo corpo ( $a_{\lambda}=$ poder absorvente) depende da temperatura, assim como da composição do material da superficie do corpo não negro. No equilíbrio, as taxas de energia emitida e absorvida pelo corpo devem ser iguais. Assim, sendo $R_{\lambda C}$ a radiância espectral do corpo, temos:

Taxa de emissão $(t, \lambda, A)=$ Taxa de absorção $(t, \lambda, A)$,

$$
R_{\lambda C}=a_{\lambda} R_{\lambda}
$$

Agora, suponha que na mesma cavidade é colocado um corpo negro. Nesse caso, a radiação emitida pela cavidade será totalmente absorvida pelo corpo negro (pois, por sua definição, $\left.a_{\lambda C N}=1\right)$. Assim o balanço de energia, como feito para o caso anterior fica:

$$
R_{\lambda C N}=R_{\lambda}
$$

Esse resultado mostra que a emissão de radiação no interior da cavidade é equivalente à emissão de um corpo negro.

Usando os resultados das equações (2) e (3) temos então que:

$$
R_{\lambda C N}=F(T, \lambda)=R_{\lambda C} / a_{\lambda}
$$

Ou seja, a partir do conhecimento da emissão (espectro) de um corpo negro $F(T, \lambda)^{23}$, e do conhecimento do poder absorvente ${ }^{24} a_{\lambda}$ de um dado corpo, sua emissão espectral $R_{\lambda C}$ podia então ser conhecida ${ }^{25}$. A partir desse resultado passou então a ser

radiação eletromagnética, de maneira que é possível quantificar a densidade de energia em suas paredes e conseqüentemente a sua emissão.

${ }^{22}$ Note que a essência desse resultado pode também ser extraído diretamente da lei de Kirchhoff [equação (1)] fazendo-se $a_{\lambda C N}=1$. Essa formulação evidencia outra característica importante dos corpos negros, a de que a sua emissão independe da sua composição, já que o poder absorvente do corpo negro (grandeza que "carrega" a informação do material) tem valor fixo igual a 1.

${ }_{24}^{23}$ Função universal que dependia apenas da temperatura e do comprimento de onda.

${ }_{25}^{24}$ Ainda que este dependa do comprimento de onda e da temperatura.

${ }^{25}$ Experimentalmente falando é mais simples o processo reverso, ou seja, aquele que busca conhecer a poder absorvente dos materiais $\left(a_{\lambda}\right)$ através do conhecimento da função de distribuição do corpo negro e da determinação de $R_{\lambda C}$. 
muito importante a determinação tanto teórica como experimental da radiação de corpo negro, ou seja, $F(T, \lambda)$.

Embora aparentemente a determinação dessa função se mostrava fácil, e teoricamente exigiria apenas a perícia de um cientista habilidoso, não foi o que aconteceu e várias tentativas não lograram êxito durante o final do século XIX.

No entanto esse problema não era considerado de muita gravidade na época, ao contrário do que muitos autores apontam. Atualmente, denominamos a tentativa de solução deste como o Problema da Radiação do Corpo Negro (PRCN). Sua importância está no fato de que esse problema se mostrou como uma anomalia cuja solução não se encaixava no escopo da física clássica. Após longa revolução científica uma nova visão de mundo (paradigma) foi estabelecida: a física quântica.

\subsection{Primeiros resultados: a lei de Stefan-Boltzmann e as leis de Wien}

Em 1865, John Tyndall (1820-1893) apresentou um trabalho no qual utilizava um fio de platina aquecido a duas temperaturas diferentes. Ele concluiu que a emissão total de radiação do fio a $1200^{\circ} \mathrm{C}$ era cerca de 11,7 maior que a emissão a $525^{\circ} \mathrm{C}$.

Já em 1879, Josef Stefan (1835-1893), extraiu desses resultados de Tyndall ${ }^{26}$ que a emissão era proporcional a $T^{4}$ (medida em Kelvin). Essa derivação foi acidental, pois além de puramente empírica, foi baseada em apenas dois dados, e o fio aquecido não correspondia a um corpo negro. Segundo Jammer (1966, p.6), uma moderna repetição do experimento de Tyndall forneceu como resultado uma razão de 18,22 ao invés de 11,7.

Posteriormente, em 1884, "C. Christiansen sugeriu que pequenos buracos produzidos em cavidades isotérmicas funcionariam como radiadores de corpo negro, isto é, agiriam como pequenos pontos completamente negros" (Zanetic, 1999b, p. 107).

Nesse mesmo ano, Boltzmann (1844-1906), usando considerações termodinâmicas e eletromagnéticas para o estudo da cavidade, mostrou que a densidade de energia desta deveria ser proporcional a $T^{4}$, tal como o fluxo emitido, formalizando assim o resultado empírico obtido anos antes por Stefan.

Para chegar a esse resultado Boltzmann partiu da noção de que a pressão da radiação $(P)$ seria proporcional à densidade de energia ${ }^{27}$. De acordo com a teoria de

\footnotetext{
${ }^{26}$ No trabalho de Arruda (1992), que consultou o original de Stefan, é descrito que esse resultado foi obtido "analisando as observações sobre a taxa de esfriamento de um grande termômetro de mercúrio colhidas por Dulong e Petit" (p.6).

${ }^{27}$ Boltzmann usou para a dedução teórica da lei de Stefan o resultado de A. Bartoli, físico italiano, que chegou a conclusão de que a radiação exerce pressão. Em uma experiência de pensamento, Bartoli imaginou
} 
Maxwell e a estatística de Krönig's, Boltzmann chegou à conclusão de que $P=1 / 3 \mu$ (sendo $\mu$ a densidade de energia radiante) e de que ao se variar o volume da cavidade, haveria variação da temperatura e realização de trabalho ${ }^{28}$. Associando esse "gás de radiação" $" 29$ a temperatura $T$ e pressão $P$, ele chegou ${ }^{30}$ (já utilizando uma notação mais moderna) a

$$
\mu=\kappa T^{A}
$$

sendo $\kappa$ uma constante de proporcionalidade.

Conforme mostrado no apêndice II:

$$
\mu=\frac{4 \phi}{c}
$$

em que $\phi$ representa o fluxo (energia por área e por tempo) de radiação que atinge as paredes da cavidade. A partir deste resultado Boltzmann chegou à seguinte formulação:

$$
\phi=\sigma T^{4}
$$

Com a consideração de que as paredes do corpo negro estão em equilíbrio, o fluxo de radiação deve ser igual à radiância total ${ }^{31} R$ da superfície. Portanto:

$$
R=\sigma T^{4}
$$

conhecida hoje como a lei de Stefan-Boltzmann ${ }^{32}$.

Utilizando uma linguagem e desenvolvimentos mais modernos vamos tomar o brilho $B_{v}=B(v, T)$ como a energia emitida por unidade de freqüência no intervalo de $v$ a $v+d v$, por unidade de área, por unidade de ângulo sólido e por unidade de tempo na direção normal à superficie no interior de um corpo negro à temperatura $T$. A intensidade de radiação $K_{\lambda}=K(\lambda, T)^{33}$ é análoga ao brilho, no entanto a análise é para intervalo de

que num processo cíclico, com a ajuda de espelhos, podia-se transferir o calor na forma de radiação de um corpo frio para um corpo quente. Uma vez que a transferência de calor exige a produção de trabalho ( $2^{\mathrm{a}}$ lei da termodinâmica), ele concluiu que a radiação deveria, necessariamente, exercer uma certa pressão (Jammer, 1966 , p. 7).

${ }^{28}$ Martins (2000).

${ }^{29}$ Jammer (1966), p.7.

${ }^{30} \mathrm{O}$ desenvolvimento de Boltzmann está apresentado no apêndice II.

${ }^{31}$ A radiância total é a integral da radiância espectral em todas as frequiências, ou seja $R=\int R_{v} d v$.

${ }^{32}$ É importante observar, como aponta Fleming (2001, p.7), que a "existência da pressão de radiação, e a veracidade das fórmulas de Maxwell, só viriam a ser comprovadas experimentalmente em 1905, por Lebedev".

${ }^{33}$ Como algumas bibliografias utilizam $B_{v}$ e outras utilizam $K_{\lambda}$ procuraremos ao longo do texto utilizar as duas notações, utilizando como principal $B_{\nu}$ Note que $B_{v}=B(v, T)$ é proporcional a $K_{\lambda}=K(\lambda, T)$, já que $\lambda v=c$. Como $B_{v} d v=-K_{\lambda} d \lambda, \operatorname{com} d v=-\frac{c}{\lambda^{2}} d \lambda$, assim $B_{v}=\frac{\lambda^{2}}{c} K_{\lambda}$. 
comprimentos de onda. Note que, pela definição, $R_{\lambda C N}$ é proporcional a $K_{\lambda}$ que correspondentemente é proporcional a $B_{v}$. Dessa maneira restringiremos a busca pela equação do corpo negro à busca por $B_{\nu}\left(\right.$ ou $\left.K_{\lambda}\right)$.

O primeiro físico a fornecer uma tentativa coerente de análise teórica, obtendo uma função de distribuição espectral para a radiação de corpo negro, foi Wilhelm Wien (18641928) em 1894. Ele inicialmente apenas esboçou a forma desta função, baseando-se nas considerações termodinâmicas e eletromagnéticas de Boltzmann e chegando à expressão:

$$
B_{v}=v^{3} \varphi(v / T) \text { ou } K_{\lambda}=\lambda^{-5} f(\lambda T)
$$

Wien notou ${ }^{34}$ que se fosse reduzido o volume da cavidade, como num pistão em movimento, a densidade de energia na cavidade aumentaria, já que a radiação exerceria pressão sobre o pistão, havendo assim realização de trabalho durante a compressão. Também o movimento das paredes da cavidade ocasionaria uma mudança no comprimento de onda da radiação refletida por efeito Doppler, já que neste caso há uma fonte luminosa (as paredes da cavidade) em movimento.

Portanto, Wien concluiu que a mudança de temperatura também altera a distribuição dos comprimentos de onda, de forma que a temperatura sempre está associada com o comprimento de onda.

Conforme descreve Trigg (1971), p. 8-9:

As conseqüências quantitativas disto eram duplas. Primeiro, se são feitas comparações de coisas dependentes do comprimento de onda em duas temperaturas diferentes, não é exato comparar valores no mesmo comprimento de onda. Em lugar disso, ao se trabalhar na temperatura $T$ ', deve-se usar para comparação com o comprimento de onda $\lambda$ na temperatura $T$ um comprimento de onda $\lambda^{\prime}$ dado por:

$$
\lambda^{\prime} T^{\prime}=\lambda T
$$

Em segundo lugar, as emitâncias espectrais [equivalente no nosso texto a $K_{\lambda}$ ] para comprimentos de onda correspondentes nesta maneira variam com a temperatura de acordo com a relação:

$$
K_{\lambda} / K_{\lambda}=T^{5} / T^{, 5}
$$

Particularmente, se $K_{\lambda}$ (para uma temperatura fixa $T$ ) tem um valor máximo $K_{\lambda \max }$ no comprimento de onda $\lambda_{\max }$, então os valores de $K_{\lambda \max }$ para várias temperaturas satisfazem a relação cujo resultado é conhecido como lei do deslocamento de Wien:

${ }^{34}$ Toda essa discussão sobre a lei de Wien está exposta em Trigg (1971), p. 8-9. 


$$
\lambda_{\max } T=\text { constante ou } \frac{v_{\max }}{T}=\text { constante }
$$

Essa lei, portanto, expressa o fato de que para a distribuição espectral de corpo negro, com o aumento da temperatura, a emissão será máxima para um comprimento de onda menor e vice-versa. A ilustração abaixo nos permite visualizar o resultado desta lei. No entanto é necessário frisar que essas curvas não existiam na época. ${ }^{35}$

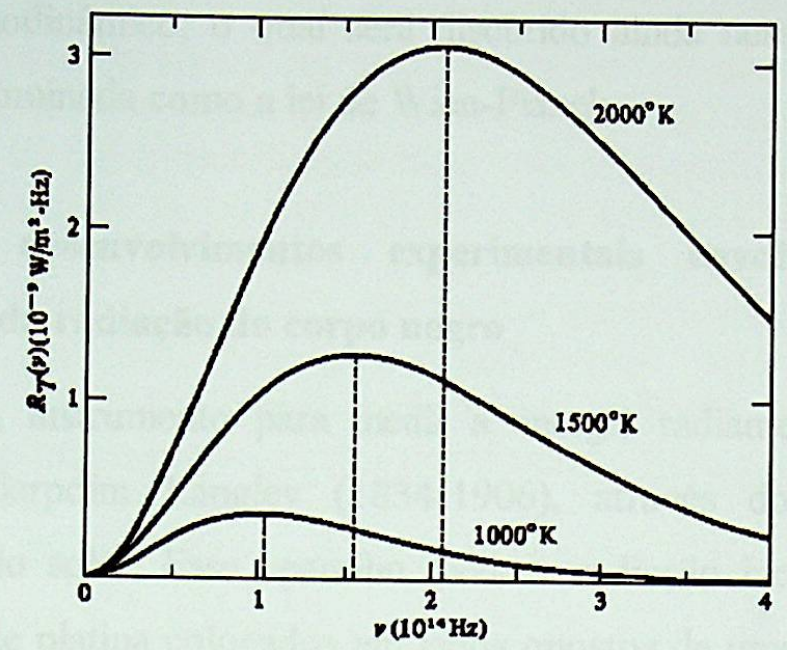

Fig.1: Visualização da lei do deslocamento de Wien. ${ }^{36}$

Apesar de Wien não ter notado, segundo Trigg (1971), essa lei implica na expressão (9). Isso pode ser observado através do cálculo do máximo dessa função.

Esse desenvolvimento de Wien facilitou a procura pela resolução do problema da radiação de corpo negro para a função $\varphi(v / T)$ [ou $f(\lambda T)$ ]. Contudo essa procura começou a se mostrar dificil.

Posteriormente, em 1896, Wien, assumindo que a freqüência da radiação emitida por qualquer molécula do corpo negro era uma função da sua velocidade e aplicando a distribuição de Maxwell-Boltzmann (e, portanto, a mecânica estatística), chegou a uma expressão que, embora baseada em argumentos duvidosos ${ }^{37}$, foi verificada experimentalmente em 1897 e 1899, exceto na região do visível (grandes comprimentos de onda) e temperaturas de até $4000^{\circ} \mathrm{C}$. Esse resultado ficou conhecido como a lei de Wien e teve boa acolhida experimental para a época:

\footnotetext{
${ }^{35}$ Não conseguimos através da literatura pesquisada delimitar como foi a evolução da obtenção experimental destas curvas.

${ }^{36}$ Fonte: Eisberg (1994), p.21.

${ }^{37}$ Esse argumento de Wien foi baseado no trabalho de Albert Abraham Michelson (1852-1931) que, em 1887 , tentou resolver o problema assumindo que a fórmula de Maxwell para a distribuição de velocidades das moléculas num gás também valeria para as moléculas do sólido que emitia radiação de corpo negro.
} 


$$
K_{\lambda}=c_{1} \lambda^{-5} e^{\left(-\frac{c_{2}}{\lambda T}\right)} \quad \text { ou } \quad B_{v}=\eta v^{3} e^{\left(-\frac{\beta v}{T}\right)} \Rightarrow \mu_{v}=\alpha v^{3} e^{\left(-\frac{\beta v}{T}\right)} \quad 38
$$

Com $\alpha, \eta, \beta, c_{1}$ e $c_{2}$ constantes.

Em uma série de papers, entre 1887 e 1899, Planck derivou essa lei através de um desenvolvimento termodinâmico, o qual será discutido ainda nesse capítulo. Atualmente essa formulação é denominada como a lei de Wien-Planck.

\subsection{Alguns desenvolvimentos experimentais envolvendo os primeiros} resultados do estudo da radiação do corpo negro

O bolômetro ${ }^{39}$, instrumento para medir a energia radiante, foi desenvolvido em 1880 por Samuel Pierpoint Langley (1834-1906), através do estudo da absorção atmosférica da radiação solar. Esse aparelho mede a radiação incidente e absorvida por dois fios escurecidos de platina colocados em lados opostos de uma ponte de Wheatstone; com o aumento da temperatura do fio, este tem seu valor de resistência alterado. Logo empregado na espectroscopia, o bolômetro só teve importância fundamental para o estudo da radiação de corpo negro após o desenvolvimento de fontes de radiação adequadas.

$O$ estudo experimental da radiação do corpo negro foi realmente efetivado com o uso do bolômetro combinado à primeira cavidade isotérmica desenvolvida por Otto Lummer (1860-1925) e Wilhem Wien em $1895 .^{40}$

Vários centros de pesquisa passaram então a se dedicar ao estudo experimental do problema, principalmente o Instituto Imperial Físico-Técnico de Berlin (PhysikalischeTechnische Reichsanstalt).

A confirmação da lei de Stefan-Boltzmann foi obtida em 1897 por vários pesquisadores: F. Paschen, O. Lummer, E. Pringheim, C. E. Mendenhall e F. A. Saunders. Lummer e Ernst Pringsheim (1859-1925) em Charlottenburg, Alemanha, utilizaram e ampliaram a noção de equivalência entre a radiação de cavidade e a radiação de corpo negro, utilizando uma cavidade com um furo pequeno comparado com as dimensões das paredes. Qualquer radiação que por esse buraco penetra, tem uma probabilidade muito

\footnotetext{
${ }^{38}$ Já que $\mu_{v}=4 \pi / c B_{v}$.

${ }^{39}$ Cuja denominação é derivada de "ßo $\lambda \dot{\eta}=$ feixe de luz" (Jammer, 1966, p. 5, nota 15).

${ }^{40}$ Segundo Jammer $(1966$, p.6), ambos se basearam no teorema da cavidade de Kirchhoff para a construção desse "corpo negro experimental".
} 
pequena de sair, sofrendo assim múltiplas reflexões nas paredes dessa cavidade, com alguma taxa de absorção. Dessa forma é possível dizer que toda radiação incidente é absorvida pelo corpo, e esse se mostra uma boa aproximação de um corpo negro. Portanto, pode-se usar a radiação oriunda do interior da cavidade e que passa pelo furo como uma amostra de radiação de corpo negro ${ }^{41}$.

Duas cavidades foram usadas, uma de cobre para temperaturas acima de $877 \mathrm{~K}$ e uma de ferro para temperaturas de 799 a $1561 \mathrm{~K}$. A cavidade de cobre foi imersa em uma mistura fundida de nitrato de sódio e nitrato de potássio; a temperatura do banho podia ser mantida constante dentro de um ou dois graus durante meia hora pelo controle de uma fonte de gás incandescente. A cavidade de ferro era aquecida por meio de um forno especial de paredes duplas (...) no qual os gases quentes da chama passavam ao redor da cavidade dentro das paredes internas do forno, depois entre as duas paredes, e então pelo cano da chaminé. Temperaturas até $755 \mathrm{~K}$ eram medidas por meio de termômetros de mercúrio; temperaturas maiores, por um termopar. (Trigg, 1971, p.12-13)

Lummer e Pringsheim então passaram a especular como a emissão espectral do corpo negro variava com o comprimento de onda em uma dada temperatura, ou seja, procuraram obter as curvas de distribuição espectral. Os resultados foram publicados em uma série de artigos entre 1899 e 1900 . Os procedimentos de medida eram os mesmos, mas agora eles utilizavam um prisma antes de medir a energia, espalhando a luz e fazendo uma varredura das freqüências.

...Várias cavidades foram usadas, a temperaturas de 85 a $1800 \mathrm{~K}$. As temperaturas mais baixas foram conseguidas pela imersão em ar líquido $(85 \mathrm{~K})$, água fervente $(373 \mathrm{~K})$, e nitrato de potássio fundido (por volta de $600 \mathrm{~K}$, dependendo da composição exata). Altas temperaturas, acima de $1800 \mathrm{~K}$, eram obtidas por aquecimento elétrico. (Trigg, 1971, p. 13)

Os comprimentos de onda estudados variavam de 1 a 18 mícrons, região espectral na qual o vapor de água e o dióxido de carbono, presentes na atmosfera, absorvem fortemente certos comprimentos de ondas, especialmente em 1.8, 2.7 e 4.5 mícrons. Isso dificultava as medidas. Para resolver o problema "eles fecharam o espectrômetro e o bolômetro em um container no qual o ar foi secado e quimicamente purificado de dióxido de carbono, de forma que a necessária correção foi grandemente reduzida" (Trigg, 1971, p.14).

Também outra complicação é que experimentalmente é sempre necessária a certificação de que apenas a radiação de interesse atinge o bolômetro.

${ }^{41}$ Trigg (1971), p.11. 
No primeiro artigo sobre essas medidas, Lummer e Pringsheim procuraram apenas medir o $K_{\lambda \max }$ e o $\lambda_{\max }$ com o intuito de verificar a lei de deslocamento de Wien.

Posteriormente Lummer e Pringsheim compararam seus resultados com a lei de Wien. Inicialmente plotaram as curvas da energia em função do comprimento de onda para várias temperaturas. Embora a concordância com a curva teórica de Wien parecesse satisfatória à primeira vista, eles testaram os dados experimentais de outra forma. Com a formulação de Wien (equação (12)),

$$
K_{\lambda}=c_{1} \lambda^{-5} e^{\left(-\frac{c_{2}}{\lambda T}\right)}
$$

Tomando o logaritmo ${ }^{42}$ de ambos os lados temos:

$$
\log K_{\lambda}=\log \left(c_{1} \lambda^{-5}\right)-\left(c_{2} / \lambda T\right) \log e
$$

Ou seja:

$$
\log K_{\lambda}=\log \left(c_{1} \lambda^{-5}\right)-\left[\left(c_{2} / \lambda\right) \log e\right](1 / T)
$$

Ou reescrevendo da seguinte forma:

$$
F(x)=C_{a}+C_{b} x
$$

$\operatorname{Com} \mathrm{F}(\mathrm{x})=\log K_{\lambda}$

$$
\begin{aligned}
& \mathrm{C}_{\mathrm{a}}=\log \left(c_{1} \lambda^{-5}\right) \\
& \mathrm{C}_{\mathrm{b}}=-\left[\left(c_{2} / \lambda\right) \log e\right] \\
& \mathrm{x}=1 / T
\end{aligned}
$$

obtém-se a equação de uma reta.

Assim, Lummer e Pringsheim plotaram $\log K_{\lambda}$ (para um $\lambda$ fixo) em função de $1 / T$, a fim de procurar obter retas.

... A natureza dos argumentos usados para deduzir a fórmula de Wien era tal que a quantidade $c_{2}$ deveria ser uma constante da natureza, enquanto $c_{1}$ poderia variar de uma série de observações para outra, mas deveria ser constante através de qualquer série [isto é, $c_{1}$ "carrega" informação do material].(Trigg, 1971, p.17)

Em outro trabalho Lummer e Pringsheim apresentaram curvas isocromáticas que pareciam linhas retas, mas os valores de $c_{1}$ e $c_{2}$ variavam com o comprimento de onda. Ambos se puseram em dúvida sobre a validade da equação de Wien. Apenas num terceiro

\footnotetext{
${ }^{42}$ É necessário tomar cuidado com bibliografias estrangeiras, pois muitas vezes é tomado log como sinônimo de ln. Aqui log é o logarítimo na base 10.
} 
trabalho a evidência ficou óbvia. Eles concluíram firmemente que a lei de Wien-Planck era inválida.

\subsection{O teorema da eqüipartição da energia ${ }^{43}$}

Em 1845, J. J. Waterston (1811-1883) enviou um paper para a Royal Society em que concluía que "num meio misto a velocidade quadrática média é inversamente proporcional ao peso específico das moléculas" ${ }^{24}$. Seu trabalho foi veementemente recusado e considerado sem sentido na época. Entretanto, como estava seguro da importância do seu trabalho passou a circulá-lo pessoalmente entre os cientistas.

Cinco anos depois, uma curta passagem de seu texto foi lido no $21^{\circ}$ encontro da Associação Britânica, em que dizia que "equilibrio de pressão e calor entre dois gases ocorre quando o número de átomos em unidade de volume é igual, e a vis viva de cada átomo é igual". 45

Apenas quarenta anos depois, em 1885, seu artigo foi finalmente publicado. Em 1860, Maxwell (provavelmente ciente do trabalho de Waterston) havia dado sua primeira formulação do teorema da eqüipartição da energia: “dois diferentes conjuntos de particulas distribuirão suas velocidades, assim que suas vires vivae forem iguais". 46

Inicialmente o resultado de Maxwell só incluía partículas perfeitamente esféricas e posteriormente ele estendeu seu enunciado para o caso de uma mistura de partículas de qualquer forma, além de incluir a rotação.

Em 1868, Boltzmann generalizou o teorema para partículas que não necessariamente fossem rígidas, mas tinham um número interno de graus de liberdade, como, por exemplo, a vibração.

Também Maxwell removeu certas restrições na interação entre as partículas e mostrou, usando coordenadas Lagrangianas para sistemas com um número arbitrário de graus de liberdade, que a eqüipartição de energia acontece se

... os pontos materiais podem atuar em todas as distâncias e de acordo com qualquer lei consistente com a conservação de energia. A única

\footnotetext{
${ }^{43} \mathrm{O}$ teorema de eqüipartição de energia afirma que num conjunto composto por um grande número de partículas idênticas individuais, que se movimentam ao acaso trocando energia entre si através de colisões, a energia total contida neste sistema é igualmente partilhada, em média, por todas partículas. Ou seja, se a energia total é $E$ e se há a presença de $N$ partículas, a energia média de cada partícula será $E / N$.

${ }^{44}$ Citado por Jammer, 1966, p.12.

${ }^{45}$ Ibidem. A palavra vis viva, ou força viva, carrega de certa maneira o sentido de energia cinética, energia de um corpo em movimento. Esse termo era usado em oposição a vis morta, associada a um corpo parado no ponto mais alto (energia potencial).

${ }^{46}$ Ibidem, p. 13.
} 
suposição que é necessária para a prova direta é que o sistema, se deixado neste estado em movimento, irá, mais cedo ou mais tarde, passar através de cada fase que é consistente com a equação de energia. ${ }^{47}$

Dessa maneira no final do século XIX a eqüipartição de energia "estava no ar" e muitos artigos se ocupavam com esse assunto. Mas havia sérios problemas para efetivar sua compreensão e aceitação, principalmente por que não se encaixava nos dados experimentais de calor específico para um gás. ${ }^{48}$

\subsection{O desenvolvimento de Rayleigh e a correção de Jeans}

Em junho de 1900, Lord Rayleigh (1842-1911) tentou resolver o PRCN usando a equipartição de energia. Ele partiu do pressuposto de que na cavidade estariam dispersas ondas estacionárias somente com freqüências fixas, determinadas pela geometria da caixa, ou seja, a radiação poderia vibrar somente em freqüências fixas determinadas pelo seu comprimento.

Dessa maneira a radiação na cavidade deveria ser composta pela superposição de ondas estacionárias possíveis dentro desta. Seria assim necessário efetuar o cálculo do número de diferentes modos de ondas estacionárias com comprimento de onda entre $\lambda$ e $\lambda+d \lambda$ por unidade de volume que poderia existir na cavidade. De acordo com a lei de equipartição de energia, cada um desses modos deve ter a mesma energia média.

Essas considerações levaram Rayleigh à sua equação (com $k_{1}$ e $k_{2}$ constantes):

$$
K_{\lambda}=k_{1} T \lambda^{-4} \text { ou } B_{v}=k_{2} v^{2} T
$$

Seu resultado não é coerente com os resultados experimentais para pequenos comprimentos de onda, pois a curva diverge para altas energias, ou seja, há uma tendência ilimitada para altas freqüências.

\footnotetext{
47 Jammer (1966), p. 14.

${ }^{48}$ Esse problema só foi solucionado com a fisica quântica.
} 


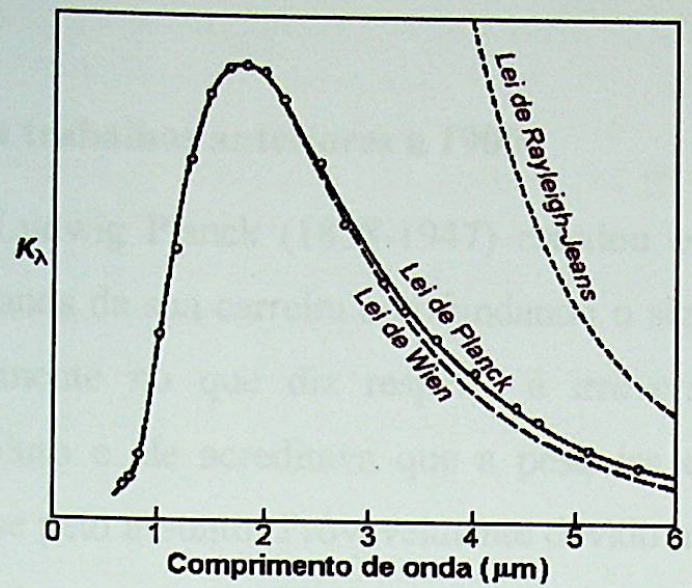

Fig.2: Pontos experimentais e leis de radiação. ${ }^{49}$

Muito posteriormente essa tendência levou o nome de catástrofe do ultravioleta ${ }^{50}$, por Paul Ehrenfest (1880-1933) em 1911. Contudo, na época da publicação, o artigo de Rayleigh não chamou muito a atenção e não existia sentido trágico algum com relação aos resultados discrepantes.

Em 1905, data posterior à solução do PRCN por Planck, James Jeans (1877-1946) corrigiu a formulação de Rayleigh, produzindo a expressão que hoje conhecemos como equação de Rayleigh-Jeans. Segundo Whitaker (1979a), Rayleigh não calculou em sua formulação a constante de proporcionalidade, pois era evidente para ele que a sua expressão não era satisfatória. Ele apenas sugeriu "incluir um fator exponencial de corte para levar a resultados sensatos" (p.109).

... Apesar do seu proeminente papel nos livros-textos de física, a fórmula [de Rayleigh-Jeans] não atuou em nenhuma parte de toda a fase originária da teoria quântica. Planck não aceitou o teorema da equipartição como fundamental, e portanto ignorou-o. Provavelmente nem Rayleigh nem Jeans consideravam o teorema universalmente válido. A "catástrofe do ultravioleta" (...) apenas transformou-se num assunto de discussão numa fase posterior da teoria quântica. (Kragh, 2000, p.33)

Segundo Klein (1966) para Jeans não deveria haver um equilibrio termodinâmico da radiação, o que explicaria a inabilidade de se resolver o problema da radiação do corpo negro com a equipartição de energia.

O próprio Jeans, em sua curta descrição sobre a teoria dos quanta, não menciona a contribuição de Rayleigh e nem mesmo a correção que ele próprio realizou (Jeans, 1953).

\footnotetext{
${ }^{49}$ Fonte: Richtmyer (1955).

${ }^{50}$ Pois uma das conseqüências do desenvolvimento de Rayleigh, embora não verificada experimentalmente, seria a de que conforme se aumentasse a freqüência em direção ao ultravioleta no espectro, a energia tenderia ao infinito.
} 


\section{O trabalho de Planck}

\subsection{Planck e seus trabalhos anteriores a 1900}

Max Karl Ernst Ludwig Planck (1858-1947) estudou os trabalhos de Clausius e dedicou os primeiros 50 anos da sua carreira aprofundando o significado da segunda lei da termodinâmica, principalmente no que diz respeito à irreversibilidade. Para Planck a segunda lei era um absoluto e ele acreditava que a pesquisa em física era a busca por absolutos, daí seu interesse pelo assunto. Provavelmente devido a sua formação e estudo na área é que Planck não tentou resolver o PRCN pelo teorema da eqüipartição de energia, e se o fizesse certamente chegaria à formulação de Rayleigh. Planck também não tinha familiaridade com a estatística de Boltzmann e Gibbs e era avesso à teoria molecular. ${ }^{51}$

A segunda lei da termodinâmica evidencia que a tendência natural de um sistema isolado é mudar de tal forma que sua entropia aumente. No estado de equilíbrio essa entropia tem um valor máximo. Planck vislumbrou uma possibilidade de estudo da radiação de corpo negro através do cálculo da entropia de uma cavidade adiatérmica mantida a temperatura constante, uma vez que este sistema configura uma situação de equilíbrio. Assim ele procurou estudar a situação de equilíbrio utilizando o eletromagnetismo de Maxwell (emissão de dipolo, modelando a emissão e absorção de radiação por ressoadores) e a termodinâmica.

Para tal intento, Planck rejeitou a interpretação estatística da termodinâmica de Boltzmann, esperando que esta pudesse ser evitada e que "o princípio do aumento da entropia pudesse ser preservado intacto como um teorema rigoroso em alguma teoria mais compreensivel e fundamental" (KLEIN, 1966, p.25).

Provavelmente procurando por subsídios para fundamentar o estudo da radiação de corpo negro através do cálculo da entropia, em março de 1895, Planck apresentou um trabalho, para a Academia de Ciências de Berlim, cuja linha de pesquisa divergia de suas anteriores, e no qual discutia "o problema do espalhamento ressonante de ondas eletromagnéticas planas por um dipolo oscilante de dimensões pequenas comparadas ao comprimento de onda" (KLEIN, 1966, p.25).

Em fevereiro de 1896, Planck

... estendeu seus estudos para o amortecimento de radiação de seus osciladores carregados, e ele ficou impressionado pela diferença entre amortecimento de radiação e amortecimento por meio da ordinária resistência do oscilador. Amortecimento de radiação era um mecanismo

\footnotetext{
${ }^{51}$ Jammer (1966), p.14.
} 
completamente conservativo que não requeria um mecanismo para invocar a transformação de energia em calor, ou para fornecer outra característica constante do oscilador de forma a descrever esse amortecimento. Planck pensou que isto poderia ter grandes implicações para esta questão fundamental da irreversibilidade e da segunda lei. Como ele colocou "o estudo do amortecimento conservativo parece para mim ser de grande importância, uma vez que abre a perspectiva de uma possível explicação geral de processos irreversíveis por meio de forças conservativas - um problema que exige a pesquisa em física teórica mais urgentemente a cada dia. (KLEIN, 1966, p. 25).

No ano seguinte (fevereiro de 1897), Planck deu início a um estudo que se estendeu por mais de dois anos sobre a irreversibilidade da radiação, procurando assim deduzir a lei de Wien.

... Ele começou asseverando que ninguém tinha explicado com sucesso como um sistema governado por interações conservativas podia evoluir irreversivelmente para um estado final de equilibrio termodinâmico. (...) Planck então anunciou seu próprio programa para derivar a segunda lei da termodinâmica para um sistema constituído de radiação e osciladores carregados numa cavidade com paredes refletoras. Ele introduziria nenhum amortecimento além do amortecimento da radiação, mas tomaria - mecanismo básico para irreversibilidade como sendo a alteração da forma da onda eletromagnética pelo processo de espalhamento - sua aparentemente irreversível conversão da onda plana incidente para onda esférica emergente. $O$ último objetivo deste programa seria a explicação da irreversibilidade para sistemas conservativos e, como um valioso subproduto, a determinação da distribuição espectral da radiação de corpo negro.

Planck tinha grandes esperanças: seu objetivo era precisamente correto para um discípulo de Clausius. Teria sido uma esplêndida conclusão para seu trabalho em termodinâmica, e teria colocado um fim, de uma vez por todas, às afirmações de que a segunda lei era meramente uma matéria de probabilidade. (KLEIN, 1966, p.25).

Num artigo de maio 1899, Planck apresenta $a$ e $b$, duas constantes universais segundo ele. Utilizando dados experimentais para a radiação de corpo negro ele calcula esses valores $^{52}$. Planck percebe que essas constantes, juntamente com a velocidade da luz $c$ e a constante gravitacional $\mathrm{G}$, poderiam servir para definir novas unidades de massa, comprimento, tempo e temperatura, que ele nomeou como "unidades naturais". Segundo ele, essas novas unidades deveriam ser verdadeiras "independentemente dos corpos particulares ou substâncias, deveriam necessariamente reter seu significado por todos os

\footnotetext{
${ }^{52} a=0,481810^{-10} \mathrm{~s} . \operatorname{deg}$ (que na verdade era $h / k$ ) e $b=6.88510^{-27} \mathrm{~cm}^{2} \mathrm{~g} / \mathrm{s}$ (Jammer, 1966, p. 46).
} 
tempos e todas as culturas, incluindo extraterrestres e não humanas" ${ }^{153}$. Essas constantes seriam importantes, pois se encaixariam em sua visão de absoluto.

A constante $b$ foi logo renomeada $(h)$ e reinterpretada no artigo de dezembro de 1900.

\section{A derivação da lei de Wien}

Planck fez também várias tentativas e escreveu vários artigos procurando desenvolver uma derivação mais rigorosa da função de distribuição de Wien, aplicando a termodinâmica em processos eletromagnéticos. Assim Planck tentou mostrar que "as equações de Maxwell-Hertz, quando aplicadas a ressoadores ${ }^{54}$ com condições iniciais arbitrárias, levariam a processos irreversiveis convergindo para um estado estacionário cuja distribuição de energia era a da radiação de cavidade"55. Em seu estudo de absorção e emissão Planck pensou que tinha encontrado um processo irreversível na interação entre ressoadores absorventes e emissores.

Boltzmann foi quem apontou a principal falha nos propósitos de Planck, pois

... as equações da eletrodinâmica não podiam produzir uma abordagem monotônica para o equilíbrio assim como as equações da mecânica; ambas precisavam ser complementadas por suposições estatísticas. Nada nas equações da eletrodinâmica proibiria, por exemplo, a inversão do processo de espalhamento de Planck. (KLEIN, 1966, p.25)

Finalmente Planck se convenceu de que os processos estatísticos eram necessários e introduziu a hipótese de "radiação natural", usando o teorema $\mathrm{H}$ e de acordo com a qual as vibrações parciais harmônicas compondo uma onda de radiação térmica são completamente incoerentes.

Comparando a emissão e a absorção dos ressoadores, Planck obteve como condições de equilíbrio, somente usando princípios de eletrodinâmica clássica a equação ${ }^{56}$ :

$$
\mu_{v}=\frac{8 \pi}{c^{3}} v^{2} U
$$

\footnotetext{
${ }^{53}$ Citado por Klein (1966), p.26.

${ }^{54}$ A palavra ressoador atualmente pode ser entendida sem prejuizo conceitual como oscilador. Mantivemos o termo ressoador para permanecermos fiéis aos textos originais e históricos sobre 0 assunto.

${ }_{55}$ Zanetic (1999a), p.117-118.

${ }^{56}$ No apêndice III há um desenvolvimento detalhado desse problema da interação entre a radiação da cavidade e os ressoadores, no qual chegamos a essa expressão.
} 
Com $U=\bar{U}=U(v, T)^{57}$ a energia média vibracional de um ressoador linear à temperatura $T$ e $\mu_{v}=\mu(v, T)$ a densidade da radiação dentro de uma cavidade à temperatura $T$ por unidade de freqüência no intervalo entre $v$ e $v+d v$.

A partir desse resultado e da própria lei de Wien $\left(\mu_{v}=\alpha v^{3} e^{\left(-\frac{\beta v}{T}\right)}\right)$, por simples substituição Planck chegou ao resultado:

$$
U=C v e^{\left(-\frac{\beta \nu}{T}\right)}
$$

Tomando o logaritmo neperiano (base $e$ ) de ambos os lados da equação, e lembrando que $\ln e=1$,

$$
\ln U=\ln C+\ln v-\frac{\beta v}{T} \ln e
$$

De maneira que

$$
\frac{1}{T}=-\frac{\ln U}{\beta v}+\frac{1}{\beta v}(\ln C+\ln v)
$$

Planck estava familiarizado da termodinâmica que

$$
\frac{\partial S}{\partial U}=\frac{1}{T} \text { ou seja } S=\int \frac{1}{T} d U
$$

Com $S$ igual a entropia de um ressoador. Assim:

$$
S=\int-\frac{\ln U}{\beta v} d U+\int \frac{(\ln C+\ln v)}{\beta v} d U
$$

A menos de uma constante aditiva:

$$
\begin{gathered}
S=-\frac{1}{\beta v}(U \ln U-U-(\ln C+\ln v) U) \\
S=-\frac{U}{\beta v}(\ln U-1-\ln C-\ln v)
\end{gathered}
$$

Como $\ln e=1$,

$$
S=-\frac{U}{\beta v} \ln \left(\frac{U}{e C v}\right)
$$

Segundo Klein (1966), Planck convenceu-se de que esta definição era a única possível no sentido de que "se, e somente se, a entropia tivesse essa forma ele poderia

${ }^{57}$ Atualmente obtemos o valor de U com eqüipartição de energia (Jammer, 1966, p.12). 
provar que a entropia total do sistema aumentava monotonicamente para um valor de equilibrio". Dessa maneira, em um certo sentido, Planck completou seu programa, pois "ele realmente usou a segunda lei para fixar a função de entropia e portanto a distribuição espectral da radiação do corpo negro" (p.26).

Utilizando então esses princípios, Planck chegou inicialmente à sua lei de Wien, que foi publicada em maio de 1899 :

$$
\begin{gathered}
\frac{\partial S}{\partial U}=-\frac{1}{\beta v}\left[\ln \left(\frac{U}{e C v}\right)+U \cdot \frac{1}{U}\right] \\
\frac{\partial S}{\partial U}=-\frac{1}{\beta v}\left[\ln \left(\frac{U}{e C v}\right)+1\right]=-\frac{1}{\beta v} \ln \left(\frac{U}{C v}\right) \\
\frac{d^{2} S}{d U^{2}}=-\frac{1}{\beta v} \cdot \frac{1}{U} \\
\frac{d^{2} S}{d U^{2}}=\frac{c o n s t}{U}
\end{gathered}
$$

Segundo Kangro (1972) $d^{2} S / d U^{2}$ é a variação do aumento da entropia. Apenas para esta última Planck atribuiu um sentido físico (março 1900):" a medida numérica da irreversibilidade do processo ou para a não compensada transformação de trabalho em calor". A entropia em si mesma - ele argumentou - não tem sentido fisico" ${ }^{\text {58. }}$.

É importante salientar a circularidade no trabalho de Planck pois ele utilizou a própria lei de Wien para derivá-la pela via da entropia.

... Consistente com sua suposição com relação à irreversibilidade associada com a "radiação natural", ele então mostrou que a "entropia elétrica total" $S_{t}=\sum S+\int s d V$, em que a soma se estende sobre todos os osciladores e a integração sobre todos os elementos de volume $d V$ do campo de radiação com densidade de entropia $s$, é uma função de estado que aumenta com o tempo e alcança um máximo no equilíbrio. Planck agora assumiu que uma pequena porção de energia passa de um oscilador de freqüência $v$, entropia $S$ e energia $U$, para outro de freqüência $v^{\prime}$, entropia $S^{\prime}$ e energia $U^{\prime}$. Os princípios da entropia e da energia requerem que $\delta S_{t}=\delta S+\delta S^{\prime}=0$ e $\delta U+\delta U^{\prime}=0$ (Jammer, 1966, p.15)

Assim, esse resultado com a equação (17) nos fornece:

${ }^{58}$ Citado por Zanetic (1999b), p. 127. 


$$
\begin{gathered}
\delta S+\delta S^{\prime}=-\frac{\delta U}{\beta v} \ln \left(\frac{U}{e C v}\right)-\frac{U}{\beta v} \frac{e C v}{U} \delta U-\frac{\delta U^{\prime}}{\beta v^{\prime}} \ln \left(\frac{U^{\prime}}{e C v^{\prime}}\right)-\frac{U^{\prime}}{\beta v^{\prime}} \frac{e C v^{\prime}}{U^{\prime}} \delta U^{\prime}=0 \\
-\frac{\delta U}{\beta v} \ln \left(\frac{U}{e C v}\right)+\frac{\delta U}{\beta v^{\prime}} \ln \left(\frac{U^{\prime}}{e C v^{\prime}}\right)-\frac{e C}{\beta}\left(\delta U+\delta U^{\prime}\right)=0 \\
\delta U\left[-\frac{1}{\beta v} \ln \left(\frac{U}{e C v}\right)+\frac{1}{\beta v^{\prime}} \ln \left(\frac{U^{\prime}}{e C v^{\prime}}\right)\right]=0 \\
\frac{1}{\beta v} \ln \left(\frac{U}{e C v}\right)=\frac{1}{\beta v^{\prime}} \ln \left(\frac{U^{\prime}}{e C v^{\prime}}\right) \\
\frac{1}{\beta v} \ln \left(\frac{U}{C v}\right)=\frac{1}{\beta v^{\prime}} \ln \left(\frac{U^{\prime}}{C v^{\prime}}\right)
\end{gathered}
$$
considerados.

Sendo a expressão do lado esquerdo uma constante para todos os osciladores

$$
\frac{1}{\beta v} \ln \left(\frac{U}{C v}\right)=c t e=\rho
$$

Tomando o exponencial de ambos os lados:

$$
U=C v \exp (\rho \beta v)
$$

Da comparação com eq. (15) temos que $\rho=-1 / T$, de maneira que:

$$
U=C v \exp \left(-\frac{\beta v}{T}\right)
$$

Que em combinação com a equação (14) chega-se à lei de radiação de Wien, conforme equação (12).

\subsection{Os artigos de 1900}

$$
\mu_{v}=\alpha v^{3} \exp \left(-\frac{\beta v}{T}\right)
$$

Logo no início de 1900, medidas de Lummer e Pringsheim mostraram que a lei de Wien não se ajustava bem para o intervalo de pequenas freqüências. Nesse ano, muitos cientistas passaram a tentar encontrar novas formulações para a função de distribuição.

Em março de $1900 \mathrm{M}$. Thiesen chegou a algo parecido com o que Rayleigh fez, em junho de 1900. Em outubro do mesmo ano Lummer e E. Jahnke chegaram a uma equação que de acordo com a escolha dos parâmetros envolvidos, se reduzia ora à expressão de Wien, ora à de Thiesen, ora à de Rayleigh. Assim parecia que, dependendo da faixa de 
comprimento de onda em que se trabalhasse, o fenômeno era regido por equações diferentes.

Ainda em outubro de 1900, Heinrich Rubens (1865-1922) e Ferdinand Kurlbaum (1857-1927) estabeleceram uma série de medidas mostrando que a lei de Wien não era válida para pequenas freqüências. Poucos dias antes de apresentarem seus resultados (25 de outubro de 1900), ambos comunicaram o fato a Planck que passou a procurar por uma nova formulação. Ele resolveu o problema conseguindo uma expressão satisfatória para a função de distribuição e apresentou seu artigo na Sociedade Alemã de Física: "Sobre um aperfeiçoamento da equação de Wien para o espectro". Contudo Planck não apresentou um desenvolvimento teórico satisfatório nesse artigo.

\section{$O$ artigo de 19 de outubro de $1900^{59}$}

Nesse artigo Planck imaginou que talvez a equação (18) não era completamente válida e passou a construir, segundo suas próprias palavras,

... expressões completamente arbitrárias para a entropia que, embora sejam mais complicadas que a expressão de Wien, ainda parecem satisfazer tão completamente todos os requisitos da termodinâmica e da teoria eletromagnética. ${ }^{60}$

\section{Dessa maneira ele foi atraído}

... para uma das expressões assim construídas que é aproximadamente tão simples como a expressão de Wien e que mereceria ser investigada já que a expressão de Wien não é suficiente para cobrir todas as observações. ${ }^{61}$

Essa expressão era:

$$
\frac{d^{2} S}{d U^{2}}=\frac{a}{U(b+U)}
$$

Integrando essa expressão:

$$
\frac{1}{T}=\frac{d S}{d U}=a \int \frac{1}{U(b+U)} d U
$$

\footnotetext{
59 Artigo original: PLANCK, Max. Über eine verbesserung der Wienschen Spektralgleichung. Verhandlungen der Deutschen Physikalischen Gesellschaft, 2, 202-204 (1900). Versão inglesa: On an improvemente of Wien's equation for the spectrum. In: Planck's Original Papers in Quantum Physics. Português: Sobre um aperfeiçoamento da Equação de Wien para o Espectro. Revista Brasileira de Ensino de Física, vol. 22, n.4, p. 536-537. Tradução: Nelson Studart.

Esse artigo foi lido na encontro da Sociedade Germânica de Física em 19 de outubro de 1900.

${ }^{60}$ Citado por Zanetic (1999b), p. 127.

${ }^{61}$ Ibidem, p. 127.
} 


$$
\frac{1}{T}=a^{\prime} \ln \left[\frac{U+b}{U}\right]
$$

$\operatorname{Com} a^{\prime}=-\frac{a}{b}$

$$
\begin{gathered}
\exp \left(\frac{1}{T a^{\prime}}\right)=\frac{U+b}{U}=1+\frac{b}{U} \\
\frac{b}{U}=\exp \left(\frac{1}{T a^{\prime}}\right)-1 \\
U=\frac{b}{\exp \left(\frac{1}{T a^{\prime}}\right)-1}
\end{gathered}
$$

Jammer (1966, p.18) afirma que a partir dessa construção Planck então chegou à sua lei de radiação que se ajustava bem aos dados experimentais.

Igualando as equações (12) e (14):

$$
\begin{array}{r}
\frac{8 \pi}{c^{3}} v^{2} U=\alpha v^{3} e^{\left(-\frac{\beta v}{T}\right)} \\
U=C v e^{\left(-\frac{\beta v}{T}\right)}=\frac{C v}{\exp \left(\frac{\beta v}{T}\right)}
\end{array}
$$

Segundo Jammer, comparando as equações (21) e (22) e levando-se em conta que $a^{\prime}$ e $b$ são funções de $v$, Planck obteve:

$$
U=v \phi\left(\frac{v}{T}\right)
$$

Em que $\phi\left(\frac{v}{T}\right)$ é uma função de $\frac{v}{T}$. Assim ele concluiu que:

$$
U=\frac{c t e v}{\exp \left[\frac{c^{\prime} v}{T}\right]-1}
$$

De maneira que:

$$
\begin{aligned}
& U d U=\frac{c t e v}{\exp \left[\frac{c^{\prime} v}{T}\right]-1} d U \quad \mathrm{e} \\
& K_{\lambda} d \lambda=\frac{C \lambda^{-5}}{\exp \left[\frac{c}{\lambda T}\right]-1} d \lambda \text { ou }
\end{aligned}
$$




$$
\text { ou } \mu_{v}=\frac{A v^{3}}{\exp (B v / T)-1}
$$

Com $c^{\prime}, C, A$ e $B$ constantes.

\section{$O$ artigo de 14 de dezembro $1900^{62}$}

O resultado do artigo de outubro não satisfez Planck. Em suas próprias palavras:

Mas, ainda que a fórmula da radiação estivesse perfeita e irrefutavelmente correta, teria sido, afinal de contas, apenas uma fórmula de interpolação descoberta por um feliz acaso de raciocínio e isso nos teria deixado relativamente insatisfeitos. Em conseqüência, a partir do dia da descoberta, dispus-me a dar-lhe uma interpretação física, o que me levou a examinar as relações entre entropia e probabilidade segundo os conceitos de Boltzmann. Após algumas semanas do mais intenso trabalho que já realizei na vida, as coisas começaram a clarear e visões inesperadas revelaram-se a distância. ${ }^{63}$

Planck, assim, abandonou de certa maneira seu desenvolvimento termodinâmico e optou por usar o conceito probabilístico de entropia. Para tal ele usou a Memória de Boltzmann de 1877 sobre a mecânica estatística probabilística. Utilizando para a entropia de um sistema de $N$ osciladores de freqüência $v$ o resultado ${ }^{64} S=k \ln W$, com $k$ a constante de Boltzmann e $W$ o número de distribuições compatíveis com a energia do sistema.

Na seqüência para calcular a "probabilidade termodinâmica" do estado no qual uma certa energia estava dividida entre muitos osciladores (ressoadores) de mesma freqüência, quer dizer, o número de modos nos quais essa divisão poderia ser feita, foi essencial que Planck imaginasse a energia $(U)$ desses osciladores composta por um número finito de idênticas unidades. Este por si só não deveria ter sido um passo inovador: Boltzmann faziao freqüentemente como uma ferramenta computacional, como fez particularmente na Memória de 1899 que Planck usou como guia. ${ }^{65}$

Muitos autores atribuem a autoria da quantização de energia a Planck no artigo de dezembro de 1900, mais especificamente nesta passagem:

Se se considera $E$ uma quantidade continuamente divisível, esta distribuição poderia ser realizada num número infinito de modos.

\footnotetext{
62 Original: Zur Theorie des Gesetzes der Energievertilung im Normalspektrum. Verhandlungen der Deutschen Physikalischen, 2, 237-245, 1900. Versão em inglês: Kangro (1972). Tradução do título: Sobre a teoria da lei de distribuição de energia do espectro normal.

${ }^{63}$ Citado por Zanetic (1999b), p. 129.

${ }^{64} \mathrm{Na}$ verdade, Boltzmann utilizava essa expressão na forma $S=R / N \log W$, com $R$ a constante de Clapeyron e $N$ o número de Avogadro. Foi Planck que em 1900 substituiu R/N por k.

${ }^{65}$ Klein (1966), p.27.
} 
Consideramos, contudo - e este é o ponto essencial de todo o cálculo - $E$ composto de um número bem definido de partes iguais e empregamos para este propósito a constante da natureza $h=6,55 \cdot 10^{-27}$ erg seg. Esta constante multiplicada pela freqüência $v$ dos ressoadores dá o elemento de energia $\varepsilon$ em erg, e dividindo $E$ por $\varepsilon$ obtemos o número $P$ de elementos de energia que são distribuídos entre os $N$ ressoadores. Se a razão assim calculada não é um inteiro, tomamos para $P$ um inteiro na vizinhança ${ }^{66}$

Planck adotou esse procedimento, pois, se considerasse a energia contínua, seria impossivel calcular a probabilidade de o ressoador adquirir certa energia, visto que haveria infinitos modos de distribuí-la entre os ressoadores. Assim, Planck usou a energia quantizada como um truque matemático no qual ele imaginava que se tomando o limite de $\varepsilon$ tendendo a zero, a distribuição de energia poderia ser tomada como contínua. Ou seja, para ele o fato de que a energia estivesse quantizada deveria ser apenas um truque matemático não trazendo intrinsecamente nada de novo: “... em nenhum lugar deste artigo, nem em nenhum dos seus outros escritos, Planck colocou em proeminência o fato fundamental de que Ué um múltiplo inteiro de hv"(Jammer, 1966, p. 22).

Assim, assumindo que a energia total do sistema $U_{N}=N U$ consistiria de $P$ elementos $\varepsilon$, ou seja $U_{N}=P \varepsilon$, a distribuição da energia se daria de múltiplas formas entre os $N$ osciladores.

Interpretando $W$ ("complexions"), como o número possivel de distribuir os $P$ elementos de energia entre os $N$ osciladores, Planck obteve ${ }^{67}$ para $N \gg>1$ :

$$
W=\frac{(N+P-1) !}{(N-1) ! P !}
$$

Usando assim a aproximação de Stirling $N !=N^{N}$

$$
W=\frac{(N+P)^{N+P}}{N^{N} P^{P}}
$$

Na seqüência de seu artigo, sem mostrar os detalhes dos cálculos, Planck afirma que utilizando as equações (14) e (16) e a relação $S=k \ln W$, obtém-se o espectro de corpo negro dado pela equação (25).

Nesse artigo ainda Planck obteve um valor muito acurado para o número de Avogadro e também para a carga elétrica do elétron.

... Eu estou convencido que, com a particular sensibilidade de Planck para a importância das constantes naturais, foram estes resultados que

\footnotetext{
${ }^{66}$ Citado por Zanetic (1999b), p. 132-133.

${ }^{67} \mathrm{O}$ desenvolvimento está no apêndice IV.
} 
garantiram a ele que os quanta eram mais que uma hipótese ad hoc, apenas útil para chegar à lei da radiação. (Klein, 1966, p.28)

Infelizmente contemporâneos de Planck não apreciaram estes resultados; os handbooks apresentavam determinações rústicas do número de Avogadro, ignorando o valor de Planck. (Klein, 1966, p.28)

\section{$O$ artigo de $1901^{68}$}

No artigo de dezembro de 1900, Planck apresentou poucos desenvolvimentos matemáticos, afirmando que iria apresentar cálculos mais detalhados em artigo posterior, o que ele fez em 1901.

No entanto, gostaríamos de ressaltar que este último artigo apresentava, além de cálculos detalhados, uma grande diferença no que diz respeito à quantização de energia.

No artigo de 1900 Planck iniciou seu desenvolvimento baseado na hipótese de que $\varepsilon=h v$, sem nenhuma justificativa para essa igualdade. Também está evidente que a idéia de quantização, mesmo sendo um truque matemático, não estava clara para Planck, pois este afirmou que $P$, o número de elementos de energia que são distribuídos entre os $\mathrm{N}$ ressoadores, poderia não ser um número inteiro. ${ }^{69}$

Sobre a quantização ainda, três décadas depois, em uma carta a R. W. Wood, "Planck descreveu que aquilo tinha sido um "ato de desespero", tomado contra seu natural pacifismo e espirito não-aventureiro" (Klein, 1966, p.27).

Já no artigo de 1901, Planck refina sua quantização tomando explicitamente $P$ como um número inteiro. Além disso, ele não impõe inicialmente a condição de que $\varepsilon=h v$, igualdade que é estabelecida por ele através do desenvolvimento abaixo.

No artigo de dezembro de 1900 , Planck calculou o valor de $W$. Se o substituirmos na expressão para a entropia dos $N$ osciladores $S_{N}=k \ln W$.

$$
S_{N}=k[(N+P) \ln (N+P)-N \ln N-P \ln P]
$$

$$
\begin{aligned}
& \text { Como } U_{N}= N U=P \varepsilon \Rightarrow P=\frac{N U}{\varepsilon} \\
& S_{N}=k\left[\left(N+\frac{N U}{\varepsilon}\right) \ln \left(N+\frac{N U}{\varepsilon}\right)-N \ln N-\frac{N U}{\varepsilon} \ln \frac{N U}{\varepsilon}\right]
\end{aligned}
$$

\footnotetext{
${ }^{68}$ Original: Über das gesetz der energieverteilung im Normalspektrum. Annalen der Physik, 4, 553-563, 1901. Português: Sobre a lei de distribuição de energia no espectro normal. Tradução: Ildeu de Castro Moreira. Revista Brasileira de Ensino de Física, vol. 22, n.4, p. 538-542.

${ }^{69}$ Observação feita pelo professor Roberto Martins no Simpósio Comemorativo do Centenário da Constante de Planck, realizado na UNICAMP em 2000.
} 


$$
\begin{gathered}
S_{N}=k N\left[\left(1+\frac{U}{\varepsilon}\right) \ln N\left(1+\frac{U}{\varepsilon}\right)-\ln N-\frac{U}{\varepsilon} \ln N \cdot \frac{U}{\varepsilon}\right] \\
S_{N}=k N\left[\left(1+\frac{U}{\varepsilon}\right) \ln N+\left(1+\frac{U}{\varepsilon}\right) \ln \left(1+\frac{U}{\varepsilon}\right)-\ln N-\frac{U}{\varepsilon} \ln N-\frac{U}{\varepsilon} \ln \frac{U}{\varepsilon}\right] \\
S_{N}=k N\left[\left(1+\frac{U}{\varepsilon}\right) \ln \left(1+\frac{U}{\varepsilon}\right)-\frac{U}{\varepsilon} \ln \frac{U}{\varepsilon}\right]
\end{gathered}
$$

Como a entropia é uma grandeza extensiva, isto é $S_{N}=N S$, podemos encontrar a entropia de um único oscilador:

$$
S=k\left[\left(1+\frac{U}{\varepsilon}\right) \ln \left(1+\frac{U}{\varepsilon}\right)-\frac{U}{\varepsilon} \ln \frac{U}{\varepsilon}\right]
$$

A seguir, Planck mostrou que a lei de deslocamento de Wien pode ser enunciada pela simples relação $S=f\left(\frac{U}{v}\right)$. Comparando esse resultado com a expressão obtida acima para $S$, necessariamente o elemento de energia deveria ser proporcional à freqüência. Assim Planck demonstrou a igualdade $\varepsilon=h v$.

Ainda, usando $\partial S / \partial U=1 / T$ ele obteve a energia média $U$ dos osciladores de freqüência $v$ :

$$
\begin{gathered}
\frac{\partial S}{\partial U}=k\left[\frac{1}{h v} \cdot \ln \left(1+\frac{U}{h v}\right)+1-\frac{1}{h v} \cdot \ln \left(\frac{U}{h v}\right)-1\right]=\frac{1}{T} \\
\frac{1}{T}=\frac{k}{h v} \cdot \ln \left(\frac{1+\frac{U}{h v}}{\frac{U}{h v}}\right)=\frac{k}{h v} \ln \left(1+\frac{h v}{U}\right) \\
\frac{h v}{k T}=\ln \left(1+\frac{h v}{U}\right) \\
\exp \left(\frac{h v}{k T}\right)=1+\frac{h v}{U}
\end{gathered}
$$

Assim:

$$
U=\frac{h v}{\exp (h v / k T)-1}
$$

Utilizando, portanto, a equação (14) Planck obteve a sua lei de distribuição de energia: 


$$
\begin{gathered}
\mu_{v}=\frac{8 \pi h v^{3}}{c^{3}} \frac{1}{\exp (h v / k T)-1} \text { ou } \\
K_{\lambda} d \lambda=\frac{8 \pi c h}{\lambda^{5}} \frac{1}{\exp \left[\frac{h c}{k \lambda T}\right]-1} d \lambda
\end{gathered}
$$

Integrando sobre todas as freqüências, Planck obteve a lei de Stefan-Boltzmann e estabeleceu a relação entre $k^{4} / h^{3}$ e $\sigma$. Dos valores de $\sigma$ e $h / k$ ele calculou a constante de Planck com o valor $h=6,55 \times 10^{-27}$ erg.s.

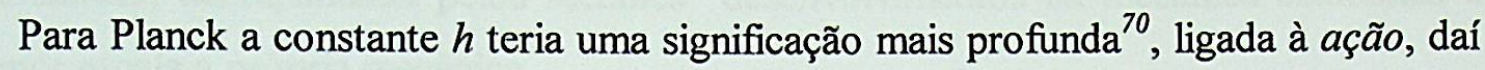
o nome quantum de ação. Essa constante foi assim chamada, pois tem a dimensão de ação, que é energia multiplicada pelo tempo e cuja dedução é oriunda do princípio de mínima ação. Sabemos hoje que a constante $h$ não tem essa significação proposta por Planck, além do que, como colocado por De Broglie, L. (1958), isso levaria a muitas complicações, pois não existe uma mecânica de conservação da ação e seria dificil representar uma grandeza que não se conserva como pertencente a uma estrutura atômica.

Em 1905, em carta a Ehrenfest, Planck afirmou ser possível que a constante $h$ tivesse algum significado direto na eletrodinâmica, pois tinha as mesmas dimensões e também a mesma ordem de magnitude de $e^{2} / c^{71}$

É importante salientar aqui a diferença entre a quantização de energia como entendemos hoje e aquela que de certa maneira Planck estava propondo. $\mathrm{O}$ conceito de elementos de energia pensados por Planck era aplicável somente ao mecanismo de interação entre a matéria e a radiação.

Planck também utilizava as fórmulas do eletromagnetismo de Maxwell, que supõem a emissão e a absorção de energia contínua. Dessa forma a energia de cada ressoador e a energia total de um conjunto de ressoadores de determinada freqüência não podiam ser descontínuos. Era apenas o oscilador de freqüência $v$ que podia emitir e absorver energia em múltiplos de $h v .^{72}$

\footnotetext{
${ }^{70}$ Segundo Roberto Martins, a escolha da letra $h$ para a constante de Planck provavelmente tenha sido pelo fato de que esta caracteriza a radiação de corpo negro numa cavidade, que em alemão é hohlraum = objeto oco.

${ }^{71}$ Klein (1966), p.28.

${ }^{72}$ Jammer (1966), p.28.
} 
Planck não estendeu seu conceito de quantização para o resto da natureza, ou seja, ele entendeu que apenas no caso particular do corpo negro era possível se tratar o oscilador como tendo energia quantizada. Hoje em dia, segundo a mecânica quântica, sabemos que qualquer sistema que possua estados ligados (ou ainda, que esteja "preso" por um potencial sendo limitado a uma região do espaço, como o caso do oscilador harmônico) irá possuir estados quantizados, ou seja valores discretos de energia ${ }^{73}$.

Procuramos mostrar neste breve histórico que todo o trabalho de Planck é muito rico conceitualmente e matematicamente, como também envolve todos os grandes ramos da física clássica: a eletrodinâmica (usada para estudar a emissão dos ressoadores), a termodinâmica, acompanhada pelos recentes desenvolvimentos na mecânica estatística e em menor escala a própria mecânica.

Dessa maneira, estudar a solução do PRCN é compreender melhor a própria estrutura da fisica clássica que antecedeu à teoria quântica, e conseqüentemente também aprofundar a compreensão desta última, através do contato com as dificuldades teóricas da época e as soluções encontradas. E, no que respeita particularmente o início do desenvolvimento da mecânica estatística, esse estudo ressalta a discretização da energia praticada por Boltzmann cerca de 30 anos antes de sua aplicação no PRCN. Vale mencionar estas palavras de Cássio Costa Laranjeiras (2002, p. 169-170)

Este método de trabalho, que vimos chamando de "método de discretização de energia" (...) marca um importante aspecto da heurística Boltzmanniana que qualquer quantidade contínua é considerada como um limite de uma quantidade discreta. Este tratamento se constituiu em uma fonte de inspiração para Planck, quando do tratamento de questões relacionadas a radiação de corpo negro no final do século XIX e início do $\mathrm{XX}$.

No entanto, toda essa riqueza não é aproveitada na formação de cientistas e professores e basicamente encontramos apenas a quantização de energia destacada na maior parte da literatura básica sobre a resolução do PRCN por Planck.

Ao contrário da opinião vigente nestes textos, julgamos que não tenha sido a quantização a grande contribuição de Planck, já que nos parece que ele mesmo não tenha se convencido muito a seu respeito. Além da inserção da constante $h$ na fisica, que ele mesmo percebeu como importante e fundamental, o ponto central de todo o seu desenvolvimento estava na entropia do corpo negro em equilibrio. Entretanto, como discutiremos mais adiante neste trabalho, o cálculo termodinâmico de Planck não é nem

\footnotetext{
${ }^{73} \mathrm{E}$ essa quantização não é necessariamente igual a múltiplos de $h v$.
} 
mesmo citado em muitos livros históricos, de divulgação científica, ou mesmo manuais didáticos.

\section{Desenvolvimentos posteriores}

\subsection{Repercussão e conseqüências da solução de Planck para o PRCN}

Planck admitiu em sua autobiografia que estava insatisfeito com seu desenvolvimento e tentou sem sucesso inserir o $h$ na estrutura da física clássica. ${ }^{74}$

Embora sua formulação matemática tenha se mostrado satisfatória, seu desenvolvimento teórico não chamou atenção, não evocando rapidamente um abandono da fisica clássica. Em 1909, por exemplo, Lorentz afirmou que "não podemos dizer que o mecanismo do fenômeno tenha sido invalidado [pela teoria de Planck], e deve ser admitido que é dificil ver a razão para esta distribuição de energia por porções finitas, que não são iguais entre cada um, mas variam de um ressoador para outro". (Jammer, 1966, p. 24)

Assim, a dedução teórica de Planck não foi muito discutida na época, sua lei foi confirmada e aceita, já que se adequava aos fenômenos e a constante $h$ se mostrava como um truque matemático sem importância. Outra dificuldade para sua aceitação é que esta não representava nenhuma conservação, já que não existe nenhum princípio de conservação da ação (energia $x$ tempo). Também como Lorentz observou, Planck não levou em conta a interação da radiação com o éter, cujo escopo teórico ainda fazia parte da fisica teórica.

Albert Einstein (1879-1955), em 1906, foi o primeiro a reconhecer uma inconsistência lógica no trabalho de Planck. Na primeira parte de sua resolução Planck tratou a energia dos osciladores como uma variável continua ${ }^{75}$, como estabelecido na teoria eletromagnética e depois tratou essa mesma energia como discreta, assumindo valores múltiplos de $h v$. Para que a consistência interna do trabalho de Planck fosse mantida cada porção de energia $\varepsilon=h \nu$ deveria ser pequena comparada com a energia média $U$ de um ressoador, propiciando assim que a quantização fosse desprezível. E este não era o caso, como Einstein mostrou em 1909.

No entanto, essa inconsistência interna no trabalho de Planck não foi suficiente para que Einstein rejeitasse seu trabalho, ele apenas observou que a teoria da radiação é que deveria ser alterada.

\footnotetext{
${ }^{74}$ Jammer (1966), p.22.

${ }^{75}$ Como discutido no apêndice III.
} 
Peter Joseph Wilhelm Debye (1884-1966) também trabalhou procurando sanar a inconsistência lógica no trabalho de Planck. Sua resolução para o problema, em 1910, é muito parecida com aquela apresentada nos manuais didáticos atualmente. Inicialmente ele calculou o número $N d v$ de ondas estacionárias com frequiência entre $v$ e $v+d v$ numa caixa de volume unitário:

$$
N d v=\frac{8 \pi v^{2}}{c^{3}} d v
$$

Ao assumir que as $N d v$ vibrações consistiam de $f(v)$ quanta de energia contendo cada uma a energia $h v$, ele propôs assim uma quantização da energia sem a necessidade do conhecimento das propriedades e do mecanismo dos ressoadores:

$$
u d v=\frac{8 \pi h v^{3}}{c^{3}} f(v) d v
$$

Definindo "radiação de corpo negro" como a "mais provável radiação", isto é, como o estado com o maior número possível de distribuições de quanta $f(v)$ sobre os $N d v$ receptores, Debye provou usando a fórmula combinatória de Planck que neste caso $f(v)=[\exp (h v / k T)-1]^{-1}$, um resultado que em combinação com a fórmula anterior implica na lei de Planck da radiação. (Jammer, 1966,p.26)

\subsection{O trabalho de Einstein}

Em 1905, no artigo "num ponto de vista heurístico concernente à produção e transformação da luz", ano da publicação de outros quatro grandes trabalhos, entre os quais a teoria da relatividade especial, Einstein discutiu o efeito fotoelétrico ${ }^{76}$ e propôs que a radiação fosse composta por um número finito de quanta de energia (que hoje denominamos de fótons ${ }^{77}$ ). Para chegar a esse resultado Einstein também se utilizou, entre outros, do conceito de entropia.

No entanto, mesmo conhecendo o trabalho de Planck, Einstein não se baseou neste para desenvolver sua teoria e não usou o termo $h v$. Embora até mesmo cite o desenvolvimento de Planck para a resolução do problema da radiação de corpo negro.

760 efeito fotoelétrico, cuja denominação foi posterior a 1905, consistia da emissão de elétrons da superfície de um metal ao se incidir radiação de determinadas freqüências. Três aspectos básicos do fenômeno não conseguiam ser explicados pela teoria ondulatória da luz. Primeiramente a energia cinética máxima dos elétrons emitidos não dependia da intensidade da luz. Em segundo lugar havia uma freqüência mínima da radiação a partir da qual o fenômeno acontecia. E por fim mesmo para intensidades bastante baixas de radiação os elétrons podiam ser quase que instantaneamente emitidos (isto é, não era necessário um tempo longo para absorção de energia do campo elétrico por parte do material e posterior emissão).

${ }^{77}$ O termo fóton foi introduzido por G.N. Lewis em 1926 (Jammer, 1966, p. 30). 
Ele chegou à conclusão de que:

... na propagação de um raio de luz emitido de uma fonte pontual, a energia não é distribuída continuamente sobre volumes crescentes de espaço, mas consiste de um finito número de quanta de energia localizados em pontos do espaço que se move sem divisão, e podem ser absorvidas ou geradas apenas como unidades completas. ${ }^{78}$

Ou seja, a radiação monocromática comporta-se como se consistisse de quanta independentes de energia de magnitude $R \beta v / N, \operatorname{com} R$ sendo a constante dos gases e $N$ o número de Avogadro ${ }^{79}$. Ou seja, enquanto a quantização de Planck se relacionava com a interação da luz com a matéria, Einstein quantizava a radiação em trânsito e também assumiu que a interação da luz com a matéria consistia da emissão e absorção de tais quanta.

Suas idéias confrontavam com a tão já bem estabelecida compreensão da luz pelo modelo ondulatório. Contudo, apesar de que na época não fosse notório, os experimentos realizados até então que evidenciavam a natureza ondulatória para a luz, não provavam que ela não podia também ser granular. De certa maneira, Einstein inseriu na discussão onda ou partícula para a luz o conectivo $e$, abolindo o ou. Até então esse possivel aspecto dual para a luz nunca fora colocado em questão.

Entretanto, em particular, esse trabalho de Einstein não foi levado a sério, pois não explicava os fenômenos de interferência, difração e polarização da luz. O primeiro autor a utilizar a noção de quanta de luz de Einstein foi Johannes Stark (1874-1957), em 1907, sugerindo inclusive que a quantização de energia se aplicava até mesmo aos elétrons ${ }^{80}$.

Em 1914, estudando o efeito fotoelétrico, Robert Andrews (1868-1953) realizou a primeira determinação direta da constante de Planck, que corroborou o resultado calculado por Planck. Com essa confirmação o quantum de ação transformou-se numa realidade fisica.

Em 1922, Arthur Holly Compton (1892-1962) realizou um experimento idealizado por Stark em 1909, no qual confirmou a hipótese dos quanta de luz e sua transferência de momento.

Contudo, o completo entendimento da natureza dual da luz, só foi obtido com o estabelecimento da mecânica quântica, visto que as dificuldades na aplicação simultânea dos modelos corpuscular e ondulatório para a luz levaram à rejeição das idéias de Einstein.

\footnotetext{
${ }^{78}$ Extraído da tradução para o inglês do referido artigo de Einstein (Penrose, 1998).

${ }^{79} R / N=k$ e $\beta=h / k$.

${ }^{80}$ Martins, Roberto (2000).
} 
Podemos notar essa discordância no ato da indicação de Einstein para membro da Academia de Ciências Prussiana, em junho de 1913. Num documento assinado pelos mais eminentes físicos alemães, entre os quais se encontrava Planck, foi declarado ao término da recomendação:

... podemos dizer que não existe, entre os grandes problemas nos quais a física moderna é tão rica, um único em que Einstein não tenha feito uma importante contribuição. Que ele possa às vezes ter errado o alvo em suas especulações, como, por exemplo, em suas hipóteses dos quanta de luz, não pode realmente ser tomado muito contra ele, pois não é fundamentalmente possível introduzir novas idéias, como na maioria das ciências exatas, sem ocasionalmente se arriscar. ${ }^{81}$

Segundo Jammer (1966), o trabalho de Planck de outubro de 1900, continha certas implicações que, ao serem reconhecidas por Einstein, afetariam de maneira decisiva os fundamentos da física. Segundo esse autor, as raízes da teoria quântica podem ser vislumbradas num artigo de Einstein de 1909, "no estado presente do problema da radiação", no qual ele calculou as flutuações da energia radiativa num volume parcial $V$ de uma cavidade isotérmica a temperatura $T$. Sendo $E_{v}$ a energia instantânea com freqüência entre $v$ e $v+d v, \bar{E}_{v}$ a energia média e $E_{f l u t}$ a flutuação de energia $\left(E_{f l u t}=E_{v}-\bar{E}_{v}\right)$, ele chegou à seguinte expressão:

$$
\overline{E_{f l u t}^{2}}=\bar{E}_{v} h v+\frac{c^{3} \overline{E_{v}^{2}}}{8 \pi v^{2} V d v}
$$

O segundo termo da soma na equação acima seria então

... a flutuação média da energia ao quadrado devido a interferências entre ondas parciais, como Einstein mostrou em seu artigo por uma simples análise dimensional e como Lorentz subseqüentemente demonstrou em detalhes rigorosos. Isto é, portanto, exatamente o termo que tinha sido esperado com base na teoria ondulatória ou Maxwelliana da luz. O primeiro termo, por outro lado, enquanto inexplicável deste ponto de vista, podia facilmente ser tomado, como Einstein apontou, com base em sua hipótese dos quanta de luz... ${ }^{82}$

Jammer coloca ainda que a razão definitiva para a descoberta estatística da dualidade da luz foi a lei de radiação de Planck. Segundo esse autor se a radiação era tratada na forma

\footnotetext{
${ }^{81}$ Citado por Jammer (1966), p.44.

82 Ibidem, p.38.
} 


$$
\frac{d^{2} S}{d U^{2}}=\frac{\text { const }}{U^{2}}
$$

que desembocaria na lei de Rayleigh-Jeans, o cálculo da flutuação de energia daria o segundo termo da equação (34), o que corresponderia a uma compreensão ondulatória para a luz. Já se a lei de Wien for usada na forma [equação (18)]:

$$
\frac{d^{2} S}{d U^{2}}=\frac{\text { const }}{U}
$$

o cálculo da flutuação de energia se restringiria ao primeiro termo da soma da equação (34), o que corresponderia a uma compreensão corpuscular para a luz.

Assim Planck, ao realizar a sua interpolação entre as equações (18) e (35) da forma [equação (20)]:

$$
\frac{d^{2} S}{d U^{2}}=\frac{a}{U(b+U)}
$$

fez um amálgama dos aspectos ondulatórios e corpusculares para a luz, embora ele não tenha percebido o fato.

... esta conclusão também segue do fato de que para baixas freqüências, o range de validade da equação (1.10) [equação (35)], o primeiro termo da soma sob discussão pode ser negligenciado em comparação com o segundo, enquanto que para altas freqüências, em que a equação (1.8) [equação (18)] é válida, a equação (1.19)[equação (34)] se reduz para $\overline{E_{f u t}^{2}}=\bar{E}_{v} h v$, a fórmula de flutuação para partículas de um gás ideal. ${ }^{83}$

\subsection{Alguns dos trabalhos posteriores de Planck}

Numa revisão sobre teorias para a radiação em 1910, Planck, dispondo as teorias num espectro, colocou a sua teoria como central, a de Rayleigh-Jeans à extrema direita e a de Einstein (entre outros) completamente oposta a esta última.

Para Einstein a radiação seria considerada como uma coleção de independentes partículas de quanta de luz-energia. Planck não aceitava esse ponto de vista, embora estivesse inteiramente compromissado com o quantum. Também "estava certo de algo mais: a descontinuidade expressa por seu quantum de ação era real e deveria ser levada em conta" (Klein, 1966, p.24). Ele chegou à conclusão de que deveria concordar com posições mais radicais como a de Einstein, mas somente para o caso do problema da radiação do corpo negro.

\footnotetext{
${ }^{83}$ Jammer, 1966, p. 45.
} 
Planck não queria abrir mão dos desenvolvimentos de Huygens, Maxwell e Hertz, o que já não ocorria com relação à mecânica, pois ele acreditava que talvez não fossem tão geralmente válidas as equações de Hamilton.

Em um artigo lido em 1911 para a Sociedade Física Alemã, Planck revisou sua teoria inicial, no qual procurava rebater as críticas recebidas, principalmente por Lorentz.

... A objeção foi basicamente que a intensidade da radiação em altas freqüências era muito baixa, enquanto que nestas freqüências o quantum de energia era muito grande. Como conseqüência o tempo que um oscilador levaria para absorver um quantum deveria ser excessivamente grande, e o oscilador poderia não ser capaz de absorver um quantum completo se a radiação fosse cortada. (Klein, 1966, p.30)

$\mathrm{Na}$ verdade essa aparente contradição poderia ter sido resolvida com a solução de Einstein para o efeito fotoelétrico, mas Planck não foi por esse caminho.

Ele propôs ao invés disso abandonar sua hipótese de que a energia de um oscilador tinha que ser um múltiplo inteiro de $h v$ e poderia portanto absorver ou emitir energia somente em unidades discretas. Em sua nova teoria o oscilador poderia absorver energia continuamente, como no caso clássico... (Klein, 1966, p.30)

Contudo, a emissão ainda continuava quantizada.

Com essa teoria Planck também eliminava um problema de consistência interna de sua teoria, pois classicamente não era possível os osciladores terem energias descontínuas.

Em 1912, completando sua assim chamada "segunda teoria", Planck chegou a uma nova expressão para a quantização de energia com um termo adicional, o que correspondia ao fato de que a energia do oscilador não era nula no zero absoluto de temperatura, ficava em $h v / 2$. Hoje conhecida como energia de ponto-zero. Planck também nesse artigo realizou mudanças significativas no conceito de probabilidade de emissão dos osciladores.

Ainda sobre a complexa relação de Planck com a conceituação dos quanta, vale reproduzir um trecho do prefácio, escrito em novembro de 1912, do seu livro sobre radiação térmica:

Enquanto muitos físicos, de índole conservadora, rejeitam as idéias que desenvolvi, ou, de qualquer forma, mantêm uma atitude de expectativa, alguns autores têm-nos atacado por razão oposta, a saber, como sendo inadequadas, e foram compelidos a suplementá-las com suposições de uma natureza ainda mais radical, por exemplo, pela suposição de que qualquer energia radiante, mesmo que se desloque livremente no vácuo, consiste de quanta ou células indivisíveis. Desde que nada é provavelmente um obstáculo maior para o desenvolvimento bem sucedido de uma nova hipótese que a transgressão de suas fronteiras, eu tenho sempre defendido uma conexão tão próxima quanto 
possível entre a hipótese quântica e a dinâmica clássica, e por não caminhar fora das fronteiras da última até que fatos experimentais deixem nenhum outro caminho aberto. Eu tenho tentado manter este ponto de vista na revisão deste tratado, necessária para uma nova edição. (Planck, 1959, p. viii)

Em 1914, Planck colocou o $h$ governando somente a interação entre osciladores e partículas livres, sendo que a absorção e emissão de radiação seguiam as leis clássicas. Planck estava sempre argumentando sobre a lei de radiação e tentando restringir o uso do quantum para um mínimo suficiente para derivar aquela lei.

\subsection{O Primeiro Congresso de Solvay}

Por volta de 1910 poucas pessoas estavam envolvidas com as questões da quantização de energia. No entanto, os pesquisadores sobre a radiação do corpo negro estavam convencidos de que "era necessário introduzir descontinuidade (mas não estava claro qual descontinuidade) ${ }^{m 84}$. Os quanta de luz pareciam incompatíveis com a natureza ondulatória da luz e desta maneira também não eram aceitos.

O físico W. Nerst convenceu o químico belga Ernest Solvay (1838-1922) a financiar um congresso para a discussão do problema dos quanta. Este ficou conhecido como o primeiro congresso de Solvay, consagrado ao exame do problema dos quanta. Esse encontro ocorreu em Bruxelas entre os dias 30 de outubro e 3 de novembro de 1911 e só teve como participantes cientistas convidados ${ }^{85}$, entre os quais Planck figurou como o personagem central.

Entre as conclusões gerais, foi de certa maneira estabelecido, que era necessário introduzir algum tipo de descontinuidade na física e que talvez fosse necessário alterar as leis da fisica. Nesse congresso Hendrik Antoon Lorentz (1853-1928) expôs que o PRCN era ainda "o mais misterioso e mais dificil problema de ser entendido" $"$.

\footnotetext{
${ }^{84}$ Martins (2000).

${ }^{85}$ Goldschmidt, Nernst, Planck, Brillouin, Rubens, Solvay, Sommerfeld, Lindmann, Maurice de Broglie, Lorentz, Knudsen, Warburg, Perrin, Hasenöhrl, Hostelet, Wien, Herzen, M. Curie, Jeans, Rutherford, Poincaré, Einstein, Langevin, Kammerling-Onnes.

${ }^{86}$ Citado por Zanetic (1999b), p. 146.
} 
Finalizando esse breve histórico, gostaríamos de parafrasear o tom irônico de Roberto Martins, em palestra proferida em 2000: "no fim tudo deu certo, e resultou na atual mecânica quântica, que todos compreendem perfeitamente". 


\section{II - O FUNCIONAMENTO DA CIÊNCIA, A EDUCAÇÃO CIENTÍFICA E OS MANUAIS DIDÁTICOS: DISTORÇÕES PARA A FÍSICA E O SEU ENSINO}

Neste capítulo discutimos o referencial epistemológico que norteia nossa visão histórico-filosófica para o problema da radiação de corpo negro (PRCN), assim como delimita nossa visão do funcionamento da ciência. Através deste referencial analisamos, então, a educação científica e o uso que esta faz dos manuais didáticos que, em geral, distorcem a história da ciência. Propomos também alterações na estrutura do treino científico, visando a formação de professores e cientistas.

\section{O referencial teórico: a epistemologia de Thomas S. Kuhn ${ }^{87}$}

O físico, historiador e filósofo da ciência Thomas S. Kuhn, em 1962, escreveu o livro "A Estrutura das Revoluções Científicas", no qual apresentou sua tese sobre o desenvolvimento da ciência que, em aspectos gerais, confrontava de maneira radical com os modelos até então em voga como o empirismo lógico e o racionalismo crítico de Karl R. Popper ${ }^{88}$.

Para Kuhn o desenvolvimento científico ocorre por ciclos, é fortemente ancorado na comunidade científica e respaldado por paradigmas. Suas idéias contrariam de certa maneira a noção de que a ciência deveria ser produzida objetivamente, com apoio em uma base empírica e guiada pela lógica. Também contraria a noção de um progresso cumulativo da ciência, como muitas vezes os manuais didáticos nos induzem a acreditar.

\section{Fase pré-paradigmática}

$\mathrm{Na}$ epistemologia kuhniana, o período anterior ao estabelecimento de qualquer ciência madura (pré-paradigmática), que busque um diálogo proficuo com um mesmo conjunto de fenômenos naturais, é regido pelo aparecimento de várias "escolas" ou correntes diferentes de pensamento, as quais se restringem basicamente à discussão profunda das bases dessa ciência. Por não haver um corpo qualquer de crenças comuns

\footnotetext{
${ }^{87}$ Este breve sumário da proposta epistemológica de Thomas Kuhn foi baseado no seu livro "A Estrutura das Revoluções Científicas", de 1962. Em trabalhos posteriores Kuhn amenizou algo da radicalidade presente nesse livro como, por exemplo, a questão da incomensurabilidade entre paradigmas e a ausência de teorias alternativas no período da ciência normal.

${ }^{88}$ No Empirismo Lógico, um enunciado ou conceito só é significante na medida em que for fundamentado na experiência e só é aceito se for passível de formulação na linguagem lógica. No racionalismo crítico de Karl Popper, um modelo hipotético-dedutivo, a ciência não se caracteriza pela busca de fundamentos
} 
bem estabelecido, cada trabalho é forçado a construir novamente seu campo de estudos desde os fundamentos. $\mathrm{Na}$ ausência desse esquema conceitual, todos os fatos pertinentes ao desenvolvimento de determinada ciência têm probabilidade de parecerem igualmente semelhantes e o progresso científico é lento.

Quando, pela primeira vez no desenvolvimento de uma ciência da natureza, um indivíduo ou grupo produz uma síntese capaz de explicar boa parte daquele conjunto de fenômenos conhecidos e atrair a maioria dos praticantes da ciência, as demais escolas começam a desaparecer gradualmente e um único paradigma é estabelecido, o qual produz uma nova definição mais rígida do campo de estudos. Inicia-se assim um período conhecido como ciência normal.

\section{O paradigma e a ciência normal}

A noção de paradigma, conceito fundamental da epistemologia de Kuhn, deve ser entendida como o conjunto de tudo aquilo que une os membros de uma comunidade científica. Nas palavras de Kuhn, paradigmas seriam:

(...)as realizações científicas universalmente reconhecidas que, durante algum tempo, fornecem problemas e soluções modulares para uma comunidade de praticantes de uma ciência. (Kuhn, 2000, p.13)

Dessa maneira não podemos tomar a palavra paradigma apenas como o conjunto de teorias e leis físicas, mas também como o de suas aplicações instrumentais. Uma determinada visão de mundo, relativa aos fenômenos estudados, consolida também uma metodologia característica do paradigma aceito pela comunidade científica. O paradigma informa ao cientista que entidades a natureza contém ou não contém, além de como essas entidades se comportam. Essa informação fornece um mapa cujos detalhes são elucidados pela pesquisa científica amadurecida.

Também a noção de paradigma está intrinsecamente vinculada ao período chamado ciência normal, no qual, através da instrução e treinamento científico, o cientista familiariza-se com o paradigma dominante, e trabalha sob o respaldo deste. Ou seja, a ciência normal seria

...a pesquisa firmemente baseada em uma ou mais realizações científicas passadas. Essas realizações são reconhecidas durante algum tempo por uma comunidade científica específica como proporcionando os fundamentos para sua prática posterior. (Kuhn, 2000, p.29) 
Quando uma comunidade científica estabelece um paradigma, define um critério para a escolha de problemas que, enquanto o paradigma for aceito, poderemos considerar como dotados de uma solução possível. Esses são os únicos problemas que a comunidade admitirá como científicos ou encorajará seus membros a resolver. Outros problemas, mesmo muitos dos que eram anteriormente aceitos, passam a ser rejeitados como metafísicos ou como não pertencentes à ciência em questão.

Em geral, os cientistas não estão orientados para a descoberta do novo, mas sim procuram ampliar, estender e refinar o alcance e a precisão com os quais o paradigma vigente pode ser aplicado. Kuhn posiciona o cientista como um solucionador de complexos quebra-cabeças instrumentais, conceituais e matemáticos. Neste jogo o paradigma fornece o contexto, as "peças" que devem ser encaixadas e inclusive possíveis soluções. Nessa fase da prática científica, podemos dizer que o desenvolvimento da ciência é cumulativo.

Uma vez que o cientista está amparado pelo paradigma e acredita fielmente neste, por vezes ele reprime novidades fundamentais, pois estas não dizem respeito à sua concepção do mundo. Havendo discrepância entre a teoria e o experimento, inicialmente o eventual fracasso da pesquisa não se reflete sobre a ciência e seu paradigma, mas sobre a inabilidade do cientista normal em não saber manipular e estender adequadamente o paradigma vigente.

\section{As anomalias}

A ciência normal assim se desenvolve, até que surgem fatos ou eventos que o paradigma não comporta e precisam ser solucionados. São as anomalias, isto é:

... o reconhecimento de que, de alguma maneira, a natureza violou as expectativas paradigmáticas que governam a ciência normal. Segue-se então uma exploração mais ou menos ampla da área em que ocorreu a anomalia. Esse trabalho somente se encerra quando a teoria do paradigma for ajustada, de tal forma que 0 anômalo tenha se convertido no esperado. (Kuhn, 2000, p.78)

\section{A crise e a revolução cientifica}

Quando o anômalo não é convertido com sucesso no esperado, a ciência entra então num período de crise, no qual são realizadas tentativas (até mesmo desesperadas) de solucionar esses problemas e novas teorias especulativas e desarticuladas surgem na expectativa de indicar o caminho para novas descobertas. Isso é o que Kuhn chama de ciência extraordinária, em oposição à ciência normal. 
O período de crise, ao provocar uma proliferação de versões para o paradigma, enfraquece as regras de resolução dos quebra-cabeças da ciência normal, de tal modo que acaba permitindo a emergência de um novo paradigma e subseqüente batalha pela sua aceitação pela comunidade científica.

Segundo Kuhn, ocorre aí uma revolução científica, episódio de desenvolvimento não cumulativo, no qual um paradigma antigo é total ou parcialmente substituído por um novo, incompatível com o anterior, que transforma a imagem que se tem da natureza, permitindo que esta seja vislumbrada por perspectivas nunca antes mesmo imaginadas. Freqüentemente, um novo paradigma emerge, pelo menos na fase embrionária, antes que uma crise esteja bem desenvolvida ou tenha sido explicitamente reconhecida.

O período de crise e a conseqüente revolução científica englobam assim a consciência prévia da anomalia, a emergência gradual e simultânea de um reconhecimento tanto no plano conceitual como no plano da observação e a conseqüente mudança das categorias e procedimentos paradigmáticos. Kuhn afirma que normalmente as revoluções científicas são proporcionadas por jovens cientistas, que ainda não têm um compromisso sério e longo com os paradigmas vigentes.

As revoluções são em geral permeadas por muita resistência, visto que a confiança e aceitação nos paradigmas dominantes são condições essenciais para a ciência normal. Kuhn fala literalmente em conversão da comunidade científica ao novo paradigma, devido às resistências encontradas e por fatores que em geral escapam à esfera aparente da ciência. Por exemplo, uma das razões pelas quais Kepler se tornou copernicano dizia respeito a um certo misticismo com relação ao Sol.

\section{Desenvolvimento não cumulativo da ciência}

A epistemologia de Kuhn apresenta a concepção de desenvolvimento científico não cumulativo, ou seja, numa visão mais panorâmica sobre a ciência, esta não é construída tijolo por tijolo, com cada um dos cientistas ampliando e somando conhecimentos àquilo que seus antepassados construíram. Isso ocorre porque cada revolução culmina na reformulação de um paradigma ou em outro paradigma incomensurável com o anterior, pois "mudam conceitos, métodos e aplicações"89.

Portanto, a evolução da ciência não seria uma superposição de conhecimentos, pois ocorre com o surgimento de racionalidades distintas das anteriores - uma nova visão de mundo - que não deixam de explicar boa parte daquilo que o paradigma anterior já 
solucionava. "Paradigmas sucessivos nos ensinam coisas diferentes acerca da população do universo e sobre o comportamento dessa população"..$^{90}$ Assim, "durante as revoluções, os cientistas vêem coisas novas e diferentes quando, empregando instrumentos familiares, olham para os mesmos pontos já examinados anteriormente"

Para entendermos melhor essa noção de desenvolvimento científico em Kuhn, que muitas vezes é até mesmo recorrente, fornecemos este exemplo extraído da sua obra que diz respeito ao paradigma estabelecido por Newton:

[O paradigma que resultou da obra de Newton] teve como efeito uma nova mudança, parcialmente destrutiva, nos problemas e padrões considerados legítimos para a ciência. A gravidade, interpretada como uma atração inata entre cada par de partículas de matéria, era uma qualidade oculta no mesmo sentido em que a antiga "tendência a cair" dos escolásticos. Por isso, enquanto os padrões de concepção corpuscular permaneceram em vigor, a busca de uma explicação mecânica da gravidade foi um dos problemas mais dificeis para os que aceitavam os Principia como um paradigma. Newton devotou muita atenção a ele e muitos dos seus sucessores do século XVIII fizeram o mesmo. A única opção aparente era rejeitar a teoria newtoniana por seu fracasso em explicar a gravidade e essa alternativa foi amplamente adotada. Contudo nenhuma dessas concepções acabou triunfando. Os cientistas, incapazes, tanto de praticar a ciência sem os Principia, como de acomodar essa obra aos padrões do século XVII, aceitaram gradualmente a concepção segundo a qual a gravidade era realmente inata. Pela metade do século XVIII tal interpretação fora quase universalmente aceita, disso resultando uma autêntica reversão, (o que não é a mesma coisa que retrocesso), a um padrão escolástico. (Kuhn, 2000, p.139-140)

Sinteticamente podemos assim dizer que, para Kuhn, a evolução do conhecimento científico se processa pela descoberta de anomalias e a posterior invenção de novidades teóricas, incompatíveis com as anteriores.

\subsection{A origem de um novo paradigma: a física quântica}

Pensando na epistemologia de Thomas Kuhn, podemos apontar o trabalho de Planck como um dos desencadeadores da crise que permitiu a eclosão de um novo paradigma: a física quântica. Este paradigma trouxe uma nova visão de mundo, incompatível com a fisica clássica, que começou a apresentar problemas no final do século XIX e início do século XX.

\footnotetext{
${ }^{89}$ Zanetic (1999a), p.39.

${ }^{90}$ Kuhn (2000), p.137.

${ }^{91}$ Ibidem, p.145.
} 
Vários textos apontam como anomalias da física clássica o PRCN, o cálculo do calor específico dos sólidos e ainda o problema que mais tarde foi identificado como o efeito fotoelétrico. Esses problemas, apesar de tentativas reiteradas de cientistas renomados e treinados na ciência normal, não estavam sendo resolvidos, embora a impressão que se tivesse era a de que logo um cientista mais habilidoso conseguiria fazê-lo.

Entretanto, mesmo tomando o PRCN como uma das anomalias para a física clássica, não podemos apontar exatamente em que momento a crise foi estabelecida. Contudo também nos é lícito interpretar a solução de Planck para o PRCN com a apresentação do quantum de ação como um dos mais fortes fatores provocativos da crise paradigmática que originou a física quântica.

Muitos historiadores apontam Planck como o precursor da fisica moderna, visto que introduziu a idéia de quantização e muitos autores situam o nascimento da teoria quântica no artigo de outubro de 1900 de Planck, pois neste ele resolveu o PRCN. Já outros autores consideram que o nascimento da teoria quântica está no artigo de dezembro, pois lá já estava o quantum de ação e a quantização. Jammer prefere considerar esta última data, pois lá já estava o gérmem da concepção de junção entre as teorias ondulatória e corpuscular para a luz. Segundo esse autor a dualidade onda-partícula para a luz é a principal característica da teoria quântica.

No entanto, acreditamos que só se possa falar em quantização por parte de Planck no seu artigo de 1901, pois no artigo de dezembro de 1900 ele admitiu a hipótese dessa divisão não ser um número inteiro e dessa maneira bastaria pegar um número inteiro próximo; isso não é quantização.

Outro fator importante a se considerar é que, conforme procuramos mostrar no primeiro capítulo, a quantização proposta por Planck não é da mesma natureza daquela que aceitamos atualmente, e o próprio Planck não a julgou importante ou revolucionária e tentou encaixá-la na estrutura clássica. Da mesma forma as conseqüências para o trabalho de Planck não foram imediatas, pois este não foi entendido na época e não suscitou maiores atenções.

Ao se pensar no funcionamento da ciência baseado na epistemologia de Kuhn, temos que ter em mente que

qualquer tentativa de datar a descoberta será inevitavelmente arbitrária, pois a descoberta de um novo tipo de fenômeno é necessariamente um acontecimento complexo, que envolve o reconhecimento tanto da existência de algo, como de sua natureza. (...) Mas se tanto a observação como a conceituação, o fato e a assimilação à teoria, estão 
inesperadamente ligados à descoberta, então este é um processo que
exige tempo.

Assim, mesmo considerando o trabalho de Planck como muito importante para o desenvolvimento da física quântica, estaríamos cometendo um erro grosseiro se apontássemos o seu trabalho como o fundador da quantização, como muitos textos históricos e didáticos colocam.

Também sabemos que não podemos apontar o estabelecimento da crise com a publicação do trabalho de Planck. Podemos apenas fazê-lo com certa propriedade a partir do congresso de Solvay, no qual podemos notar a profusão de teorias, o debate acirrado e filosófico, além da importância, dificuldade e urgência com que os cientistas estavam tratando a questão: indícios que nos permitem caracterizar a crise paradigmática, segundo a epistemologia de Thomas Kuhn, e vislumbrar a revolução científica que estava para acontecer.

\section{A concepção sobre a ciência promulgada pela educação científica e os manuais didáticos}

A idéia que se faz normalmente da investigação científica é a de que os cientistas se comportam como exploradores e inventores ousados que, analisando os fatos como eles se apresentam, sem preconceitos ou qualquer espécie de resistência, procuram produzir novidades factuais ou teóricas. Procuramos mostrar que, segundo a epistemologia de Thomas Kuhn, o funcionamento da ciência não é desta maneira, pois durante a ciência normal o paradigma molda e restringe as análises e resultados apresentados pelos cientistas, além do fato de que a comunidade científica normalmente resiste à apresentação de novidades fundamentais.

Embora possa parecer à primeira vista que essa resistência e visão formada do mundo possam prejudicar o desenvolvimento da ciência, que deixa de certa maneira de ser objetiva, estes fatores também são necessários à sua evolução, segundo Kuhn, pois sem uma "adesão profunda a uma maneira particular de ver o mundo", o cientista não se intera dos problemas a serem analisados e a natureza das soluções. Ou seja, a funcionalidade da ciência normal, guiada estritamente por paradigmas, é dupla: de um lado, permite a articulação do paradigma pelo acréscimo de novos problemas e suas soluções, e de outro, faz surgir problemas "praticamente insolúveis" que a levam à crise e à revolução científica.

${ }^{92}$ Kuhn (2000), p. 81. 
Essas características do funcionamento da ciência estão intimamente ligadas com a maneira como a comunidade científica foi treinada para fazer ciência, ou seja, à educação científica, que prepara e autoriza o estudante para a prática científica, fornecendo-lhe todo o escopo de realizações científicas passadas.

(...) Embora raramente na sua forma original, hoje em dia essas realizações são relatadas nos manuais científicos elementares e avançados. Tais livros expõem o corpo da teoria aceita, ilustram muitas (ou todas) as suas aplicações bem sucedidas e comparam essas aplicações com observações e experiências exemplares. Uma vez que tais livros se tornaram populares no começo do século XIX (e mesmo mais recentemente, como no caso das ciências amadurecidas há pouco), muitos clássicos famosos da ciência desempenharam função similar. A Física de Aristóteles, o Almagesto de Ptolomeu, os Principia e a Óptica de Newton, a Eletricidade de Franklin, a Química de Lavoisier e a Geologia de Lyell - esses e muitos outros trabalhos serviram, por algum tempo, para definir implicitamente os problemas e os métodos legítimos de um campo de pesquisa para as gerações posteriores e praticantes da ciência.(Kuhn, 2000, p.29-30)

Kuhn argumenta que a educação científica não é feita iniciando-se o aluno no meio científico, mas sim pela resolução de exercícios semelhantes, seja com lápis e papel, ou seja com instrumentos num laboratório, modelados da mesma forma, o que o leva a soluções concretas que são aceitas como paradigmas.

No início e por algum tempo, resolver problemas é aprender coisas relevantes a respeito da natureza. $\mathrm{Na}$ ausência de tais exemplares, as leis e teorias anteriormente aprendidas teriam pouco conteúdo empírico. Esses exercícios também não são retirados dos textos originais, pois o processo de evolução dos conceitos da física normalmente não desperta muito interesse nos cientistas.

Nesse processo todo, os manuais didáticos têm um papel primordial na educação científica, pois é nesses textos que o aluno encontrará a estrutura do paradigma aceito e os exercícios que o levarão a internalizar e aprender a aplicar essa estrutura.

Assim, pela própria maneira de como a ciência normal é estabelecida, os manuais didáticos mostram ao futuro cientista uma ciência pronta, acabada e segura em suas definições (produto). E mesmo dispondo de uma gama variada destes manuais, eles apenas diferem em pormenores. Esses manuais só existem por que os cientistas, sob o respaldo de paradigmas, estão de acordo sobre o que cada estudante deve saber da matéria.

(...) esses textos freqüentemente parecem implicar que o conteúdo da ciência é exemplificado de maneira ímpar pelas observações, leis e teorias descritas em suas páginas. Com quase igual regularidade, os mesmos livros têm sido interpretados como se afirmassem que os 
métodos científicos são simplesmente aqueles ilustrados pelas técnicas de manipulação empregadas na coleta de dados de manuais, juntamente com as operações lógicas utilizadas ao relacionar esses dados às generalizações teóricas desses manuais.(Kuhn, 2000, p. 20)

Se, por exemplo, o estudioso da dinâmica newtoniana descobrir o significado de termos como "força", "massa", "espaço" e "tempo", será menos porque utilizou as definições incompletas (embora algumas vezes úteis) do seu manual, do que por ter observado e participado da aplicação desses conceitos à resolução de problemas.

Esse processo de aprendizagem através de exercícios com papel e lápis ou através da prática continua durante todo o processo de iniciação profissional. $\mathrm{Na}$ medida em que o estudante progride de seu primeiro ano de estudos em direção à sua tese de doutoramento, os problemas a enfrentar tornam-se mais complexos, ao mesmo tempo em que diminui o número dos precedentes que poderiam orientar seu estudo. (Kuhn, 2000, p.72)

Segundo o pensamento de Kuhn, um sintoma expressivo de uma revolução científica pode ser notado quando os manuais didáticos começam a ser total ou parcialmente reescritos, pois não condizem mais com a nova visão da natureza. Os manuais comunicam o vocabulário, a sintaxe da linguagem científica contemporânea, a estrutura dos problemas ou mesmo as normas da nova ciência normal.

Contudo, o objetivo de tais livros é inevitavelmente persuasivo e pedagógico. Um conceito de ciência deles haurido terá tantas probabilidades de assemelhar-se ao empreendimento que os produziu como a imagem de uma cultura nacional obtida através de um folheto turístico ou um manual de línguas... (Kuhn, 2000, p.19-20)

Essa ausência dos episódios revolucionários da ciência nos textos didáticos e nos livros de divulgação é o que Kuhn chama de "invisibilidade das revoluções científicas".

Dessa maneira, a busca pela transmissão sintética da estrutura do paradigma e a omissão dos aspectos revolucionários da construção do conhecimento científico, contribuem para a produção de uma educação científica calcada nos produtos da ciência, completamente omissa e, na maior parte das vezes, como verificaremos mais adiante com relação ao PRCN, enganadora no que diz respeito aos processos e à evolução dos conceitos da fisica.

... uma vez reescritos [os manuais] dissimulam inevitavelmente não só o papel desempenhado, mas também a própria existência das revoluções que os produziram. A menos que tenha experimentado pessoalmente uma revolução durante a vida, o sentido histórico do cientista ativo ou do leitor não especializado em literatura de manual englobará somente os 
resultados mais recentes das revoluções ocorridas em seu campo de
interesse.

Deste modo, os manuais começam truncando a compreensão do cientista a respeito da história de sua própria disciplina e em seguida fornecem um substituto para aquilo que eliminaram. É característica dos manuais científicos conterem apenas um pouco de história, seja um capítulo introdutório, seja, como acontece mais freqüentemente, em referências dispersas aos grandes heróis de uma época anterior. Através dessas referências, tanto estudantes como profissionais sentem-se participando de uma longa tradição histórica. Contudo, a tradição derivada dos manuais, da qual os cientistas sentem-se participantes, jamais existiu. Por razões ao mesmo tempo óbvias e muito funcionais, os manuais científicos (e muitas das antigas histórias da ciência) referem-se somente àquelas partes do trabalho de antigos cientistas que podem facilmente ser consideradas como contribuições ao enunciado e à solução dos problemas apresentados pelo paradigma dos manuais. Em parte por seleção e em parte por distorção, os cientistas de épocas anteriores são implicitamente representados como se tivessem trabalhado sobre o mesmo conjunto de cânones estáveis que a revolução mais recente em teoria e metodologia científica fez parecer científicos. Não é de admirar que os manuais e as tradições históricas neles implícitas tenham que ser reescritas após cada revolução científica. Do mesmo modo, não é de admirar que, ao ser reescrita, a ciência apareça, mais uma vez, como sendo basicamente cumulativa. (Kuhn, 2000, p.175-176)

Por que, então, os manuais transmitem uma concepção irreal do funcionamento da ciência? E muito mais: por que distorcem a história? Por quais razões as revoluções e as dificuldades intrínsecas de cada paradigma são omitidas? Por que não abordam a filosofia da ciência tão necessária nos períodos revolucionários? E o pior: por que ninguém faz nada frente a essas omissões e distorções? Kuhn nos fornece mais algumas pistas para refletirmos sobre estas questões que também serão discutidas na próxima seção deste capítulo:

... Para preencher sua função não é necessário que [os manuais] proporcionem informações autênticas a respeito do modo pelo qual essas bases foram inicialmente reconhecidas e posteriormente adotadas pela profissão. Pelo menos no caso dos manuais, existem até mesmo boas razões para que sejam sistematicamente enganadores nesses assuntos.

(...) A tentação de escrever a história passada a partir do presente é generalizada e perene. Mas os cientistas são mais afetados pela tentação de reescrever a história, em parte porque os resultados da pesquisa científica não revelam nenhuma dependência óbvia com relação ao contexto histórico da pesquisa e em parte porque, exceto durante as crises e as revoluções, a posição contemporânea do cientista parece muito segura. Multiplicar os detalhes históricos sobre o presente ou o passado da ciência, ou aumentar a importância dos detalhes históricos 
apresentados, não conseguiria mais do que conceder um status artificial à idiossincrasia, ao erro e à confusão humanos.

(...) Disso resulta uma tendência persistente a fazer com que a

História da Ciência pareça linear e cumulativa, tendência que chega a afetar mesmo os cientistas que examinam retrospectivamente suas próprias pesquisas. (Kuhn, 2000, p.174-177).

Acreditamos, assim, que de certa maneira distorcer a história e afastar a filosofia da ciência da própria ciência seria uma tentativa de não alterar o conceito de objetividade e racionalidade da ciência, o que poderia pôr em dúvida sua eficiência, seu papel na sociedade contemporânea e mesmo diminuir o enaltecimento e valorização do trabalho individual do cientista, já que o papel de solucionador de quebra-cabeças pode ser considerado como inferior frente à noção de espírito empreendedor e descobridor.

Também consideramos que essas omissões e distorções são uma maneira de limitar o aprendizado do cientista apenas aos produtos da ciência, que já são por demais variados e suficientes para anos de estudo.

Como também apontado por Kuhn, o cientista normal não teria necessidade explícita de conhecer a filosofia da ciência, a qual, pode até mesmo atrapalhá-lo, pois há urgência em publicações e um mergulho na filosofia implicaria dispêndio de tempo e energia em reflexões que muitas vezes não produziriam resultados.

... Os manuais, por visarem familiarizar rapidamente o estudante com o que a comunidade cientifica contemporânea julga conhecer, examinam as várias experiências, conceitos, leis e teorias da ciência normal em vigor tão isolada e sucessivamente quanto possível. Enquanto pedagogia, essa técnica de apresentação está acima de qualquer crítica. Mas, quando combinada com a atmosfera geralmente a-histórica dos escritos científicos e com as distorções ocasionais ou sistemáticas examinadas acima, existem grandes possibilidades de que essa técnica cause a seguinte impressão: a ciência alcançou seu estado atual através de uma série de descobertas e invenções individuais, as quais, uma vez reunidas, constituem a coleção moderna dos conhecimentos técnicos. $\mathrm{O}$ manual sugere que os cientistas procuram realizar, desde os primeiros empreendimentos científicos, os objetivos particulares presentes nos paradigmas atuais. (Kuhn, 2000, p.178)

\section{A história e a filosofia da ciência nos manuais didáticos: adulterando a física e o seu ensino}

Conforme procuramos mostrar acima, a educação científica visa formar cientistas normais, que acreditam e usam como respaldo de seus trabalhos o paradigma vigente. Em tal sistema, o principal instrumento utilizado é o manual didático, que transmite apenas os 
produtos da ciência, distorcendo e até mesmo omitindo os processos do desenvolvimento científico e dessa maneira adulterando e banindo a história e a filosofia da ciência dos seus relatos.

Gostaríamos então de procurar analisar, discutir e apontar outros aspectos da questão, inicialmente resumindo brevemente nossa concepção de História baseada no historiador E. H. Carr. ${ }^{93}$

Acreditamos que a História consiste em ver o passado com os olhos do presente, com seus problemas e com a mentalidade que forja o historiador. A função da História seria a de fomentar uma compreensão mais rica do presente através de uma compreensão também mais rica do passado, ou seja, manter um eterno diálogo entre o presente e o passado, sendo este um processo social.

... nós podemos visualizar o passado e atingir nossa compreensão do passado somente através dos olhos do presente.

(...)

A função do historiador não é amar o passado ou emancipar-se do passado, mas dominá-lo e entendê-lo como a chave para a compreensão do presente. (Carr, 1996, p. 25)

A História, então, em ambos os sentidos da palavra - significando tanto o exame conduzido pelo historiador quanto os fatos do passado que ele examina, é um processo social em que os indivíduos estão engajados como seres sociais(...) $\mathrm{O}$ passado é inteligível para nós somente à luz do presente; só podemos compreender completamente o presente à luz do passado. Capacitar o homem a entender a sociedade do passado e aumentar o seu domínio sobre a sociedade do presente é a dupla função da história. (Carr, 1996, p. 60-61)

Além da compreensão do presente à luz do passado e vice-versa, a história tem sua razão de existir também como provedora de beneficios para o futuro, já que

a convicção de que viemos de algum lugar está veiculada de perto à convicção de que estamos indo para algum lugar. Uma sociedade que perdeu a confiança na sua capacidade de progredir no futuro rapidamente deixará de preocupar-se com seu progresso no passado.(Carr, 1996, p. 165)

Assim a história deve estar sendo constantemente reconstruída e interpretada de formas diversas sob influência do presente. Podemos observar algo parecido com esse fenômeno em alguns filmes. A época em que um filme épico, por exemplo, é feito acaba influenciando no vestuário, na maquiagem e até na maneira de agir de alguns personagens. A Cleópatra interpretada por Liz Taylor, por exemplo, possuía uma maquiagem carregada, característica do período no qual o filme foi feito. Analogamente muitas vezes não 
conseguimos nos desvencilhar do presente para pensar o futuro. É comum em visões futuristas da década de 70, como Jornada nas Estrelas, pretensamente representada no século XXIII, encontrarmos disquetes imensos e até mesmo computadores gigantes, o que reflete, na verdade, a tecnologia da época na qual o filme foi feito e uma certa dose de falta de visão futurista.

De maneira análoga historiadores da ciência ou mesmo cientistas, acabam impregnando seus trabalhos por suas concepções (conscientes ou não) sobre o que é ciência, como ela funciona, seus procedimentos, sua importância e suas relações de natureza social. Além do mais, como afirma Koyré, muitas vezes ocultam-se os erros cometidos deixando, assim, de se descortinarem os procedimentos adotados na construção do conhecimento.

Todos os apontamentos acima indicam uma certa subjetividade da história, que por si só não constitui um problema. A dicotomia entre fato e interpretação na história, conforme atesta Carr, é um dilema do historiador e é um reflexo da natureza humana.

O homem, salvo nos primeiros anos da infância e nos últimos da velhice, não é totalmente envolvido pelo seu meio ou incondicionalmente sujeito a ele. Por outro lado ele nunca é totalmente independente dele nem o domina incondicionalmente.(Carr, 1996, p. 65)

No entanto, muitas vezes, essa visão do presente, as concepções individuais e certas crenças correspondentes ao funcionamento da ciência, ocasionam uma (re)interpretação muito distorcida da história da ciência (consciente ou não). Esse problema é mais grave para o caso dos textos acadêmicos, cuja busca por uma apresentação didática leva a simplificações grosseiras, além da omissão de conflitos e complicações importantes.

Aprofundando nossa discussão com relação à história que tem como pano de fundo a filosofia da ciência, citaremos dois tipos de fazer histórico da ciência: a reconstrução racional da ciência e a quase-história.

A reconstrução racional da ciência, pensada por Imre Lakatos, seria a (re)interpretação da história de forma a procurar solidificar concepções de natureza metodológica. Ou seja, Lakatos pensa que ao fazer história da ciência, o historiador inicialmente deve escolher através de qual filosofia da ciência ele quer interpretar a história que quer construir. Assim, o historiador

... ao elaborar a história interna, será em alto grau seletivo: omitirá tudo o que seja irracional à luz de sua teoria da racionalidade. (...) A história interna não é, exatamente, uma seleção de fatos metodologicamente

\footnotetext{
${ }^{93}$ Esta discussão é feita de maneira bastante rica em Zanetic (1989).
} 
interpretados: pode ser, às vezes, uma versão radicalmente modificada

dos mesmos. (Lakatos, 1987 , p. 40)

Tendo assim como base a sua maneira de compreender como a ciência funciona, ou mesmo como ela deveria ser, o historiador deveria suprimir os conflitos, os erros e tudo o que the parecesse irracional, para descrever o desenvolvimento da ciência como se os cientistas tivessem o tempo todo se comportado racionalmente. Dessa maneira a história é literalmente reconstruída para satisfazer a concepção metodológica da ciência que o historiador defende.

Também para Lakatos cada metodologia da ciência demarca de maneira diversa a separação entre história interna e externa. Essa delimitação é importante pois a história interna possui uma autonomia que a externa não possui e dessa maneira esta última "é irrelevante para a compreensão da ciência" 94 . No entanto, embora considere a história externa como secundária, para Lakatos esta deve complementar a reconstrução racional da ciência.

Outro tipo de apresentação da história da ciência, pensada por Whitaker (1979a; 1979b), é a quase-história, cuja intenção filosófica não é explícita como na reconstrução racional, e na qual não há muitas vezes um processo consciente de deturpação mas que, ao nosso ver, propicia a proliferação do que chamamos de distorções da história da ciência. Para esse autor, na literatura há uma espécie de material

que parece histórico, mas no qual não há tentativa de conduzir à história verdadeira: o objetivo é exclusivamente transformar em aceitáveis os fatos científicos, e a "história" está lá para fornecer um referencial dentro do qual os fatos científicos se ajustam facilmente, parecem "fazer sentido" e podem ser facilmente lembrados para propósitos de exame. Também fornece, talvez, uma pequena luz sobre os duros fatos da ciência em si. (Whitaker,1979a, p.108)

Esse tipo de história é o que o autor chama de quase-história. Ela é tida "mais freqüentemente meramente como um resultado causado mais propriamente por um erro de pensamento no desejo por ordem e lógica, como uma conveniência para se ensinar e aprender". 95

Contudo essas descrições logicamente ordenadas no tempo acabam levando o leitor a acreditar que foi realmente dessa maneira que as idéias se desenvolveram e evoluíram historicamente.

\footnotetext{
${ }_{94}^{94}$ Lakatos (1987), p. 12.

${ }^{95}$ Whitaker (1979b), p.239.
} 
A quase-história não aceita o aspecto social da ciência, já que o anúncio de uma descoberta nesta é quase que instantaneamente entendido e aceito, sendo que as controvérsias provocadas são irrelevantes. A presença destes conflitos nos relatos históricos pode mesmo atrapalhar, colocando em dúvida a veracidade dos fatos científicos, e daí a necessidade de excluí-los na quase-história. Assim, são ignorados

os processos que necessitam de muito tempo e esforço, o detalhado exame da evidência, a comparação e contraste de diferentes linhas de pensamento, e a construção e teste de hipóteses após hipóteses, tudo o que leva ao ato criativo (Whitaker,1979b, p.240).

Como conseqüência, a "quase-história apresenta as descobertas de novos conceitos cientificos como um de dois extremos, tanto quase trivial ou quase mistica" ${ }^{\text {"96. }}$ Ou as descobertas são apresentadas de forma lógica a banalizá-las, ou o cientista é colocado como um gênio absoluto, que através de um "insight" e pouca dedicação chegou àquela conclusão. Dougal (1976) afirma que a descoberta de Planck pode ser colocada nestes termos. Muitos textos apresentam Planck como um gênio, ressaltando, no entanto, sua descoberta como uma inspiração de momento. Não é explicitado nesses escritos todo o trabalho de Planck com a termodinâmica e seus estudos anteriores sobre a radiação de corpo negro, além do árduo trabalho até o "ato de desespero".

Também Whitaker aponta que a quase-história afasta o estudante, pois a ciência não é apresentada como um trabalho duro, criativo e desafiador, mas sim como algo trivial ou exclusividade de gênios. Dessa forma não é mostrado, portanto, o funcionamento real da ciência.

Cabe aqui uma observação sobre a reconstrução racional da ciência e a quasehistória. Não estamos julgando esses "procedimentos históricos" como ruins ou estamos dizendo que sempre produzem uma história da ciência distorcida e irreal ${ }^{97}$. A própria noção de história verdadeira e real, sabemos, é uma visão idealista, haja vista a apontada dicotomia entre fatos e interpretação, que não deixa de ser uma característica intrínseca da história.

$\mathrm{O}$ que pretendemos mostrar aqui é que, principalmente nos manuais didáticos, foco do nosso estudo, a pobre reconstrução racional da ciência e a quase-história, acabam

\footnotetext{
${ }^{96}$ Whitaker (1979b), p. 239.

${ }^{97}$ Embora de maneira superficial, não deixamos de produzir neste trabalho uma reconstrução racional da ciência, pois pautamos nossa visão do funcionamento da ciência na epistemologia de Thomas Kuhn. E sem dúvida, alguém que queira forçar a história da ciência rigidamente acoplada a justificar essa epistemologia, praticará também uma pobre e distorcida reconstrução racional.
} 
muitas vezes distorcendo de maneira grosseira e enganosa os desenvolvimentos científicos, acrescentando fatos e fazendo alegações históricas inexistentes. Ou muitas vezes apenas induzindo o leitor a interpretações errôneas.

Também temos claro que não é possível que os manuais didáticos sejam escritos de maneira a não conter nenhuma das distorções discutidas. A própria objetividade destes textos e a busca por síntese acabam propiciando essas distorções além de generalizações indesejáveis por parte do leitor. $\mathrm{O}$ que estamos criticando é o fato de que esses relatos sejam demasiadamente pobres e divirjam drasticamente dos estudos de vários filósofos e historiadores profissionais. Infelizmente é esse tipo de problema que ocorre na maioria dos relatos nos manuais didáticos e até mesmo em textos pretensamente históricos sobre o PRCN, como pretendemos mostrar no próximo capítulo.

\section{Preparando os futuros cientistas e professores de física também para eventuais revoluções: diminuição e flexibilização dos conteúdos, história e filosofia da ciência.}

Embora estejamos de acordo com o fato de que ciência normal de certo modo justifica a educação científica atual, calcada em produtos e realizada através de exercícios modelados da mesma forma, não acreditamos que essa seja a melhor maneira de formar nossos cientistas e, principalmente, nossos professores de física.

Reconhecemos que é necessário ao futuro cientista que praticará, muito provavelmente, a ciência normal, dominar a linguagem, as aplicações e as normas dos paradigmas vigentes, e para tanto os manuais e a resolução de exercícios mostram-se imensamente eficientes. Também há razões explícitas e compreensíveis para que o cientista não se interesse pela evolução dos conceitos da física.

No entanto, nossa concepção e idealização sobre ensino universitário (que também pode ser estendido para o ensino médio) de física vão um pouco além desse horizonte. Julgamos que o sistema de ensino atual poderia ser modificado, não deixando inclusive de ser conveniente para a ciência normal. E mais ainda: embora isso possa parecer um tanto romântico, consideramos que um papel importante da educação científica seja o de preparar os cientistas e mesmo professores de física para eventuais futuras revoluções científicas e também prepará-los como intelectuais que aliam o aspecto técnico funcional a um conhecimento da construção de sua área de conhecimento.

Não defendemos, de maneira alguma, que não seja realizado o estudo detalhado das aplicações e da estrutura do paradigma. Este é mesmo necessário para o próprio 
desencadeamento de crises paradigmáticas já que "a novidade normalmente emerge apenas para aquele que, sabendo com precisão o que deveria esperar, é capaz de reconhecer que algo saiu errado". 98

No entanto, há também um outro lado: "o treino cientifico não é planejado para produzir alguém capaz de descobrir facilmente uma nova abordagem para os problemas existentes" ${ }^{99}$. Acreditamos que o ensino universitário de física deveria sofrer alterações a ponto de possibilitar a problematização de algumas crises produtivas da história da fisica e, quem sabe, descortinar campos ou temas potenciais de emergência de novas crises.

Delineamos a seguir resumidamente nossa visão para um ensino de Física mais rico, que implicitamente resulta na diminuição do uso dos manuais didáticos comumente usados na educação científica e conseqüente diminuição dos efeitos limitadores e/ou nocivos que estes propiciam. Ao mesmo tempo, teríamos a oportunidade de apresentar propostas temáticas que propiciassem a apresentação dos elementos acima assinalados.

\section{Diminuição e Flexibilização dos conteúdos}

Da forma como os currículos padrões estão estabelecidos, o aluno passa tempo demais resolvendo exercícios e aplicando manipulações matemáticas, muitas vezes de maneira mecânica, já que não tem tempo para analisá-los de forma mais profunda e conceitual. Também nas avaliações lhe são cobradas apenas as soluções.

Além disso, o estudante precisa passar por uma gama bastante extensa e variada de disciplinas, cujo conjunto pretende fornecer ao estudante uma visão plena de toda a fisica. No entanto essa visão plena carece de profundidade e até mesmo de bases seguras. Ernst Mach já havia feito observação do gênero:

Eu acredito que a quantidade de matéria necessária para uma educação útil, tal como a que deveria ser oferecida a todos os alunos de uma escola preparatória, é muito pequena... Eu não conheço nada mais terrível do que pobres criaturas que têm aprendido tanto. Em vez daquela capacidade de julgamento que talvez tivesse se desenvolvido neles ainda que não tivessem aprendido nada, seus pensamentos deslizam tímida e hipocriticamente atrás de palavras, princípios, e fórmulas, constantemente pelos mesmos caminhos. O que eles têm adquirido é uma teia de aranha de pensamentos muito débeis para ser suporte seguro, mas suficientemente complicados para produzir confusão. ${ }^{100}$

\footnotetext{
${ }_{98}^{98}$ Kuhn (2000), p.92.

${ }^{99}$ Ibidem, p.207-208.

${ }^{100}$ Citado por Laranjeiras (1994), p. 90.
} 
Esse tipo de formação prepara profissionais extremamente treinados nos desenvolvimentos matemáticos, mas, com poucas exceções, desprovidos de conteúdo e mesmo conceitos da física. Temos visto, em nossa restrita experiência, cientistas e professores muito mal formados com relação a temas básicos da ciência, visto que não tiveram tempo, estímulo e muitas vezes até mesmo oportunidade para refletir sobre os conteúdos aprendidos.

Além de tudo isso, como já comentamos neste trabalho, os cientistas e professores são formados sob uma visão idealista do funcionamento da ciência. E é essa visão deturpada que estes vão propagar quando forem os agentes da educação científica.

Julgamos, portanto, que esse tipo de formação não é benéfico mesmo apenas para a formação de cientistas normais, pois não lhes fornece subsídios para desenvolver autonomia, tato científico e reflexão sobre suas práticas. Com relação aos professores de física essa situação é pior ainda, pois concepções distorcidas da ciência e da sua história também dificultam a assimilação de muitos dos seus conceitos.

Acreditamos que essa formação deveria ser alterada com a diminuição dos conteúdos abordados nos cursos de física, de modo que os fundamentos da física fossem trabalhados de maneira mais profunda e rica. Assim, estaríamos formando físicos e professores mais autônomos e que não necessitariam cursar tantas outras disciplinas, já que sozinhos eles poderiam selecionar e estudar os conteúdos que julgassem importantes e necessários a cada formação.

\section{A importância da história e filosofia da ciência}

Entendemos que aprofundar e enriquecer o estudo de determinado conteúdo seja contextualizá-lo e de certa maneira problematizá-lo. Ou seja, não apenas se prender ao estudo dos resultados e à resolução de exercícios, mas também aos processos de evolução e ao contexto das "descobertas". Tudo isso também possibilita o debate sobre o funcionamento e o papel da ciência e a compreensão desta como ente histórico e calcado em filosofia. Acreditamos que estas condições são essenciais para autonomia científica, reflexão sobre a ciência e suas práticas, além da compreensão do próprio arcabouço teórico dos modelos.

Nessa educação científica que idealizamos, a história e a filosofia da ciência têm papel crucial. Também julgamos que a preparação dos professores e estudantes de física para o estudo de crises passadas e áreas de potenciais crises e revoluções científicas futuras 
só poderá ser feita com um conhecimento sólido nos fundamentos, e o entendimento do desenvolvimento histórico da ciência e de sua filosofia.

O próprio Kuhn aponta que a filosofia da ciência pode não ser necessária na ciência normal, mas tem um papel preponderante na ciência extraordinária, sendo inclusive um sintoma a apontar crises paradigmáticas:

... A proliferação de articulações concorrentes, a disposição de tentar qualquer coisa, a expressão de descontentamento explícito, o recurso à filosofia e ao debate sobre os fundamentos são sintomas de uma transição da pesquisa normal para a extraordinária. (Kuhn, 2000, p.123)

... Creio que é sobretudo nos períodos de crises reconhecidas que os cientistas se voltam para a análise filosófica como um meio para resolver as charadas da sua área de estudos. Em geral, os cientistas não precisaram ou mesmo desejaram ser filósofos. $\mathrm{Na}$ verdade, a ciência normal usualmente mantém a filosofia criadora ao alcance da mão e provavelmente faz isso por boas razões. Na medida em que o trabalho de pesquisa normal pode ser conduzindo utilizando-se do paradigma como modelo, as regras e os pressupostos não precisam ser explicados. No Cap.4, observamos que o conjunto das regras, buscado pela análise filosófica, não precisa nem mesmo existir. Isso não quer dizer que a busca de pressupostos (mesmo os não existentes) não possa eventualmente ser uma maneira eficaz de enfraquecer o domínio de uma tradição sobre a mente e sugerir as bases para uma nova. Não é por acaso que a emergência da física newtoniana no século XVII e da Relatividade e da Mecânica Quântica no século XX foram precedidas e acompanhadas por análises filosóficas fundamentais da tradição de pesquisa contemporânea. (Kuhn, 2000, p.119-120)

Podemos dessa maneira também diminuir o preconceito a essas áreas mais humanas que existe por boa parte dos cientistas, diminuindo também com distorções grosseiras para a história da ciência e propiciando um maior debate sobre o real funcionamento da ciência e seu papel na sociedade. Dessa maneira colocaríamos os cientistas em uma posição menos fictícia e não apenas como seres de inteligência, tato e espírito inventor supremo.

Estendemos também para o nível universitário e formação de professores a posição de Laranjeiras de que é necessária a definição de conteúdos a serem ensinados, pretendendo com isso

... além de reduzir o elenco de informações que hoje saturam com superficialidade os currículos de física, enfatizar conceitos chaves e estruturadores das teorias científicas. Neste sentido a história da ciência nos permite visualizar quais conceitos têm permitido a articulação e/ou transformação de uma ciência, a elaboração de novas teorias, a utilização de novos métodos e novos instrumentos conceituais. (Laranjeiras, 1994, p. 92) 


\section{A leitura de textos originais da ciência}

Dada a própria natureza do funcionamento da ciência e da educação científica, não se faz necessária para a formação de cientistas a leitura de textos originais da ciência, pois os manuais sintetizam o instrumental necessário para se fazer ciência normal.

(...) o estudante fia-se principalmente nos manuais, até iniciar sua própria pesquisa, no terceiro ou quarto ano de trabalho graduado. Muitos currículos científicos nem sequer exigem que os alunos de pós-graduação leiam livros que não foram escritos especialmente para estudantes. Os poucos que exigem leituras suplementares de monografias e artigos de pesquisa, restringem tais tarefas aos cursos mais avançados, e as leituras que desenvolvem os assuntos tratados nos manuais. Até os últimos estágios da educação de um cientista, os manuais substituem sistematicamente a literatura científica da qual derivam. Dada a confiança em seus paradigmas, que torna essa técnica educacional possível, poucos cientistas gostariam de modificá-la. Por que deveria o estudante de Física ler, por exemplo, as obras de Newton, Faraday, Einstein ou Schrödinger, se tudo que ele necessita saber acerca desses trabalhos está recapitulado de uma forma mais breve, mais precisa e mais sistemática em diversos manuais atualizados? (Kuhn, 2000, p.207-208)

No entanto, ao almejarmos uma formação mais completa, sólida e autônoma para nossos cientistas e professores, a leitura de textos originais passa a ser um outro instrumento muito importante para o aprendizado da fisica. Essa prática se mostra muito eficiente na compreensão da história e filosofia da ciência e da evolução dos conceitos da fisica.

Vemos nos textos originais da ciência uma forma de trabalho escolar em que o aluno tem a possibilidade de acompanhar a evolução da construção científica e até mesmo se entusiasmar com ela.

No entanto, um texto original em si é muito complexo, pois engloba uma evolução histórica, uma filosofia não atual, além de que não foi escrito para leigos e assim exige conhecimento científico da época em que foi escrito. Por outro lado, um texto de um manual didático é extremamente o contrário, pois nele só estão contidos elementos que o autor julga serem acessíveis ao leitor, sem mostrar a vinculação entre esses elementos. Assim, tanto num tipo de texto quanto no outro há dificuldades a serem superadas pelos alunos, e estas são de natureza diferente.

Apesar da riqueza pedagógica que a leitura de originais da ciência no ensino da fisica pode proporcionar, devemos estar atentos para o fato de que este despende muito tempo e trabalho de contextualização, exigindo considerável esforço de linguagem e 
73

compreensão, alem da seleção de textos e traduções confiáveis e estratégias adequadas para sua utilização.

Conforme alerta Dion (1997), é necessário que ao se utilizar o original da ciência o professor tenha objetivos bem definidos, compreensão profunda do conteúdo do original, familiaridade com a história e cuidado no planejamento das estratégias de ensino:

pelo que pudemos levantar, o texto original parece se constituir num instrumento adequado para o diálogo entre concepções, desde que seja parte de uma seqüência de atividades e estratégias que ao se complementarem, forneçam os elementos necessários para o estabelecimento desse diálogo autêntico. (Dion, 1997, p.9)

... o estabelecimento de um diálogo entre leitor atual e documento original da ciência, em situações de ensino-aprendizagem, sugere a organização do material dentro de uma seqüência planejada, que associe sua leitura a outros tipos de atividades, como experiências, resolução de problemas, etc., e que esse material seja trabalhado num ambiente que favoreça a explicitação de concepções, através de um contexto de significados. (Dion, 1997, p. 162) 


\section{III - O ENSINO DO PROBLEMA DA RADIAÇÃO DO CORPO NEGRO E OS TEXTOS ACADÊMICOS}

Neste capítulo discutimos as principais dificuldades de abordagem do problema da radiação de corpo negro apontadas pela literatura e presentes nos livros acadêmicos. Analisamos alguns desses livros procurando explicitar essas dificuldades e outros problemas.

\section{Dificuldades de abordagem do problema da radiação do corpo negro (PRCN)}

Embora estejamos aqui procurando destacar a importância da história e da filosofia da ciência para o ensino da física, sabemos que o seu uso está intimamente ligado com as razões pelas quais ensinamos física.

Acreditamos que a história e a filosofia da ciência devam ser parte integrante do ensino da física, pois nossas metas são levar o aluno, em qualquer nível escolar, a entender de forma mais profunda a própria fisica, seu funcionamento passado e atual e o papel que a ciência desempenha na sociedade. Entendemos que fisica também é cultura, e dessa forma não pode deixar de ser pensada em relação à sua história e filosofia.

Portanto se, para a formação de um cidadão não profissional em física, consideramos importante uma localização dos principais eventos da fisica ao longo da história, como a apresentação de Bernal em "Science in history", defendemos que um cidadão profissional em física deverá, além de dominar conteúdos específicos das principais teorias da fisica, conhecer o processo de construção multifacetada desses conteúdos. Aqui alguns estudos de caso singulares poderão desempenhar o papel de um "laboratório epistemológico"101, que transcende a metodologia de solução-de-problemas dominante em nossos manuais, referido por Osvaldo Pessoa no parágrafo seguinte. Enquanto esta última metodologia tem um apelo pragmático considerável, é pobre na exploração da natureza do conhecimento físico.

Em contraposição aos nossos anseios, caso o objetivo do ensino de física seja aquele no qual o aluno "conheça as leis da área" e possa "saber resolver equações", provavelmente a história não tenha um papel importante, como ressalta Pessoa Jr. (1996).

\footnotetext{
101 "Laboratório epistemológico" é um termo utilizado pelo cientista e filósofo francês Georges Canguilhem e pode significar que, ao tratarmos de um determinado tema da ciência no ensino, devemos situar esse tema tanto no seu contexto histórico quanto no contexto filosófico/metodológico. Por exemplo, no caso do trabalho de Planck, discutir o papel desempenhado pelo teorema da equipartição de energia ou situar a noção de
} 
Pensando especificamente no ensino do problema da radiação do corpo negro no nível superior, notamos que este normalmente é tratado em disciplinas isoladas de Física Moderna, ou mesmo em cursos de Introdução à Física Quântica, numa abordagem superficial e, ao nosso ver, problemática.

Queremos evidenciar que, sejam quais forem os objetivos desse ensino e conseqüente necessidade (ou não) do uso da história e filosofia da ciência, várias dificuldades apresentam-se aos alunos. Destacamos nas linhas a seguir alguns destes problemas, os quais são indissociáveis entre si e estão intimamente ligados aos manuais acadêmicos utilizados nessas disciplinas: as abordagens superficiais, a omissão quanto aos desenvolvimentos experimentais e as distorções para a história da ciência.

\subsection{Abordagens superficiais}

O problema da radiação do corpo negro costuma ser apresentado nos cursos universitários de física como uma introdução à física moderna e como responsável pelo desenvolvimento da mecânica quântica. Justamente por causa desse caráter introdutório e pelo fato de que esses cursos objetivam prioritariamente a compreensão e manipulação de leis físicas, a abordagem do assunto freqüentemente é bastante superficial, ocasionando várias das outras complicações citadas adiante.

Como salientado por Arruda (1992) o PRCN "tem uma história complexa, rica em detalhes os quais dificilmente são abordados em sala" (p.2). Consideramos também que esse tratamento pouco profundo e a preocupação excessiva com a aplicação de leis propiciam a não internalização desse conhecimento de forma satisfatória pelos alunos, inclusive no que diz respeito propriamente à física da questão. Noções como corpo negro, radiância espectral, ou mesmo a importância física do problema, acabam sendo mal entendidas.

\section{2. Ênfase nos desenvolvimentos teóricos em detrimento aos experimentais}

A concepção de que os desenvolvimentos teóricos da ciência são mais importantes do que a atividade experimental parece ser difundida tanto entre o público leigo como na comunidade científica. Os trabalhos teóricos acabam sendo objeto de destaque em

"corpo negro" na sua textura de época tendo presente a textura atual para poder praticar a história recorrente de Bachelard, valorizada por Canguilhem. 
detrimento aos experimentais. Lévy-Leblond no prefácio do livro "Sources et Évolution de la Physique Quantique"102 também faz essa observação com relação à física quântica:

Pode-se aliás formular a promessa de que um segundo volume desta empreitada venha em breve render homenagem ao trabalho dos experimentais que não foi menor: Bohr sem Rutherford, de Broglie sem Davisson e Germer, Fermi (teórico) sem Fermi (experimental), Feynman sem Lamb, somente podem ilustrar uma face das medalhas tenham comorativas dos triunfos dessa física. Que esses trabalhos práticos não pesquisas teóricas exceto no meio profissional, a mesma notoriedade das filosóficas e metafisicas tenham sido objeto de tantas interpretações necessidade de corrigir freqüentemente dúbias apenas reforçam a contemporânea.

As atividades teóricas e experimentais, sem dúvida, impõem o desenvolvimento de diferentes habilidades, contudo não é possível realizar uma medida precisa da ordem de importância destas. Compreendemos, também, que ambas exijam do cientista muita criatividade, esforço e uma certa dose de espírito empreendedor.

Notamos também que em alguns textos didáticos, ou mesmo históricos, é atribuída uma certa genialidade aos teóricos, enquanto aos experimentais é resguardada a tarefa, em certo sentido inferior, de comprovação de teorias, ou mesmo a tentativa de refutá-las. Essa discriminação dos desenvolvimentos práticos acaba levando os textos a relatarem apenas os desenvolvimentos teóricos, banalizando a experimentação, afinal a crença é de que os pesquisadores práticos apenas "tiveram o trabalho de realizar medidas", como se essa atividade não tivesse problemas intrínsecos.

Compreendemos também que as relações entre a teoria e os desenvolvimentos experimentais são bastante complexas e nem sempre os desenvolvimentos históricos necessitam descrevê-las. O trabalho científico não exige que a teoria e a prática estejam sempre vinculadas, além do que o domínio de uma prática não é inteiramente regulável. Há muitas situações em que a prática é a aplicação da teoria, impondo uma relação de precedência entre ambas, mas isso não é sempre verdadeiro. Existem teorias absolutamente abstratas e de caráter experimental impossível, em contrapartida algumas práticas não possuem qualquer teoria, são técnicas.

No entanto para o caso do PRCN houve um desenvolvimento teórico e experimental simultâneo. Embora a maioria dos textos sobre o assunto, como o de Jammer (1966), acabe citando os desenvolvimentos experimentais, o destaque costuma ser voltado para os feitos teóricos. Normalmente não são descritos, por exemplo, os procedimentos de

${ }^{102}$ Leite Lopes \& Escoubès (1994). Título traduzido: "Fontes e Evolução da Física Quântica". 
medida, os corpos negros "reais", os problemas experimentais da época (tanto tecnológicos quanto relacionados ao conhecimento físico), e também não encontramos explicitações maiores do intercâmbio entre teoria e experimento no PRCN. Nas abordagens consultadas, os desenvolvimentos experimentais funcionavam apenas para a comprovação e/ou refutação dos desenvolvimentos teóricos.

Esse problema de abordagem também é levantado por Dougal (1976) ao afirmar que "muitos autores têm sido seletivos demais em suas escolhas de qual material teórico incluir e, o que é pior, eles têm excluido de seus relatos quase tudo além de referências mais gerais aos resultados de experimentos apropriados." (p.438)

Acreditamos que a exclusão da parte prática da abordagem do PRCN, torna-a muito mais abstrata, dificultando sua compreensão, assim como o entendimento de sua história e mesmo do conhecimento físico. Perguntas como estas evidenciam nossa preocupação com os desenvolvimentos práticos: como entender a noção de corpo negro sem conhecer os motivos pelos quais houve a necessidade de idealizá-lo? Como compreender a importância dessa idealização sem conhecer um corpo negro experimental? Será possível entender parte da física do PRCN sem a noção do funcionamento de um bolômetro, e de como se realiza(va)m essas medidas? O que é a radiância espectral no laboratório? Como medi-la? Como os desenvolvimentos teóricos dependeram dos experimentais? Quais as dificuldades experimentais da época e quais delas dificultavam os desenvolvimentos teóricos?

Além desses pontos, acreditamos existirem ainda outros, para os quais uma abordagem experimental mais detalhada facilitaria a compreensão. Por exemplo, os resultados experimentais são citados como sendo a medida da densidade de energia da radiação do corpo negro dentro de um forno e não, como de fato é, da energia de uma amostra de radiação saindo do forno (Dougal, 1976). Esses detalhes parecem banais, porém podem gerar mal entendidos e generalizações indesejáveis por parte do aluno.

Como alternativa de apresentação da solução do PRCN por Planck, o autor citado acima propõe a inclusão dos desenvolvimentos experimentais de Paschen, Lummer e Pringsheim e Rubens. Todavia sua proposta também não vai além da citação das experiências e resultados.

O texto de Trigg (1971) destaca o trabalho de Lummer e Pringsheim de verificação da lei de Stefan-Boltzmann e da determinação da distribuição espectral da radiação de corpo negro, cuja conseqüência foi a constatação da não validade da lei de Wien. Contudo o autor ainda apresenta informações insuficientes sobre os experimentos. 
Como proposta de "atividade experimental" em ensino superior envolvendo o PRCN, encontramos a proposta de GUIMARÃES (1999). Nesta, os alunos já recebem os valores experimentais em forma de tabela ${ }^{103}$ contendo os dados da radiância espetral de um corpo negro em função do comprimento de onda. A tarefa colocada aos alunos é a de ajustar esse valores numéricos à curva teórica proposta por Planck. Na verdade o objetivo dessa atividade é evidenciar o tratamento preliminar dos dados que os físicos experimentais na maior parte das vezes precisam desenvolver. Essas manipulações vão muito além de uma simples transformação de coordenadas feitas nos laboratórios didáticos.

\subsection{Distorções da história do PRCN}

Pensando especificamente nas distorções da história da ciência discutidas no capítulo anterior, apontamos algumas deturpações inerentes ao ensino do problema da radiação de corpo negro:

Ênfase no uso da equipartição de energia. $O$ teorema da equipartição da energia era recente e não completamente aceito na época do trabalho de Rayleigh ou mesmo Jeans. $\mathrm{O}$ reconhecimento da importância desse teorema é muito posterior, e hoje é fundamental para a Física Clássica. Dessa maneira passou a ser conveniente para os autores de textos didáticos descreverem a solução do problema da radiação de corpo negro através da teoria clássica de Rayleigh-Jeans, mas usando a condição de Planck $E=n h v$. Aos estudantes e leitores desses textos resta a impressão de que a solução para o problema da radiação do corpo negro se processou dessa forma.

Alterações na cronologia dos fatos. Grande parte dos manuais didáticos, e até mesmo textos históricos, apresentam erroneamente, a distribuição de Planck como uma extensão ao trabalho de Rayleigh (Dougal, 1976). E o que é pior, muitas vezes o fazem como uma continuação ao desenvolvimento de Rayleigh-Jeans (Dougal, 1976; Bassalo, 1996; Whitaker, 1979a), como se Rayleigh e Jeans tivessem desenvolvido a formulação juntos, ou ao mesmo tempo, ou ainda como se Rayleigh-Jeans fosse o nome de um cientista apenas. Sabemos que Jeans fez sua correção cinco anos após a publicação do trabalho de Rayleigh.

Também muitos textos apresentam um sentido trágico irreal ao trabalho de Rayleigh e abusam da nomenclatura "catástrofe do ultravioleta" criada somente em 1911 por Paul Ehrenfest.

${ }^{103}$ Retirada do texto de Eisberg \& Resnick. 
Ausência da termodinâmica no trabalho de Planck. O método de Planck foi fundamentado na termodinâmica e norteado por seus estudos sobre a entropia. Suas considerações basearam-se no estudo da relação entre a entropia e a energia da cavidade. Todo esse procedimento não aparece nos manuais didáticos. Autores como Whitaker (1979) e Klein (1966) alertam para essa grave distorção para a história.

Atribuição da quantização generalizada a Planck. Os textos didáticos exageram na apresentação da quantização por Planck. Em geral, eles apresentam-na de uma maneira moderna e como um passo seguro e convicto, facilmente generalizada para o resto da física. Todavia, procuramos mostrar no capítulo I que Planck utilizou a quantização como um artificio matemático e que não deu tamanha importância para ela. Também esta só era válida para os hipotéticos osciladores harmônicos no interior da cavidade.

\section{0 problema da radiação de corpo negro em alguns textos acadêmicos}

Conforme procuramos discutir até aqui, a história e a solução do PRCN são desenvolvimentos bastante complexos e extremamente ricos, condições essenciais para que o tema seja objeto de estudo por parte de futuros cientistas e professores de física.

Basicamente, o ensino dos temas importantes da fisica são realizados através dos manuais didáticos e dessa maneira estes devem ser redigidos com bastante cuidado para que o leitor possa compreender de maneira clara e correta, além de não abrir possibilidade de interpretações errôneas sobre qualquer assunto.

No entanto, os textos didáticos sobre a solução do PRCN muitas vezes falham nos aspectos elementares discutidos até aqui neste trabalho. Para evidenciar e discutir boa parte destas falhas, selecionamos dois importantes textos sobre o assunto e analisamos suas abordagens para o PRCN:

1. Eisberg e Resnick. Física quântica. Cap. 1, p. 19-42.

2. Tipler. Física Moderna. Seção 3.4, p.85-89.

A escolha do texto de Eisberg e Resnick deve-se ao fato de que nas disciplinas de introdução à física moderna das principais instituições do país (USP e Unicamp, por exemplo) este é o texto acadêmico mais utilizado tanto nos cursos de física como engenharia. Também o tipo de abordagem do PRCN que encontramos neste texto é o mais comum na literatura.

Selecionamos o texto de Tipler por também ser bastante utilizado. Este apresenta um texto bastante sucinto, típico dos manuais didáticos vendidos em grande escala. 
Utilizamos para análise uma edição desatualizada, pois esta é encontrada com maior número de exemplares nas bibliotecas da USP e UNICAMP.

\subsection{Análise do texto referente ao livro de Eisberg e Resnick (1994)}

Sendo o livro em questão sobre física quântica, seu único intuito ao descrever o PRCN e sua solução por Planck é introduzir o assunto apresentando a quantização de energia. Provavelmente na busca por uma apresentação mais didática, os autores mesclam modernos desenvolvimentos com procedimentos tomados em 1900 e distorcem a história e o trabalho de Planck. Na busca por síntese, também banalizam o trabalho deste ou o apresentam de maneira completamente diferente, induzindo o leitor a fazer generalizações indesejáveis sobre o trabalho de Planck e sobre a própria física.

Como este livro é de uso bastante freqüente e contém problemas graves, faremos uma análise bastante detalhada do mesmo, seguindo sua seqüência de abordagem. Queremos mostrar que matematicamente não há nada errado no desenvolvimento deste texto. Entretanto, ao tentar mesclar a história em seu relato, os autores distorceram todo o seu conteúdo, até mesmo o desenvolvimento da física.

\section{Secão 1.1 - Introducão}

O livro inicialmente comenta sobre o trabalho de dezembro de 1900 de Planck que marca, segundo esses autores, o nascimento da fisica quântica. Os autores, assim como nós, valorizam o estudo da radiação térmica e também apontam que o entendimento da antiga teoria quântica permite "obter mais facilmente uma compreensão mais profunda da mecânica quântica" (p.19).

\section{Secão 1.2-Radiacão térmica}

Logo na apresentação do conceito de corpo negro já detectamos o primeiro problema. Conforme nos preocupamos em mostrar no breve histórico que fizemos, a noção de corpo negro é o foco central do nosso estudo. Procuramos deixar clara a importância de sua profunda significação e da sua natureza ideal, ou seja, corpos negros reais não existem e são uma idealização teórica, não abstraída da experiência. É claro que essa abstração foi pensada tendo um referencial experimental e uma aplicabilidade esperada. $\mathrm{O}$ texto de Eisberg e Resnick dá pouca importância ao conceito, como se ele fosse de certa maneira óbvio e real: 
... a experiência nos mostra que há um tipo de corpo quente que emite corpos netros térmicos de caráter universal. Esses corpos são chamados incidente sobre eles... (p.20) cujas superficies absorvem toda a radiação

Também, mesmo definindo corpo negro como ente experimental de uma maneira simplista, os autores dão exemplos apenas de (quase) corpos negros:

Um exemplo de um (quase) corpo negro seria qualquer objeto fuligem (por uma camada difusa de pigmento preto, tal como o negro de

Um outro exemplo de corpo negro, que veremos ser de grande importância, pode ser obtido ao considerarmos um objeto que contém uma cavidade ligada ao exterior por um pequeno orifício, (...). A radiação térmica que incide sobre o orificio vinda do exterior entra na cavidade e é refletida repetidas vezes pelas suas paredes, sendo eventualmente por elas absorvida. Se a área do orificio for muito pequena comparada com a área da superficie interna da cavidade, uma quantidade desprezível da radiação incidente será refletida para fora da cavidade. Essencialmente toda a radiação incidente sobre o orifício é absorvida; portanto, o orificio deve ter propriedades da superficie de um corpo negro. A maioria dos corpo negros utilizados em experiências de laboratório são construídos dessa forma. (p.22-23)

Conforme procuramos mostrar no capítulo I, a equivalência entre radiação de corpo negro e radiação de cavidade não é óbvia e exige toda uma construção teórica para ser aceita. Fato ignorado neste texto.

A seguir, os autores definem a radiância espectral e apresentam um gráfico desta grandeza em função da freqüência para um corpo negro a várias temperaturas (inclusive os autores apresentam uma análise bastante detalhada dessa função). A partir dessa análise e da definição da radiância (integral da radiância espectral), as leis de Stefan-Boltzmann e do deslocamento de Wien são apresentadas. Essa parte está muito bem discutida e contextualizada, como realmente deve ser para a compreensão do fenômeno e da solução do PRCN.

Também é apresentada a proporcionalidade entre a radiância do orificio da cavidade e da sua densidade de energia, sem qualquer derivação matemática, como se esse resultado fosse simples e óbvio.

Ao longo da seção são analisados alguns exemplos numéricos, que consideramos extremamente importantes. No exemplo 1-1 (p.23), apesar de não ser explicado por que podemos estudar uma estrela como um corpo negro, o uso da lei do deslocamento de Wien permite, de maneira simples, o cálculo aproximado da temperatura da superfície desta. No 
entanto, o exemplo seguinte (p.24) não merece tantos créditos, pois a lei de Kirchhoff é derivada de uma forma simplista ao extremo, diminuindo a beleza e a importância desse desenvolvimento, que apresentamos no apêndice I.

\section{Secão 1.3 - A teoria clássica da radiacão de cavidade}

$O$ início do texto permite interpretar erroneamente que o desenvolvimento tratado nesta seção foi a primeira formulação histórica para o PRCN e a única possível pela física clássica. Também é apontado que tal solução "mostrou uma série divergência entre a fisica clássica e os resultados experimentais" (p.24), como se ela tivesse sido na época uma catástrofe e motivo de preocupação para os cientistas.

Para iniciar o estudo do problema, os autores discutem ondas estacionárias em uma caixa metálica, e segundo eles, "não é necessário estudar detalhadamente o comportamento dos elétrons nas paredes da cavidade" (p.24). Todavia sabemos que da maneira como Rayleigh e Jeans trabalharam a questão, não é possível chegar à solução do PRCN. No apêndice III vimos que o estudo de Planck para o PRCN necessitou de estudos detalhados desse comportamento dos elétrons. Ainda que clássico, tal estudo foi essencial para Planck chegar à sua solução.

Os autores então, calculam (inicialmente num modelo unidimensional para depois expor o tridimensional) o número de modos de oscilação em um intervalo de freqüência $d v$. Esse cálculo não tem muito segredo e está muito bem apresentado, pensando-se em leitores iniciantes. Seu resultado é:

$$
N(v) d v=\frac{8 \pi V}{c^{3}} v^{2} d v
$$

Então, é colocado que:

Embora Planck, ao solucionar as sérias discrepâncias entre a teoria clássica e a experiência, tenha questionado certos pontos que se tinham como obviamente verdadeiros, nem ele nem outras pessoas trabalhando no problema questionaram (1-12) [equação (36)]. Era, e ainda é, geralmente aceito que (1-12) é válida.

Essa passagem é um verdadeiro disparate histórico, permitindo-nos atribuir o rótulo de quase história ao tratamento apresentado. Planck, nos trabalhos que analisamos, e que apresentamos no capítulo I, não trabalhou com essa equação.

O objetivo dos autores é calcular a densidade de energia na cavidade $\left(\rho_{T}(v)\right.$ para Eisberg e Resnick equivalente a $\mu_{\nu}$ no nosso texto) no intervalo $d v$ a uma dada temperatura 
T. Para isso é necessário multiplicar o resultado acima pela energia média $\bar{E}$ das ondas estacionárias e dividir pelo volume da cavidade. Ou seja:

$$
\rho_{T}(v) d v=\frac{8 \pi v^{2}}{c^{3}} \bar{E} d v \quad 104
$$

Na seqüência é exposto que estas ondas podem ser consideras como vários "entes do mesmo tipo que estão em equilíbrio térmico entre si. (...) Portanto, cada onda estacionária na cavidade tem, de acordo com a lei de equipartição clássica, uma energia total média $\bar{E}=k T T^{\prime 105}$ (p.31). Depois é enfatizado que tal relação fornece a energia média para as ondas independente de sua freqüência.

Assim os autores obtêm a lei de Rayleigh-Jeans:

$$
\rho_{T}(v) d v=\frac{8 \pi v^{2} k T}{c^{3}} d v
$$

A seguir, é mostrada num gráfico, a discrepância entre a lei de Rayleigh-Jeans e os resultados experimentais obtidos para baixa temperatura $\left(1500^{\circ} \mathrm{K}\right)$. Além disso o texto aponta que:

... O comportamento grosseiramente não realista da previsão da teoria clássica para altas freqüências é conhecido na física como a "catástrofe do ultravioleta". O termo sugere e enfatiza a não validade da teoria clássica nessa região.

Alem de não comentarem que a lei de Rayleigh-Jeans é razoável para baixas freqüências e altas temperaturas, os autores não apresentam nesse gráfico a importante lei de Wien, a única aceita na época pelos cientistas e que também era clássica. Sua discrepância com os resultados experimentais só foi descoberta pouco antes de Planck apresentar sua solução. Também é importante salientar que a lei de Wien falha para baixas freqüências, não havendo nenhuma catástrofe para altas freqüências, como na lei de Rayleigh-Jeans.

\section{Secão 1.4 - Teoria de Planck da radiacão de cavidade}

O texto já começa com uma barbaridade histórica:

Ao tentar solucionar a discrepância entre a teoria e a experiência, Planck foi levado a considerar a hipótese de uma violação da lei de eqüipartição da energia sobre a qual a teoria se baseava. (p.32)

104 Essa equação não existe no texto. Formulamo-la para um melhor compreensão do desenvolvimento seguido pelos autores.

${ }^{105}$ Apesar desse não ser o símbolo utilizado pelos autores, utilizaremos o símbolo $E$ para designar energia. 
Conforme procuramos mostrar no capítulo I, Planck não usou a eqüipartição de energia para resolver o PRCN, nem tão pouco essa lei era reconhecida como tal e aceita por toda a comunidade científica na época.

Analisando os dados experimentais, os autores observam que a lei clássica é válida para baixas freqüências, de maneira que a eqüipartição de energia seria válida neste caso $\mathrm{e}$ então $\bar{E} \rightarrow k T$ com $v \rightarrow 0$. Para altas freqüências, como $N(v)$ aumenta com $v^{2}$, a energia média deve tender a zero $(\bar{E} \rightarrow 0$ com $v \rightarrow \infty)$ para que $\rho(v)$ tenda a zero como nos experimentos. A seguir o texto comete outro erro grosseiro, novamente apontando que o desenvolvimento de Planck é semelhante ao de Rayleigh e Jeans:

... Planck descobriu que, nas circunstâncias que predominam no caso da radiação de corpo negro, a energia média das ondas estacionárias é uma função da freqüência $\bar{E}_{v} \ldots$ (p.32)

Em continuação é apresentada a distribuição de Boltzmann:

$$
P(E)=\frac{e^{-E / k T}}{k T}
$$

em que

... $P(E) d E$ é a probabilidade de encontrar um dado ente de um sistema com energia no intervalo entre $E$ e $E+d E, \ldots$ As energias dos entes no sistema que estamos considerando, um conjunto de ondas estacionárias [o grifo é nosso] oscilando em movimento harmônico simples em equilíbrio térmico em uma cavidade de corpo negro, são governadas por (1-20) [equação (38)]. (p.33)

Ressaltamos, com o sublinhado na frase acima, que os autores calculam a distribuição de energia das ondas estacionárias e não dos osciladores nas paredes da cavidade, como Planck fez.

Em continuação, usando um desenvolvimento moderno para se calcular a energia média, o texto obtém o valor clássico $k T$ :

$$
\bar{E}=\frac{\int E P(E) d E}{\int P(E) d E}=k T
$$

Na seqüência, é apresentada a quantização de Planck, novamente de maneira diversa da histórica:

A grande contribuição de Planck surgiu quando ele descobriu que poderia obter o corte necessário..., se modificasse o cálculo que leva a $P(E)$ e $\bar{E}$, tratando a energia $E$ como se ela fosse uma variável discreta 

[equação Quantitativamente, isto pode ser feito reescrevendo (1-21)

Planck supôs que de uma soma em vez de uma integral...

discretos, em vez de qua energia $\mathrm{E}$ poderia ter apenas certos valores fossem uniformementor valor, e que os valores discretos de energia $E=0, \Delta E, 2 \Delta E, 3 \Delta E$; isto é, ele tomou

Através de gráficos, os autores tentam mostrar que se $\Delta E<<k T \rightarrow \bar{E} \sim k T$; mas, se $\Delta E>>k T \quad \bar{E} \rightarrow 0$. Ainda sobre Planck é colocado que

... Recapitulando, Planck descobriu que ele poderia obter $\bar{E} \sim k T$ quando a diferença entre energias sucessivas $\Delta E$ for pequena, e $\bar{E} \sim 0$, quando $\Delta E$ é grande. Como ele precisava obter o primeiro resultado para baixos valores de freqüência $v$, e o segundo para grandes valores de $v$, ele obviamente precisava fazer de $\Delta E$ uma função crescente de $v$. Alguns cálculos [grifo nosso] the mostraram que se poderia tomar a relação mais simples possível entre $\Delta E$ e $v$ com essa propriedade. Isto é, ele supôs [grifo nosso] que essas grandezas fossem proporcionais... (p.34-35)

O texto chega então que $\Delta E=h v$. Note que além de nunca ter feito essas análises, os cálculos de Planck não permitiram que ele apenas fizesse uma suposição, mas sim ele pode afirmar que $\Delta E=h v$, como vimos no paper de 1901. Também, o texto desprestigia e banaliza todo o trabalho de Planck, visto que ele não fez apenas "alguns cálculos".

Usando então uma somatória no lugar de uma integral, o livro mostra que:

$$
\bar{E}=\frac{h v}{e^{h v / k T}-1}
$$

o que leva à lei de Planck

$$
\rho(v) d v=\frac{8 \pi v^{2}}{c^{3}} \frac{h v}{e^{h v / k T}-1} d v
$$

Os autores, então, apresentam um gráfico em que os dados experimentais se adequam muito bem à essa lei.

Finalizando a dedução pretensamente atribuída a Planck, o texto aponta:

... "Tudo" que ele fez foi tratar a energia das ondas estacionárias eletromagnéticas, oscilando senoidalmente com o tempo, como grandeza discreta em vez de contínua. (p.37)

Numa análise mais atenta a todo o desenvolvimento do livro, ressaltado pela passagem anterior, notamos que os autores afirmam que Planck quantizou o campo eletromagnético. Sabemos que isso não é verdade, pois Planck na verdade quantizou a energia dos osciladores, enquanto a quantização do campo eletromagnético só ocorreu anos 
depois com o trabalho de Einstein. Acreditamos que essa seja uma das principais falhas do livro e a mais difícil de ser detectada por aqueles que ainda estão aprendendo física.

No final da seção, discute-se que a Lei de Stefan-Boltzmann e a Lei do deslocamento de Wien podem ser obtidas pela fórmula de Planck. Isso está correto. Apenas é importante lembrar que na verdade, Planck usou a Lei do deslocamento de Wien em seu trabalho (na forma $S=f\left(\frac{U}{v}\right)$ ) para poder chegar a sua lei e não o procedimento inverso.

\section{Secão 1.5 - O uso da lei da radiacão de Planck na termometria}

Embora sucintamente e de maneira pobre, nesta seção são apresentadas algumas implicações experimentais muito importantes da radiação térmica.

É discutido o fato de que a lei de Planck é uma ferramenta útil para medidas de temperatura através da razão das intensidades de emissão de dois corpos. Os autores apontam também que seria possível utilizar a lei de Stefan-Boltzmann para a realização dessas medidas, no entanto comentam sobre a dificuldade de se realizar a varredura de medidas em todo o espectro. O livro também apresenta rapidamente o pirômetro ótico.

\section{Seção 1.6 - 0 postulado de Planck e suas implicacões}

Os autores, então, enunciam um "Postulado de Planck":

Qualquer ente fisico com um grau de liberdade cuja "coordenada" é uma função senoidal do tempo (isto é, executa oscilações harmônicas simples) pode possuir apenas energias totais $E$ que satisfaçam à relação

$$
E=n h v \quad n=0,1,2,3 \text {. }
$$

Onde $v$ é a freqüência da oscilação, e $h$ uma constante universal. (p.40)

Planck não estendeu a sua quantização para toda a Física. Ele apenas quantizou a energia dos osciladores. Ainda em trabalhos posteriores ele tentou diminuir a importância da quantização, apresentando cálculos em que o PRCN podia ser resolvido sem quantizar a energia dos osciladores. Apenas a emissão destes osciladores era quantizada, ainda que a energia destes fosse contínua.

Por fim, mesmo se considerarmos que Planck foi um precursor e que por isso podemos dar o seu nome para esse postulado, sabemos que o próprio não está correto, visto que osciladores harmônicos não podem possuir energia zero (falta o termo $h v / 2$ ). Assim, para que escrever este postulado? 
Acreditamos que os autores se apoiaram nesse postulado para de certa maneira redimir aquele que apontamos com um dos principais problemas do texto: a quantização da energia do campo de radiação, ao invés da energia dos osciladores da cavidade. Com esse postulado, portanto, a análise que foi feita no texto é estendida para todos os osciladores harmônicos.

Um ponto positivo dessa seção foi que, após mostrar um diagrama de energia comparando um sistema clássico (energia contínua) com um sistema quantizado, o livro calcula a quantização de energia para um pêndulo. $O$ resultado que chega, para os parâmetros do exemplo, é $\Delta E / E \sim 10^{-29}$. Assim, é mostrado de maneira didática que mesmo o mais sensível dos instrumentos não consegue observar a quantização de um sistema desse tipo. Esta só é evidente em sistemas de pequenas energias ou altas freqüências.

\section{Secão 1.7 - Um pouco de história da física quântica}

Nessa seção, os autores tentam rapidamente corrigir alguns de seus erros, mas ainda continuam cometendo vários equívocos.

Inicialmente é afirmado que o postulado de Planck não é tão abrangente na sua forma original. Corretamente, os autores apontam que Planck estudou "...o comportamento de elétrons nas paredes do corpo negro e seu acoplamento ou interação com a radiação eletromagnética dentro da cavidade" (p.42). Corretamente novamente, é dito que Planck quantizou apenas a energia dos elétrons oscilantes. Porém, eles afirmam que "somente mais tarde foi que Planck aceitou a idéia de que as próprias ondas eletromagnéticas eram quantizadas..." (p.42). Contudo, a estreita revisão bibliográfica que fizemos, incluindo sua autobiografia, não vimos qualquer referência sobre sua aceitação da quantização como compreendemos hoje, ou mesmo apenas para a luz.

O livro mostra também que a quantização foi um ato de desespero para Planck. Porém os autores afirmam que: "por mais de uma década, Planck tentou encaixar a idéia quântica dentro da teoria clássica"(p.42). Na verdade, Planck tentou o oposto, ou seja, procurou diminuir o efeito da quantização no seu trabalho, considerando a energia contínua para o oscilador. Na realidade, Planck queria levar para a fisica clássica a constante $h$, que para ele possuía um significado e importância universal. 


\subsection{Análise do texto referente ao livro de Tipler (1981)}

O problema da radiação de corpo negro é tratado neste livro em uma seção (3.4) do capítulo "A Quantização da Eletricidade, da Luz e da Energia" de maneira bastante abreviada.

Apesar da superficilidade na abordagem do problema, esse livro apresenta mais informações históricas e sobre a radiação térmica que o outro, ainda que muito breves. Mesmo assim, ele omite que o trabalho de Jeans foi posterior ao de Planck.

Logo na primeira frase do texto, o autor demonstra certo cuidado com sua descrição: "a primeira sugestão a respeito da natureza quântica da radiação proveio do estudo da radiação térmica emitida por corpos opacos" (p.85). Do ponto de vista histórico a frase é muito interessante, pois, diferentemente de outros livros que atribuem a Planck a quantização, ele diz que esta no PRCN foi uma "sugestão". Embora essa palavra possa ainda não ser estritamente correta, pois na solução de Planck não houve uma sugestão explícita, julgamos que usá-la denota importante cuidado na redação por parte do autor.

Ainda no primeiro parágrafo, não é comentado sobre a Lei de Kirchhoff, mas seu resultado é descrito: "se um corpo opaco está em equilibrio com a sua vizinhança, a taxa de absorção de radiação deve ser igual à taxa de emissão ... Portanto, um bom absorvedor deve ser um bom emissor" (p.86).

$\mathrm{Na}$ seqüência, rapidamente são descritas as propriedades da radiação térmica de uma maneira que julgamos bastante didática e adequada para um estudante que não está familiarizado com esse assunto:

... A temperaturas usuais (abaixo de $600^{\circ} \mathrm{C}$ ), a radiação térmica emitida por um corpo não é visível; a maior parte da energia está concentrada em comprimentos de onda mais longos do que os da luz visível. À medida que um corpo é aquecido, a quantidade de radiação térmica emitida cresce, e a energia irradiada inclui comprimentos de onda cada vez menores. Em aproximadamente $600-700^{\circ} \mathrm{C}$ há energia suficiente no espectro visível, então o corpo brilha e torna-se vermelho escuro, e a temperaturas maiores torna-se vermelho brilhante ou até "branco quente" (p.86).

Ao definir corpo negro, o autor também demonstra cuidado com o conceito físico: "um corpo que absorve toda a radiação incidente é chamado de corpo negro ideal" (p.86). Embora ainda julgamos sua definição e sua discussão extremamente pobres, consideramola como um avanço em relação ao outro texto analisado por deixar clara a natureza ideal da noção de corpo negro. Mais adiante no texto, ao dar exemplos de corpo negros reais, o autor reforça a idealização dessa noção: "materiais tais como veludo negro ou fuligem são 
muito próximos de corpos negros ideais, mas a melhor realização prática de um corpo negro ideal é um pequeno buraco que leva ao interior de uma cavidade ..." (p.86)

Na seqüência à definição de corpo negro, o autor apresenta a lei de StefanBoltzmann e usa esse resultado, de maneira não adequada, para apresentar uma propriedade dos corpos negros: "note que a potência por unidade de área depende somente da temperatura e não de qualquer outra característica do objeto" (p.86). Como discutimos no capítulo I essa característica é própria e indissociável da noção de corpo negro e não um resultado da lei de Stefan-Boltzmann.

Ao definir a radiância espectral, o autor apresenta a lei de deslocamento de Wien. Os gráficos, contudo, são pouco ilustrativos e não refletem claramente a lei acima, já que os picos de emissão para temperaturas diferentes estão muito próximos devido à escala do gráfico e à pouca diferença entre os valores de temperatura.

Em continuação, é dito que: "o cálculo da função de distribuição $R(\lambda)$ [radiância espectral] envolve o cálculo da densidade de energia das ondas eletromagnéticas em uma cavidade"(p.86). Embora não haja nada de errado com esta frase, neste ponto do texto ainda não havia sido comentada a equivalência entre uma cavidade e um corpo negro. Além disso, um leitor mais desatento pode interpretar que esta é a única maneira de se desenvolver o problema.

$\mathrm{Na}$ seqüência, tratando a radiação de cavidade, o autor apresenta a relação entre a potência emitida pelo buraco desta cavidade e a densidade de energia em seu interior. Embora não apresente os cálculos para se chegar a essa relação, julgamos muito importante que esse resultado seja apresentado já que relaciona a medida experimental com o cálculo teórico.

A seguir, sem mostrar qualquer cálculo, é apresentado o número de modos de ondas num intervalo $d \lambda$. Também sem justificativa alguma, o autor relaciona o cálculo envolvendo a radiação de cavidade com o cálculo para um oscilador unidimensional: "de acordo com a teoria clássica, a energia média por modo de oscilação é $k T$, a mesma que para um oscilador unidimensional" (p.87).

Na seqüência, o texto obtém a Lei de Rayleigh-Jeans, sem especificar datas e o trabalho individual de cada cientista.

Ao apresentar o trabalho de Planck, o autor comenta que este fez algumas suposições estranhas, mas não deixa claro em seu texto o que ele considera como estranho: 

concordava com valores experimedia deduzir uma função $u(\lambda)\left[\mu_{\lambda}\right]$ que

Ao contrário do texto que analisamos anteriormente, neste encontramos a referência sobre o fato de que Planck, primeiramente, encontrou sem uma fundamentação física uma expressão que levava a uma boa concordância da teoria com os dados experimentais: "ele, inicialmente, encontrou uma função empírica para reproduzir os dados e então procurou uma maneira de modificar o cálculo usual para obter essa fórmula empírica."(p.87). Além disso, ao dizer "modificar o cálculo usual", o autor propicia a interpretação de que o desenvolvimento de Planck seria uma modificação da lei de Rayleigh-Jeans. Também ao descrever as etapas seguintes para a solução do PRCN, o autor usa um desenvolvimento completamente diverso daquele de Planck, sem deixar isso claro.

... Podemos visualizar o tipo de modificação se notarmos que, para um dado tamanho da cavidade, quanto mais curto o comprimento de onda, mais modos estacionários existirão. Quando $\lambda \rightarrow 0$, o número de modos de oscilação [da radiação] aproxima-se de infinito (p.87). ${ }^{106}$

Assim, ele conclui que:

a energia média por modo [da radiação] deve depender do comprimento de onda $\lambda$ e tender a zero quando $\lambda$ tende a zero. Portanto, o resultado do teorema da eqüipartição $\bar{E}=k T$ deve ser mudado.

A energia média, para um oscilador harmônico simples unidimensional, é calculada classicamente a partir da função de distribuição de energia... (p.87)

No primeiro parágrafo da passagem anterior, o autor discute a energia média dos modos de oscilação da radiação na cavidade. Já no segundo parágrafo, sem nenhuma introdução ou explicação, o autor passa a analisar a energia média para um oscilador harmônico simples. Na seqüência, o texto continua não especificando essas duas situações fisicas diferentes:

Planck percebeu que poderia reproduzir sua função empírica calculando a energia média $\bar{E}$, supondo a energia como uma variável discreta: i.e., que pudesse ter somente os valores $0, \varepsilon, 2 \varepsilon, \ldots, n \varepsilon$ onde $n$ é um número inteiro; e, além disso, tomando $\varepsilon$ proporcional à freqüência da radiação... (p.87)

Planck não utilizou a energia média em seus trabalhos. Além disso, o texto não deixa claro que energia média é essa. Em nossa interpretação, o autor só pode estar se

${ }^{106}$ Todos os grifos neste parágrafo são nossos. 
referindo à energia da radiação no interior da cavidade, pois este não associou os osciladores à cavidade. Até este ponto do texto, só é utiliza harmônico unidimensional".

Também o autor induz o leitor a pensar que está comentando sobre a energia média da radiação, pois ao final da passagem anterior ele comenta que $\varepsilon$ é proporcional à frequiência da radiação. Note ainda como 0 autor passa diretamente para essa proporcionalidade sem justificativa.

Então, tal como no texto de Eisberg e Resnick, é calculada a energia média a partir da função distribuição de energia, agora com uma somatória ${ }^{107}$ ao invés de uma integral. Contudo, ao fazer isso é afirmado que essa energia média é dos osciladores, novamente misturando, sem argumentação alguma, entes fisicos diferentes: " $A$ energia média dos osciladores é então dada por..." (p.88).

Com cálculos análogos ao outro texto que estudamos, o autor obtém assim a distribuição de Planck. Então, através de um gráfico, é mostrada a concordância da distribuição obtida com os resultados experimentais. Logo após, é apresentado o fato de que a expressão de Planck se reduz a lei de Rayleigh-Jeans para $\lambda$ grande, e tende a zero para $\lambda$ pequeno. Por fim, encontramos na seção alguns exemplos de exercícios utilizando os conceitos e as leis apresentadas no texto.

\subsection{Comentários gerais das análises}

As pesquisas que apontam dificuldades e problemas nas abordagens sobre o PRCN em cursos universitários de Física Moderna e a análise de dois textos, que representam bem a gama pouco diferenciada da oferta de manuais didáticos sobre o assunto, nos mostram que as abordagens utilizadas não estão sendo realmente úteis para o propósito em que são utilizadas: introduzir a noção de quantização de energia. Queremos ir ainda mais além: o PRCN e a radiação térmica são áreas importantíssimas de estudo da Física e extremamente ricas para que seu estudo se limite apenas aos cursos introdutórios de fisica moderna.

Ao utilizar o PRCN para introduzir a quantização de energia, os dois livros analisados falham ao enfatizá-la como a principal contribuição de Planck, pois muito embora ele tenha realmente realizado uma quantização, esta se mostrou, na época, confusa, não compreendida e não completamente fundamentada. Também o principal detalhe

${ }^{107} \mathrm{O}$ cálculo da somatória é apresentado numa seção posterior do texto. 
esquecido por esses textos: a quantização de Planck é bastante diversa daquela que compreendemos hoje com a Física quântica.

Procuramos mostrar na análise detalhada dos textos escolhidos que a abordagem superficial é muito complicada, pois nesta cada frase tem significação profunda, complexa e esconde exaustivas reflexões e desenvolvimentos matemáticos e conceituais. A síntese, também, pode provocar no leitor uma sensação de inferioridade frente à não compreensão de fatos apresentados como óbvios. Ainda, essas abordagens superficiais nos mostram o quanto frases mal formuladas induzem a generalizações indesejáveis tanto em relação aos desenvolvimentos históricos como físicos.

Essa própria maneira superficial e equivocada de analisar o PRCN é o que ocasiona os principais problemas encontrados nas abordagens que analisamos, que dizem respeito às distorções na própria compreensão da física, do fazer científico e da história da física. Discutimos brevemente, em tom de desfecho, essas principais distorções:

a) Distorções na compreensão física ${ }^{108}$. Nos textos analisados, notamos que a simplificação excessiva na abordagem do PRCN e a superficialidade com que o tema foi tratado levaram os autores a cometerem distorções de natureza fisica. Em primeiro lugar, a falta de cuidado na redação do texto, conforme procuramos exemplificar, possibilita a um leitor iniciante várias generalizações indesejáveis e uma compreensão fisica não adequada. Em segundo lugar, a omissão em fatos, detalhes ou mesmo desenvolvimentos matemáticos, levaram os autores a distorcem explicitamente alguns conceitos físicos:

\section{- Simplificacão da nocão de corpo negro e da equivalência de sua emissão com a}

radiacão no interior de uma cavidade. Essas noções físicas são bastante sofisticadas e possuem uma estrutura conceitual e teórica bastante complexa e intimamente ligada com a experimentação. Ao apresentá-las de maneira demasiadamente simplificada, sem muitas vezes especificarem a natureza ideal do corpo negro ${ }^{109}$, os textos analisados não fornecem ao leitor uma verdadeira compreensão da radiação térmica, do PRCN e sua história.

- Quantizacões equivalentes mal explicadas. Os textos analisados não diferenciam o conceito de quantização de Planck daquele que tomamos hoje na física quântica. Além disso, os textos não são claros sobre qual ente físico eles estão quantizando: a energia dos modos de radiação no interior da cavidade ou a energia dos osciladores harmônicos

${ }^{108}$ É importante que fique claro que não estamos afirmando que os autores cometeram erros de natureza que a simplificação exagerada levou os autores a distorcerem a física.

física. Estamos apontando que a simplifição exicitamente a noção ideal de um corpo negro foi o de Tipler. O único texto em que encontro deixou muito a desejar em relação a toda complexidade do assunto. 
em suas paredes. Também não é explicado de maneira convincente por que essas situações físicas são equivalentes, e o que é pior: essa equivalência só é possível de ser entendida a partir da compreensão atual da física quântica. Em outras palavras: os textos estão tentando ensinar o que é quantização, mas a compreensão adequada dos desenvolvimentos delineados, só é possível para alguém já interado com a fisica quântica.

b) Distorções no fazer científico. Também devido à superficialidade de abordagem e ao fato de que os desenvolvimentos teóricos parecem ter mais importância no meio científico moderno, os textos analisados se mostraram omissos demais em relação aos desenvolvimentos experimentais. Essas omissões distorcem o processo de trabalho científico, dificultando até a própria compreensão do tema em estudo e banalizando a construção do saber científico. Com relação à questão apontamos os principais problemas encontrados nos textos analisados:

- Ausência de discussão sobre as medidas de radiacão térmica. Quando algum dos textos analisados apresenta alguma explicação relacionada aos desenvolvimentos experimentais, este o faz de maneira muito simplista e não fornece uma noção exata do procedimento experimental e análise do fenômeno, conjunto extremamente necessário para a compreensão da radiação térmica e para a formação de físicos e professores.

Também ao tratar demasiadamente com a noção de densidade de energia da radiação na cavidade, os textos analisados evidenciam seu enfoque teórico. Não é discutido em nenhum deles que a grandeza experimental medida não é a densidade de energia da radiação, e sim a intensidade de radiação emitida.

- Banalizacão ou excessiva genialidade para o trabalho de Planck. Notamos também nos textos consultados que o processo científico do trabalho de Planck está completamente adulterado. Estes muitas vezes induzem (de maneira explícita ou não) o leitor a entender o procedimento de Planck de forma diversa do seu trabalho original, ou ainda mesmo omitem muitos desenvolvimentos importantes. Com essas distorções, Planck ora é supervalorizado por uma genialidade incomum, pois "sozinho e de maneira breve ele foi o único a pensar em quantização", como também ora tem seu trabalho e esforço banalizado, pois não é mostrado todo o seu grande programa de pesquisa.

c) Distorções para a história da física. Na tentativa de ensinar fisica quântica a partir de uma abordagem que leve em consideração os marcos históricos, mas sem abrir mão dos 
conceitos e desenvolvimentos modernos, os textos analisados cometeram erros, por vezes grosseiros, com relação à historia da física. Apontamos abaixo os principais problemas:

Ênfase no uso da eqüiparticão de energia. Os textos apresentam a lei de RayleighJeans como o único desenvolvimento teórico que a física clássica podia produzir para explicar o PRCN. Com esse procedimento os textos comentados usam o conceito de eqüipartição de energia, que não era ainda totalmente fundamentado em 1900 e muito menos foi utilizado por Planck.

Alteracões na cronologia dos fatos. Os textos analisados, além de atribuírem uma importância exagerada ao trabalho de Rayleigh e Jeans, não especificam que o trabalho de ambos não foi conjunto. Essa falta de informação induz os leitores a pensarem que estes desenvolveram a lei em parceria, ou ainda que Rayleigh-Jeans é o nome de um cientista apenas. Talvez para se esquivar de cometer erros, ou criar dúvidas nos leitores, todos os textos omitem a data da lei Rayleigh-Jeans.

- Ausência da termodinâmica no trabalho de Planck de solucão do PRCN. Como já discutido no capítulo I, todo o trabalho de Planck e seu programa de pesquisa tinham a intenção em encontrar uma expressão apropriada para a entropia do corpo negro. Nenhum dos autores ao menos citou esse fato, quanto mais mostrou os reais desenvolvimentos de Planck. 


\section{IV - UM EXEMPLO DE INOVAÇÃO: A DISCIPLINA EVOLUÇÃO
DOS CONCEITOS DA FÍSICA}

Neste capítulo apresentamos e discutimos parte da disciplina "Evolução dos Conceitos da Física" como uma possível alternativa às abordagens criticadas no capítulo anterior.

Inicialmente procuramos evidenciar a natureza e o funcionamento da disciplina. $\mathrm{Na}$ sequiência discorremos sobre o conteúdo das notas de aula que tratam o Problema da Radiação de Corpo Negro (PRCN), destacando as principais preocupações presentes nesse texto. Também utilizando como referencial de análise as dificuldades de abordagem do PRCN apresentadas no capítulo III e as discussões sobre os textos acadêmicos de Física Moderna, procuramos ainda apontar nas notas de aula algumas novidades e outros problemas.

\section{A disciplina e sua dinâmica}

Além do tratamento comum e superficial das disciplinas de Física Moderna sobre o PRCN e sua solução por Planck, o Instituto de Física da USP em São Paulo oferece a disciplina "Evolução dos Conceitos da Física" maneira não usual, quando ministrada pelo professor João Zanetic.

Essa disciplina mantém como tema de discussão o desenvolvimento de alguns conceitos da fisica, tendo como referencial sua história e filosofia, e mantendo ainda o propósito ambicioso de ensinar física através desse referencial. Com apenas duas horas/aulas semanais, esta disciplina, talvez exageradamente e/ou pretensamente, procura desempenhar vários papéis complementares:

i. apresentar uma breve introdução à filosofia da ciência contemporânea;

ii. procurar conceituar "história da ciência" e algumas de suas exemplificações usuais;

iii. apresentar algumas exemplificações dos itens i, e/ou ii;

iv. disponibilizar, aos alunos de licenciatura e bacharelado em física, uma bibliografia básica sobre os temas abordados;

${ }^{110}$ Essa disciplina é optativa tanto para a Licenciatura como para o Bacharelado em Física, sendo oferecida durante o primeiro semestre de cada ano, nos períodos diurno e noturno. Sua carga horária é de 2 horas/aulas por semana, o que corresponde a uma disciplina de 2 créditos. O pré-requisito desta é Física Moderna I, curso que normalmente tem como livro-texto "Física Quântica" de Eisberg \& Resnick. Assim, pelo menos em tese os alunos estudaram o problema da radiação de corpo negro. 
v. esboçar uma apresentação histórico-filosófica de conteúdos de física como alternativa ao modo tradicional dominante.

Com a intenção de atingir essas metas, a disciplina é dividida em duas partes. $\mathrm{Na}$ primeira parte são analisadas algumas concepções filosóficas relativas à ciência e ao seu funcionamento. São apresentadas, através das "notas de aulas" escritas pelo professor, o método indutivo, o racionalismo crítico de Popper, a ciência normal e as revoluções de Kuhn, o anarquismo epistemológico de Feyrabend e o novo espírito científico de Bachelard. Em todos esses estudos são discutidas as possíveis implicações dessas concepções para o ensino da ciência e, particularmente, para o ensino de física nos níveis médio e superior.

Na segunda parte, buscando complementar a visão filosófica com a histórica, é introduzida a discussão sobre o uso da história da ciência no ensino. São destacadas algumas das possíveis abordagens para a história (internalista e externalista, por exemplo), além de algumas formas de construção da história internalista, como as noções de reconstrução racional pensada por Imre Lakatos e recorrência histórica de Gaston Bachelard. Posteriormente, uma história internalista sobre o PRCN e a sua solução por Planck é apresentada e discutida de forma bastante detalhada. Ao final da disciplina, é analisado um exemplo sobre história externalista: Boris Hessen e seu artigo sobre as raizes sociais e econômicas do "Princípia" de Newton.

Nesta dissertação fazemos nossas análises pensando mais especificamente na disciplina ministrada em 2000, no qual a autora principal deste participou como monitora no período diurno, mantendo a função de atendimento aos alunos, participação nas discussões em classe e correção dos trabalhos. A disciplina foi um pouco prejudicada pela greve da USP, sofrendo com isso alterações em seu cronograma e conteúdos iniciais ${ }^{111}$, porém sua abordagem com relação ao PRCN, tema do nosso estudo, ocorreu na íntegra como planejado.

Cada aula da disciplina foi composta por duas atividades: exposição do professor (com abertura para possiveis interlocuções com os alunos) e uma discussão sobre o tema da aula. Na semana precedente era sempre indicada aos alunos a leitura das "notas de aula". Essas notas contêm um texto básico de cada aula, além da bibliografia utilizada e

${ }^{111}$ Por exemplo, embora a aula sobre Bachelard tenha sido ministrada no periodo diurno, esse assunto não foi cobrado em provas e avaliações. 

maioria das aulas foi entregue aos alunos

orientar e motivar as discussões finais. ${ }^{112}$ foram realizadas através de dois trabalhos e na "resolução" de algumas questões, sendo o hos e nos roteiros de discussão em classe. Para o cálculo da nota final foi atribuído peso 7 para a nota média das provas e peso 3 para a nota média dos trabalhos. Novamente, devido às turbulências da greve, a nota dos trabalhos só foi levada em consideração se esta fosse maior que a média das provas.

\section{0 conteúdo e as intenções das notas de aula sobre o PRCN}

Com relação ao desenvolvimento histórico do PRCN contido nas notas de aula, boa parte baseia-se no primeiro capítulo de Jammer (1966). Entre outras bibliografias destacamos Osada(1972), Segrè (1987), Cline (1992), Kuhn (1978), Kangro (1972), Gamow (1974), Mehra \& Rechenberg (1982), entre outros. São dedicadas 55 páginas (cerca de 1/3) das notas de aula a esse assunto.

Logo no primeiro capítulo sobre o tema (capítulo 2), há uma breve alusão ao nascimento da física quântica e sua origem relacionada com a "inabilidade da fisica clássica em conseguir resolver alguns problemas que se afiguravam" (p.96), entre os quais é destacada a busca pela explicação para a distribuição de energia do espectro de radiação de corpo negro.

$\mathrm{Na}$ seqüência, há uma breve explanação sobre os antecedentes históricos ao problema, mais especificamente sobre o entendimento da natureza da luz ao longo da história da ciência, seguido por um breve "parênteses sociológico" baseado em Osada (1972), cuja abordagem diz respeito às necessidades de estudo da radiação de corpo negro que envolvia o controle de temperatura de altos fornos siderúrgicos e a produção de aço de qualidade.

Ainda nesse capítulo é discutido o teorema da equipartição de energia (que "estava no $a r "$ (p.106) no final do século XIX), o desenvolvimento experimental e a busca pela função de distribuição para a radiação de corpo negro, com destaque para os trabalhos de Stefan (1879), Boltzmann (1884), Michelson (1887) e Wien (1894 e 1986).

\footnotetext{
${ }^{12}$ Infelizmente no período diurno essas discussões em classe não foram frutíferas. Os alunos, em sua maioria, sempre por demais atarefados, acabavam não lendo as notas de aulas e muito menos o roteiro de questões. A turma também parecia ser bastante introvertida.

${ }^{13}$ A pretensão inicial do curso era a de propor aos alunos três trabalhos e três provas, mas com a greve ambos do curso houve ainda uma prova substitutiva, facultada a todos.
} 
O segundo capítulo sobre o PRCN (capítulo 3) se inicia com uma breve retrospectiva dos trabalhos de Planck, com destaque para aqueles sobre termodinâmica, incluindo sua derivação da lei de Wien e um trecho do referido texto original. Em continuidade, está incluso na íntegra o artigo clássico de Planck de outubro 1900, traduzido para o português por João Zanetic a partir da versão em língua inglesa de Kangro (1972). No capítulo 4 são apresentados trechos do artigo de dezembro de 1900.

Prosseguindo nesse último capítulo citado são abordados o desenvolvimento de Rayleigh e os erros de cronologia para o trabalho de Jeans, além de algumas conseqüências inéditas na época e pouco divulgadas atualmente do trabalho de Planck, como por exemplo o valor mais preciso da época para a carga elétrica elementar $e$.

No capítulo 5 das notas de aula, é apresentado um desfecho para a história internalista do quantum, com uma breve descrição dos desenvolvimentos posteriores que levaram à mecânica quântica e uma discussão sobre a recepção a essas novas idéias. Em conclusão, a partir de uma citação de Lévy-Leblond, é feita uma breve defesa à leitura de textos originais.

Analisando globalmente o tratamento dado ao PRCN pelas notas de aula, notamos que 0 assunto é abordado não apenas com o intuito de destacar sua história (ressaltando a termodinâmica do trabalho de Planck), mas também procurando enfatizar diferentes "procedimentos metodológicos, mudanças conceituais, novas interpretações de velhos resultados, crenças e dúvidas, conseqüências filosóficas e sociais" (p.103), além de uma crítica aos manuais didáticos e da valorização da leitura de textos originais da ciência.

Todos esses aspectos estão reunidos nas notas de aula com um claro propósito: ensinar fisica procurando lograr êxito nesse empreendimento, assim como propiciar ferramentas para que os alunos adquiram certa autonomia e visão crítica sobre a ciência e a atividade científica, influindo dessa maneira positivamente na formação de futuros professores, cientistas e pesquisadores em ensino de física.

Não se pode esquecer ainda que o PRCN nesta disciplina não é o foco central, pois esta procura introduzir noções de diversas propostas epistemológicas e formas diferenciadas de apresentações da história da ciência. Assim esse tema, dentro da disciplina, além de explorar uma apresentação da formulação da equação da RCN de Planck mais próxima dos eventos históricos reais que ocorreram em torno de 1900, permite problematizar uma crise ou ameaça de refutação de uma parte da física clássica então 
estabelecida. Tudo isso será acentuado na discussão de algumas preocupações suscitadas pela análise detalhada das notas de aula.

Dessa análise geral das notas de aula, destacamos a seguir algumas preocupações importantes relacionadas aos aspectos citados acima. É importante ressaltar que essas preocupações são meras classificações que auxiliam na redação do texto e compreensão das idéias, no entanto todas estão correlacionadas:

\section{- Preocupações de natureza histórica}

O conteúdo das notas de aula configura-se em sua essência numa narrativa histórica. Não um simples encadear de fatos, descobertas ou notas biográficas, como a maioria dos manuais didáticos de qualquer nível de ensino apresentam. A diferença desse texto é que a história não se separa da física e da sua filosofia, nem mesmo das relações sociais entre os cientistas e a comunidade externa.

Logo na introdução ao assunto, com uma breve apresentação da evolução do entendimento da natureza da luz até a época do trabalho de Planck, notamos a preocupação em contextualizar a história a ser trabalhada, propiciando uma ampliação dessa visão, a fim de que o PRCN não seja uma história pontual.

Também há a preocupação em resgatar a equipartição da energia não como algo consolidado, aceito e entendido, como para nós se afigura atualmente, porém como algo que na época "estava no ar" e não era ainda completamente aceito por todos, informação normalmente omitida dos textos didáticos. Ainda sobre este tema, as notas de aula destacam a citação de Jammer (1966) sobre a importância do fato de que Planck não se utilizou do teorema da equipartição de energia.

... afortunadamente para o futuro desenvolvimento da física Planck não utilizou o teorema (...) tivesse ele utilizado o teorema da equipartição de energia neste estágio de seu trabalho, ele teria chegado necessariamente à lei da radiação de Rayleigh-Jeans (...), que é incompatível com a experiência e teria provavelmente abandonado as pesquisas neste problema. (p.119)

Notamos também outras intenções de contextualização da história. Há, por exemplo, a preocupação nas notas de aula de descrever a pessoa, o cientista e os trabalhos anteriores de Planck, com destaque para a termodinâmica:

... Planck, a partir de 1878 , começou a realizar inúmeros trabalhos sobre processos irreversíveis, procurando esclarecer e estender a aplicação dos fundamentos da termodinâmica.(p.117) 
Ao contrário das notas de aula, nenhum dos livros acadêmicos que consultamos, por exemplo, destaca o papel de Planck na rigorosa derivação da lei de Wien, ou mesmo destacam esta lei.

Outra preocupação de ordem histórica nas notas de aula pode ser verificada pela forma problematizada de apresentação do PRCN, mostrando, por exemplo, a quantização de Planck como só aplicada aos radiadores, e não à energia emitida, e ainda como o próprio Planck almejava encaixar seu quantum na física clássica. A maioria dos textos sobre física moderna coloca a quantização de Planck da forma como entendemos hoje, como uma novidade de fácil aceitação e entendimento, ou ainda como algo desprovido de conflitos para Planck.

Em nenhum momento, nesse artigo [dez/1900], Planck deu um destaque especial para o fato fundamental de que a energia é um múltiplo inteiro de $\mathrm{h}$. Parece que naquela época Planck não estava totalmente convencido de que a introdução da constante $h$ era algo mais que mero artifício matemático. (p.140)

Notamos também o cuidado das notas de aula em ressaltar outras conseqüências do trabalho de Planck omitidas nos manuais didáticos, como o melhor valor calculado até então da carga elétrica elementar. Também é evidenciada a preocupação em não fornecer aos alunos apenas fontes secundárias. O texto apresenta trechos comentados dos artigos originais de Planck.

\section{- Preocupações de natureza filosófica}

A narrativa histórica do PRCN se completa com sua visão filosófica, e nas notas de aula da disciplina esse aspecto se faz presente de forma bastante acentuada. $O$ texto procura destacar o funcionamento da ciência daquela época e suas possíveis interpretações epistemológicas baseadas nas concepções filosóficas discutidas na primeira parte da disciplina, excetuando-se o método indutivo:

Já comentei o fato de que Planck tardou muito a aceitar o caráter revolucionário de sua descoberta ou invenção teórica, ou seja, traduzindo em termos de algumas das propostas epistemológicas que estudamos na $1^{a}$ parte, ele recusava a idéia de que tivesse provocado uma refutação da física clássica (Popper) ou ruptura/revolução com a ciência normal/obstáculo epistemológico da mecânica e do eletromagnetismo clássicos (Kuhn e/ou Bachelard). (p.144)

Dessa maneira fica evidente a intenção das notas de aula em desvendar o árduo processo de desenvolvimento das "descobertas" científicas, em especial o quantum de INSTITUTO DE FÍSICA 
ação, procurando, portanto, destruir idéias comumente aceitas, e muitas vezes veiculadas pelos manuais acadêmicos, da ciência como algo já pronto e estabelecido de forma lógica, cumulativa e realizada por mentes brilhantes que não se enganam:

Notamos, portanto, que uma refutação das teorias da física clássica ou uma revolução científica não ocorre de um momento para o outro. Pelo contrário, ela envolve o trabalho de uma grande quantidade de pesquisadores normais inquietos com 0 andar da carruagem dominante. As figuras geniais da física, os Planck, Einstein, Bohr, de Broglie, Lorentz, e muitos outros acima mencionados construíram façanhas, mas também cometeram muitos enganos e erros de avaliação. Planck não foi exceção. (p. 147)

Portanto, a aceitação da ruptura com a física clássica foi um processo longo e penoso tanto para Planck quanto para muitos de seus contemporâneos. A aceitação plena da teoria quântica foi concretizada na década de $20, \ldots$ (p.149)

A história da física está repleta de acontecimentos e fenômenos aparentemente simples que levaram a construções teóricas sofisticadas. Basta lembrar alguns: o movimento retrógrado dos planetas, a queda acelerada dos graves, o movimento browneano, o espalhamento de partículas alfa por anteparos metálicos finos, o efeito foto-elétrico, a ausência de movimento da Terra com relação ao éter, entre outros. Daí surgiram, respectivamente, o heliocentrismo, a mecânica clássica, a mecânica estatística, a física quântica e a relatividade.(p.97)

O texto evidencia ainda como a quantização era confusa para o próprio Planck, enfatizando também as modificações que fez em 1911 e 1914:

Max Jammer destaca que, em 1911, devido às objeções que fazia às interpretações quânticas que "condenavam" a física clássica, Planck chegou a formular uma segunda teoria onde sugeria que a absorção de energia eletromagnética seria um processo contínuo enquanto a emissão ocorreria apenas em quanta inteiros de energia e era um processo regulado pelo acaso. Ele ainda afirma que, em 1914 (!), Planck formularia uma terceira teoria que considerava tanto a absorção quanto a emissão de energia radiante como fenômenos contínuos. (p.145)

Tratando ainda sobre a dificuldade do problema e a aceitação lenta da quantização, as notas de aula discorrem sobre o congresso de Solvay (1911), cuja finalidade era entender os quanta. A frase de Lorentz citada nas notas de aula evidencia o "tamanho" do problema, já que o PRCN era ainda "o mais misterioso e mais dificil problema de ser entendido" (p.146). 
- Preocupações de natureza física

Embora o texto seja essencialmente histórico, a preocupação em discutir e ensinar fisica está em toda a apostila. Podemos notar isso desde a caracterização física do fenômeno, ou mesmo a conceituação de corpo negro, até os desenvolvimentos matemáticos e fisicos dos artigos de Planck.

Essa preocupação está também bastante transparente, por exemplo, na descrição sobre o desenvolvimento ao longo da história das curvas de distribuição, no qual são discutidos os trabalhos de Kirchhoff com o estudo das linhas de Fraunhoffer, a lei de Stefan-Boltzmann, a noção de radiância e sua correspondência com a área sob cada curva das distribuições espectrais, a lei de deslocamento de Wien (também evidenciada pelas curvas), etc.

Até mesmo tentativas incoerentes como a de Michelson estão presentes nas notas de aula ${ }^{114}$. Este procurou resolver o PRCN através da semelhança das curvas de distribuição espectral de corpo negro com a distribuição de velocidades de moléculas de um gás de Maxwell.

A preocupação com a física dos exemplos do texto, também vai nitidamente além dos desenvolvimentos matemáticos, procurando evidenciar como o conhecimento físico foi aplicado de forma abstrata à modelagem de fenômenos reais.

Além da exposição sobre os trabalhos de Planck de aprofundamento do entendimento da termodinâmica e o estabelecimento do princípio do aumento da entropia, também é discutida nas notas de aula a relação entre a entropia, equilíbrio termodinâmico e o processo de emissão de um corpo negro, imprescindível para a compreensão exata do programa de pesquisa de Planck. Esse tipo de análise envolve o entendimento físico do fenômeno e não é contemplado em outros textos acadêmicos.

Kuhn [1978] destacava que a formulação de Planck para a segunda lei era especialmente útil para o estudo de sistemas em equilíbrio e a radiação de corpo negro, que seria estudada por Planck, é um bom exemplo de equilíbrio térmico. E Kuhn acrescentava:

"Se uma distribuição inicial arbitrária de energia é injetada numa cavidade isolada, então a distribuição tenderá ao equilibrio enquanto a energia é absorvida e reemitida por quaisquer pedaços de material negro contido na cavidade. A aproximação ao equilíbrio térmico é irreversível, e a entropia portanto deve aumentar até que o equilibrio é alcançado. Se temos a fórmula para a entropia da radiação como uma função das variáveis de campo, então a função de distribuição do corpo negro seria

${ }^{114}$ É claro que a presença desse desenvolvimento nas notas de aula tem sua finalidade, visto que influenciou Wien na elaboração de sua lei de radiação. 

uma que maximizasse a entropia total da radiação na cavidade". (p.116-
117)

Planck assumiu o procedimento de Wien e tentou provar que as equações de Maxwell-Hertz, quando aplicadas a ressoadores com condições iniciais arbitrárias, levariam a processos irreversíveis convergindo para um estado estacionário cuja distribuição de energia era a da radiação de cavidade e que, portanto, determinaria o espectro da radiação do corpo negro. (p.118)

\section{- Preocupações de natureza sociológica}

Tanto as necessidades de estudo da radiação do corpo negro, quanto as atitudes e relações estabelecidas na comunidade científica da época são trabalhadas na apostila, embora pontualmente e de maneira breve.

... O fator mais importante na produção de aço de primeira qualidade é o controle delicado da temperatura dos altos fornos. Evidentemente, não se pode usar termômetros comuns para a medição de temperaturas tão altas. A fim de contornar esse problema, pesquisas foram feitas no sentido de determinar as temperaturas usando as cores das radiações térmicas, ... ${ }^{115}$

Estão também explícitas no texto algumas das controvérsias entre os cientistas com relação ao entendimento do quantum, como por exemplo, o apoio de Planck ao trabalho de relatividade de Einstein e sua oposição às idéias quânticas deste último.

\section{- Preocupação de natureza pedagógica}

A preocupação com a formação de professores secundários e universitários, assim como a de físicos e pesquisadores (tanto na área científica quanto pedagógica), permeia todo o conteúdo das notas de aulas. Está também implícita a intenção de preparar os estudantes de física para eventuais futuras crises e novos desenvolvimentos científicos.

Essas preocupações podem, por exemplo, ser notadas no cuidado e aprofundamento da apresentação do PRCN nas notas de aula, além do alerta aos problemas de ordem histórica e filosófica presentes na maioria dos textos acadêmicos.

$\mathrm{Na}$ leitura de várias fontes que abordam a física quântica, principalmente nos manuais universitários, encontramos várias apresentações sobre o desenvolvimento da radiação do corpo negro que diferem em muitos aspectos do resumo histórico aqui apresentado. (p.149)

${ }^{115}$ Osada (1972, p. 48-49) citado por Zanetic (1999b, p. 104). 
Também são mostradas no texto as incorreções na cronologia dos trabalhos de Rayleigh e Jeans. A citação de Whitaker ilustra bem o problema:

A quase-história não pode aceitar a idéia que mesmo cientistas geniais podem cometer erros. (...) Nós vemos esses efeitos na maneira como a quase-história trata a lei de Rayleigh-Jeans. Ela coloca-a últimamente temporalmente anterior à lei de Planck, pois, assim que a última fosse conhecida, a quase-história assume que ela seria adicionais procedimentida e aceita, e não haveria necessidade de estava não apenas pensando classicamente, mas não podia mesmo de Planck apareceria como uma surpresa. E o que Rayleigh teve que ser corrigido por Jeans é suprimido de tal modo que muitos estudantes imaginam que a lei foi descoberta por um

Certamente muitos de vocês devem ter lido essas palavras identificando-se com as conclusões do autor. Ele [Whitaker (1979)] chega até a sugerir que os manuais têm suas razões para assim proceder, mas adverte que devemos apresentar a física como uma área do conhecimento viva e dinâmica e não como algo já completamente estruturado. (p.150)

As notas de aula procuram também despertar o interesse pela leitura de textos originais da ciência, com uma citação de Levy-Léblond:

A gente não imagina um escritor que não tenha lido Proust e Faulkner, um filósofo que não tenha trabalhado Husserl e Sartre, um músico que não tenha ouvido Stravinski e Messiaen, um pintor que não tenha visto Picasso e Malevith. Mas a gente não se espanta que um físico não tenha lido nem Einstein nem Heisenberg - para nos manter nesse século. (...) É bom poder reviver 'em contado direto' esses esforços admiráveis, e de reencontrar o vigor e a complexidade, freqüentemente tornados insípidos e esterilizados nos manuais de ensino e nos livros de divulgação".(p.150)

\section{As dificuldades de abordagem do PRCN nas notas de aula}

Ampliando nossa análise das notas de aula da disciplina "Evolução dos Conceitos da Física", e para isso tomando como referencial o capítulo anterior desta dissertação, destacamos a seguir outros aspectos que, a nosso ver, colocam essa disciplina como uma alternativa inovadora aos outros textos do gênero.

Em primeiro lugar, o PRCN é tratado nas notas de aula com ampla abordagem, ao contrário dos textos acadêmicos analisados. A contextualização histórica é bastante ampla, profunda e cuidadosa. Também o conteúdo físico envolvido nos fenômenos e 
desenvolvimentos é trabalhado de forma clara. Apenas a preocupação em discutir a termodinâmica do trabalho de Planck e a presença dos textos originais, já evidenciam a profundidade com que o tema é abordado.

Conforme procuramos mostrar no capítulo anterior é a própria superficialidade de abordagem que ocasiona a maioria dos problemas que apontamos para o ensino do PRCN pautado nos textos acadêmicos que analisamos. Embora ainda haja uma série de inconvenientes que discutiremos adiante, podemos asseverar que as principais distorções que apontamos para os textos analisados são bastante minimizadas ou mesmo inexistentes nas notas de aula:

a) Ausência de distorções na compreensão física. Embora, conforme discutiremos mais profundamente, a noção de corpo negro ainda não está adequada nas notas de aula, não detectamos nestas distorções de natureza conceitual ou fisica. Essa ausência de distorções está intimamente ligada ao fato de que as notas de aula seguem uma abordagem mais próxima da história e mais fiel aos originais da ciência e às discussões dos historiadores.

b) Distorções no fazer científico minimizadas. Ao contrário dos textos acadêmicos analisados, o propósito da disciplina é justamente desnudar o processo científico na solução do PRCN e clarificar como o uso da história e filosofia é importante para a compreensão deste. Dessa forma, o fazer científico é corrente objeto de discussão ao longo das notas de aula. Ainda assim, a parte experimental da questão deixou muito a desejar. No entanto, como já salientamos no capítulo I, não há bibliografia relevante sobre o tema. Também é importante verificar que nas notas de aula o trabalho de Planck é tratado de uma maneira mais amena e mais de acordo com o trabalho dos historiadores: sem exaltação a sua pessoa e sem qualquer banalização ao seu desenvolvimento.

c) Ausência de distorções para a história da física. Enquanto os textos analisados no capítulo anterior apenas pretensamente se passam por históricos, já que distorcem seus desenvolvimentos no intuito de que estes façam sentido numa seqüência lógica, objetiva e pretensamente racional, nas notas de aula a presença do conflito, das dificuldades teóricas e das resistências são parte integrante da forma de abordagem.

Assim, nas notas de aula, a eqüipartição de energia não faz parte dos desenvolvimentos de Planck. Também a cronologia dos fatos não é alterada e o cálculo termodinâmico de Planck foi apresentado e discutido.

${ }^{116}$ Whitaker (1979), citado por Zanetic (1999b, p. 149). 


\section{Alguns problemas}

A noção de corpo negro. Notamos que a noção de corpo negro não é bem explorada no texto ${ }^{117}$. Não há menção ao fato dessa noção ser uma idealização, e a analogia desta com o forno de siderúrgica acaba restringindo a aplicabilidade do conceito. Também a equivalência com emissão de cavidade não é trabalhada nas notas de aula. Destacamos a seguir os trechos das notas de aula que procuram conceituar o corpo negro:

... quando qualquer objeto é aquecido, ele emite um amplo espetro de radiação, principalmente na região do infravermelho que corresponde àquela situação em que o corpo aquecido tem a aparência de um corpo frio. Quando a radiação emitida é gerada em condições de equilíbrio por uma espécie de cavidade aquecida, como é o caso de um alto forno de siderúrgica, o espectro depende apenas da temperatura. Isto quer dizer que, qualquer que seja a forma ou material - metal, vidro, ou outra substância qualquer - do alto forno, sua abertura emitirá luz que não permite o reconhecimento dos materiais nele aquecidos. (p.96)

... Kirchhoff introduzia a noção de corpo perfeitamente negro, ou simplesmente corpo negro, referente a um corpo que absorve toda a radiação nele incidente, isto é, tem uma taxa de absorção igual à unidade.

(...)

Vimos acima a referência ao estudo da radiação emitida por corpos aquecidos e seu relacionamento com um forno a altas temperaturas. (p.103)

Notamos também que as necessidades de estudo da radiação do corpo negro, ligadas ao controle da temperatura dos altos fornos, não foram trabalhadas no texto em concomitância aos desenvolvimentos teóricos e experimentais. Esse tipo de desassociação pode levar à impressão de que alguém "encomendou" para os físicos um estudo que possibilitasse o controle das temperaturas dos altos fornos. Os físicos ficaram anos tentando resolver e depois mandaram a solução para a indústria. No entanto, acreditamos que esse tipo de problema seja inerente à história internalista.

Também, não podemos deixar de pensar que as notas de aula referem-se a uma disciplina recomendada para ser cursada a partir do $7^{\circ}$ semestre do curso de licenciatura e $6^{\circ}$ semestre do curso de bacharelado. Se levarmos em consideração as disciplinas prérequisito para cada um desses cursos, verificaremos que nestas estão previstas abordagens da RCN. Esta poderia ser uma razão atenuante do problema mencionado. De qualquer 
forma, uma nova edição do "texto de evolução" (e em pretensa co-autoria) deverá dar conta de resolver a falha apontada.

Verificamos também que as notas de aula acabam não dando muita importância para algumas "sensibilidades experimentais" que poderiam auxiliar no entendimento do fenômeno. Como exemplo, podemos citar que a noção de corpo negro experimental em contraposição à abstração teórica, poderia contribuir para uma melhor compreensão desta última. Também poderia ficar explícito no texto que não medimos experimentalmente $\rho_{T}(v)$ e $\operatorname{sim} R_{T}(v)$. Embora essas duas grandezas sejam diretamente correlacionadas, os alunos muitas vezes não acham óbvia a proporcionalidade entre elas.

Destaque excessivo para o trabalho de Rayleigh. As notas de aula, assim como muitos outros textos, destacam de forma demasiada o trabalho de Rayleigh: "portanto, as duas mais significativas funções de distribuição conhecidas até então-a de Wien e a de Rayleigh - não conseguiam satisfazer todo o espectro da radiação do corpo negro" (p.124). Kragh (2000) cita a lei de Rayleigh-Jeans "apenas para descartá-la como historicamente irrelevante" (p.33).

Problemas com definições. No texto não está explícita a conceituação da grandeza radiância. Não há menção ao significado desta logo na primeira vez que o símbolo $R_{T}(v)$ aparece na apostila (p.104, como parte integrante da "curva de energia luminosa irradiada em função da freqüência e da temperatura").

Posteriormente são apresentados três "significados" diferentes para $R_{T}$. Ao tratar sobre a lei de Stefan-Boltzmann é mencionado no final do primeiro parágrafo que " $a$ radiação total era proporcional a $T^{4,118}$ (p.108). Na seqüência é mostrada a relação de Stefan-Boltzmann e o símbolo $R_{T}$ é apresentado como sinônimo de radiância. Ainda nessa página é especificado (sem mostrar símbolo algum) que a radiância total é "a energia total emitida por unidade de tempo por unidade de área por um corpo negro à temperatura $T$ "(p.108). Na seqüência está especificado o cálculo da radiância total, mas não fica explícito que seu símbolo é $R_{T}$.

Mais adiante (na página 109) a radiância espectral $R_{T}(v)$ acaba sendo definida no interior do primeiro parágrafo, todavia sem qualquer destaque. Dessa maneira fica dificil consultas posteriores ao significado físico dessa grandeza.

${ }^{118}$ Grifos nossos. 
Toda essa confusão parece banal, contudo é importante mencionar que esta não mereceria nosso destaque, se não tivéssemos detectado que os alunos reproduziram esses erros. (6) e (7) não estão discriminadas no texto.

Também notamos que as grandezas $S_{l}, S_{0}, S^{\prime}$ e $S$ (p.115) pertencentes às equações

Falta de estratégias adequadas no uso de textos originais. Conforme discutimos no capítulo II, consideramos muito importante para o aprendizado da Física a leitura de textos originais de cientistas por parte do estudante, e estes estão presentes nas notas de aula. No entanto, também alertamos sobre a dificuldade de trabalho com esse tipo de texto em atividades de ensino e a necessidade de utilização de estratégias adequadas.

Uma análise mais atenta nos mostra que os trechos de textos originais que encontramos nas notas de aula não incentivam a leitura por parte do aluno, pois não apresentam complementos explicativos e textos introdutórios. Também não houve na disciplina qualquer atividade ou trabalho escolar que exigisse a leitura do texto. Sendo assim os textos originais acabaram funcionando dentro das notas de aula muito mais como ilustração, conforme tivemos oportunidade de verificar em conversas particulares com alguns alunos: eles simplesmente não leram os originais, de maneira que estes acabam perdendo um pouco da sua função específica dentro da disciplina.

Omissões significativas. Não é mencionado nas notas de aula o fato de que o fio de platina no experimento de Tyndall não funcionava como um corpo negro e esse experimento acabou "dando certo" por acaso. Modernas reproduções do experimento forneceram valores muito diferentes (Jammer, 1966, p.6).

Também não está especificada na página 111 a data em que Wien publicou sua lei de radiação, que foi 1896.

\section{Sugestões para ampliação e melhoria do material}

Além de proporcionar, a partir do capítulo I deste trabalho, complementação para a história e a física abordada nas notas de aula, e também sanar os problemas apontados na seção anterior, propomos algumas sugestão visando ampliar a proposta pedagógica da disciplina:

- O PRCN também envolve todos os grandes ramos da física clássica: a eletrodinâmica, a termodinâmica, acompanhada pelos recentes desenvolvimentos na mecânica 
estatística, e em menor escala a própria mecânica. Assim sendo a solução do PRCN tem em sua estrutura boa parte da física clássica que antecedeu à teoria quântica. Não seria esse estudo uma ótima oportunidade para se aplicar e sintetizar esses conhecimentos?

Em extensão a essa idéia poderíamos sugerir além do tratamento aprofundado do trabalho de Planck, a inclusão, mesmo que de forma "didática", dos detalhes do desenvolvimento de Boltzmann para obtenção da lei de Stefan-Boltzmann (como no apêndice II). Da mesma maneira poderiam ser estudados os trabalhos de Kirchhoff, Wien e Rayleigh. Acreditamos que essas seriam oportunidades bastante estimulantes para se aprender física. Nossa sugestão não vai apenas no sentido de inclusão dessas análises nas notas de aula, também seria interessante que estes desenvolvimentos fossem transformados em exercícios ou trabalhos para os alunos. É claro que sempre é necessário levar em consideração que essa disciplina é de apenas duas horas semanais.

- O tipo de estrutura do texto nas notas de aula e a apresentação da Física envolvida não permitem um acompanhamento sistemático das derivações físicas. A apresentação dos resultados prontos ao nosso ver estimula o aluno a não pensar muito no significado físico deste e a efetuar uma leitura superficial, apenas buscando a história. Por exemplo, muitos alunos não sabem derivar a função de distribuição de $K_{\lambda}(\lambda, T)$ a partir da equação dada por $\rho_{T}(v)$. Seria interessante que essa estivesse inclusa no texto, ou fosse discutida durante a aula, ou mesmo apresentada como exercício aos alunos.

- Embora estejam bem descritas e discutidas nas notas de aulas as contribuições termodinâmicas de Planck e sua importância para a resolução do problema da radiação de corpo negro, seria interessante um capítulo reservado apenas para essa questão, com destaque para a discussão sobre a entropia e sua relação com a emissão de corpo negro.

- Sugerimos também incrementar a disciplina com uma atividade experimental sobre radiação de corpo negro usando uma lâmpada com filamento de tungstênio, um pirômetro e um espectrômetro. Neste experimento poderiam ser obtidos pontos que permitissem a interpolação da curva de Planck (tomando devidos cuidados de calibração e levando-se em conta que o filamento é um "corpo cinza" e não negro). Com essa curva poderiam ser pedidos aos alunos que extraíssem resultados físicos, 
como a interpretação da curva, a lei de Stefan-Boltzmann, a lei de deslocamento de

Wien, etc. Seria também muito interessante fazer experiências com os raios solares, já que podemos aproximar o sol para um corpo negro.

\section{Aprofundando melhor o significado e os objetivos da disciplina}

Acreditamos que também podemos abstrair as principais metas de uma disciplina profunda e bastante ampla como a "Evolução dos Conceitos da Física" através da análise das cobranças e avaliações realizadas pelo professor. Vamos então através das atividades propostas aos alunos procurar avaliar melhor os objetivos principais da disciplina (não apenas das notas de aula, como fizemos na seção precedente).

$\mathrm{Na}$ disciplina oferecida no primeiro semestre de 2000 , com relação ao tema sobre o PRCN, foram propostas três atividades aos alunos. Uma atividade de estudo e aplicação (na verdade uma atividade livre procurando estimular as discussões em classe), um trabalho (no qual o aluno deveria responder algumas questões) e 2 provas, podendo ainda o aluno realizar ainda uma prova substitutiva ${ }^{119}$.

Embora a atividade de estudo e aplicação não configurasse cobrança alguma aos alunos, é muito clara a sua importância para o professor, pois a mesma questão aparece no trabalho e nas provas. Nessa solicitação foi proposto aos alunos a análise da apresentação da origem da física quântica (que deu-se com a resolução do $\mathrm{PRCN}$ ) nos livros universitários de introdução à Física Moderna em contraposição à apresentação desse tema na disciplina Evolução. Também foi proposto um "exercício epistemológico", no qual o aluno deveria discorrer sobre o desenvolvimento histórico do PRCN baseado em uma das propostas epistemológicas trabalhadas na primeira parte da disciplina.

Confrontando o conteúdo das notas de aula com as avaliações, verificamos que estas últimas cobrem todo o assunto explanado nas notas, forçando de certa maneira o aluno a realizar uma leitura (pelo menos superficial) de toda a apostila para responder às questões. Apenas não foi dado destaque maior para a recepção à idéia quântica e às controvérsias até o estabelecimento da mecânica quântica. Também não foi exigida a leitura dos trechos de textos originais.

${ }^{119}$ Inicialmente essa era facultada apenas aos alunos que não puderam comparecer em algumas das provas. a greve e o encurtamento do cronograma, essa prova foi aberta a todos os interessados. Todas as provas eram iguais para as turmas dos períodos diurno e noturno. 
Através da análise das questões presentes nas atividades em anexo ao final deste capítulo, procuramos apontar alguns dos principais objetivos da disciplina e verificar em que medida estes foram atingidos:

\section{a) Destacar que o conhecimento físico e o entendimento da natureza e do funcionamento da ciência não podem ser desassociados da história e filosofia da ciência. Consequentemente o ensino de física deve ser pautado nessa perspectiva.}

Verificamos que todas as questões propostas nas atividades envolvem o desenvolvimento histório-filosófico do PRCN permeado ao conhecimento físico do assunto. Essa característica se baseia na crença de que estas noções não podem ser desvinculadas da compreensão e do ensino da física. Por exemplo, na atividade de estudo e aplicação, ao se pedir ao aluno que verificasse as diferenças de apresentação entre a disciplina de evolução e os textos acadêmicos, a intenção é que, além de explorarem os problemas histórico-filosóficos, os estudantes também se preocupassem com as derivações fisicas do assunto.

Em todas as questões há também liberdade de resposta bastante ampla, possibilitando ao aluno trabalhar mais os aspectos que lhe são triviais e agradáveis, sejam epistemológicos, físicos ou históricos. Essa é uma característica que consideramos muito importante na disciplina. Mesmo no exercício proposto de descrição do desenvolvimento da história do PRCN com base em uma das propostas epistemológicas discutidas na disciplina, o aluno tem a possibilidade de discutir também a física envolvida.

Contudo notamos que os alunos, não se aproveitaram dessa liberdade. Nas avaliações, o enfoque destes foi quase que exclusivamente histórico e a fisica foi deixada de lado e em muitos casos até mesmo desprezada, como procuraremos evidenciar. Faltaram cobranças mais diretas?

A impressão que nos fica sobre a postura dos alunos é a seguinte: na disciplina de física moderna, se o professor quer contas matemáticas, "vamos fazê-las a qualquer custo". Já na disciplina de Evolução dos Conceitos da Física, se o professor fala em história e a avaliação não exige outros esforços, então "vamos nos preocupar apenas com a história!" No entanto sabemos que os alunos estão realmente repletos de cobranças e não lhes sobra tempo para realizar o que não lhes é cobrado. Fica o dilema: devemos cobrar ou não?

Para exemplificar essa nossa discussão, apresentamos a resposta de dois alunos ao primeiro item da questão inicial do trabalho: 
1. i. Destaque e comente pelo menos três resultados que podem ser
extraídos da análise da forma das curvas de emissão do corpo negro e
que levaram vários físicos do final do século XIX a estudarem esse
fenômeno com afinco.

Essa questão sintetiza boa parte do conhecimento físico ligado às curvas de emissão da radiação de corpo negro. Para uma compreensão do fenômeno, o aluno deveria saber extrair os principais resultados físicos das curvas de emissão do corpo negro, que seriam, por exemplo, o fato de que o fenômeno parecia simples e conseqüentemente de aparente fácil resolução pela física clássica; ou mesmo que na análise dessas curvas notava-se que a emissão de um corpo negro não depende do material desse corpo, apenas da temperatura do mesmo. Também pode ser extraída a lei de Stefan-Boltzmann (o fato de que a área da curva é a radiância) e a lei do deslocamento de Wien.

Pouquíssimos alunos responderam dessa maneira à questão, este é um deles:

A sua forma [das curvas de emissão do corpo negro] é uma função apenas da temperatura, e que portanto, não depende das propriedades particulares das substâncias radiantes, o que provoca um forte interesse, pois era uma evidência de um aspecto universal da física, além de fornecer um ferramenta para "medição" de temperatura de um dado material contido numa cavidade, o que foi à época, de grande interesse tecnológico (conforme citação de Osada, pág. 104 ref. [1]).

A área sob a curva, nos dá a potência total irradiada, isto é a Radiância, à uma certa temperatura. Stefan e Boltzmann obtiveram empiricamente e teoricamente (respectivamente), é proporcional à quarta potência da temperatura correspondente. Esta concordância experimental e teórica animaram muitos físicos a procurarem explicar não apenas a radiância total mas também a forma destas curvas de emissão.

Para cada temperatura, existe uma freqüência que maximiza a potência irradiada, isto é, para cada temperatura o ponto de máximo desta curva ocorre numa freqüência diferente que a caracteriza. A relação entre a temperatura e esta particular freqüência (ou comprimento de onda), foi deduzida por Wien, sendo conhecida na literatura como a lei de deslocamento de Wien.

"Tudo isso, fortalecia ainda mais os trabalhos baseados na física clássica na tentativa de solucionar a radiação do corpo negro" (J. Zanetic, pág. 110 ref. [1]).

Talvez porque esse tipo de análise não estava localizada pontualmente nas notas de aula, a maioria dos alunos não apresentou esse tipo de análise. Eles apenas preocuparam-se com a cronologia histórica e citaram, muitas vezes sem comentar, os trabalhos de Stefan, Boltzmann e Wien, que, de certa forma, são resultados derivados da tentativa de compreensão dessas curvas. Alguns até citaram o fato de Michelson tentar uma solução 
para a função de distribuição baseado na semelhança entre as curvas de emissão do corpo negro e as curvas de distribuição de velocidade em um gás. Porém também não podemos negar que a pergunta dá margem a essas respostas.

Apresentamos outro exemplo:

C. Christiansen, em 1884, revelou um dos primeiros resultados que puderam ser extraídos da forma da curva de emissão do corpo negro. isotérmicas irradiariam pequenos buracos produzidos pelas cavidades analisou os dados de como um corpo negro. Em 1879, Josef Stefan de radiação de um fio de Tyndal - Tyndal mostrava que a emissão total de 11.7 vezes maior que platina aquecido a 1200 graus celsius era cerca Assim, Stefan comprovou emissão do mesmo fio a 525 graus celsius. elevada a quarta potência era aproximado entre as temperaturas Kelvin damente igual a 11,7. Percebeu

rcional a essa potência.

Boltzmann $v$, variação de energia luminosa entre as frequencias relação $d v$, verificando posteriormente a sua proporcionalidade em relação à radiância espectral. Esta lei ficou conhecida como deslocamento de Wien, que permite verificar que a freqüência máxima emitida por um corpo é proporcional a temperatura T. (trabalho n. 5)

Essa última resposta também evidencia um outro problema detectado na correção dos trabalhos: os alunos não se preocuparam, em grande parte, com o rigor fisico de suas afirmações.

Por exemplo, analisando a resposta acima, verificamos um excesso de confusões. Os desenvolvimentos de Christiansen são teóricos e não foram extraídos da forma das curvas de emissão de corpo negro, simplesmente por que essas não existiam ainda. Stefan também não comprovou nada, pois seus desenvolvimentos foram empíricos. Esse aluno ainda chama a radiância de radiação, e diz que a "freqüência máxima emitida por um corpo é proporcional a temperatura T", sem explicitar o que é freqüência máxima e estendendo a lei para todos os corpos. Além de uma confusão total ao comentar como Wien calculou sua lei do deslocamento.

Com relação ao problema com algumas definições presentes no texto das notas de aula discutido na seção precedente, notamos reproduções desses equívocos pelos alunos. Muitos não diferenciavam radiância espectral da radiância (Total) e até a chamavam-na de radiação (como na resposta do aluno acima). 
b) Propor um exercício de análise e reflexão sobre os manuais didáticos e a física apresentada nos cursos universitários.

Levar o estudante universitário a reflexões significativas sobre os livros textos que utilizam, mostra-se imprescindível aos futuros professores e pesquisadores em (ensino de) Física. E esse objetivo está bastante explícito no estudo orientado e evidencia o quão importante é esse tema para o elaborador da disciplina, principalmente com relação aos problemas das distorções históricas e à ausência da termodinâmica do trabalho de Planck que encontramos nos manuais didáticos.

\section{c) Preocupacão em estimular a leitura do original de Planck.}

Provavelmente pelo fato de que as perguntas formuladas permitiram respostas sem um estudo mais detalhado do original de Planck os alunos, a nosso ver, não se preocuparam em entender a fisica do trabalho de Planck. Assim, parece-nos que o texto original afigurou-se aos alunos mais como uma ilustração.

A questão 2 (item i) do trabalho proposto aos alunos pedia basicamente para o aluno discutir duas concepções fisicas do trabalho de Planck que ele acrescentou no segundo artigo. Verificamos que as respostas foram bastante incompletas. Nitidamente, ao invés de efetuarem a leitura do texto original e analisá-lo, os alunos procuraram por comentários na apostila que thes proporcionassem respostas adequadas.

Embora fosse possivel achar esses comentários nas notas de aula, os alunos se mostraram "perdidos" para responder essa questão. A maioria percebeu o fato de que a idéia de quantização de energia estava presente no segundo artigo, mas muitos não comentaram sobre o fato de que Planck também adotou a concepção probabilística de Boltzmann para a entropia.

Assim, muitos utilizaram como resposta a (semi)cópia da seguinte frase da apostila, que não contém nenhuma contribuição fisica em destaque:

Se o artigo anterior consistia basicamente de algumas hipóteses fortemente ancoradas nos dados experimentais e na incompatibilidade das expressões com a curva de emissão até então existente, o novo artigo de Planck tinha um cunho mais teórico, como o próprio título de seu artigo sugeria... (p.130)

A nossa hipótese de que os alunos não leram o texto original é também reforçada pelo fato de que nenhum aluno em momento algum das avaliações citou qualquer trecho do mesmo. 


\section{V - DISCUSSÕES FINAIS: APONTANDO ALGUNS DOS
PROBLEMAS DO ENSINO DO PRCN E AMPLIANDO SEU
POTENCIAL PEDAGOT GICO POTENCIAL PEDAGÓGICO}

O PRCN e sua solução por Planck são tratados nos cursos universitários de Física apenas nas disciplinas introdutórias de Física Quântica. Ao analisarmos alguns dos manuais didáticos que tratam do assunto, percebemos a importância de um trabalho de pesquisa que refletisse e sugerisse mudanças no ensino deste conteúdo.

Procurando estudar a questão, inicialmente nos aprofundamos no conhecimento fisico, histórico e filosófico do assunto, embora tenhamos nos limitado à literatura básica sobre o tema. Como resultado deste estudo apresentamos um breve histórico delineado no capítulo I, que inclusive presta-se ao aprendizado da questão para estudantes de fisica com conhecimentos básicos em física clássica e moderna. Mesmo de maneira ainda não elaborada, esse texto pode servir de referencial para se ensinar física numa abordagem histórico-filosófica.

$\mathrm{Na}$ seqüência deste trabalho, pautados na nossa maneira de enxergar o funcionamento da ciência (epistemologia de Thomas Kuhn), analisamos a educação científica e sua dependência quase que exclusiva dos manuais didáticos que, na busca por síntese conceitual e abrangência de conteúdos, propagam uma noção distorcida dos processos científicos.

Dessa maneira, para uma avaliação do ensino do PRCN, analisamos dois textos acadêmicos sobre o tema. Como resultados principais, percebemos que os manuais didáticos analisados, principalmente devido às abordagens superficiais e sintéticas em relatos pretensamente históricos, não estão atingindo seus objetivos principais: conceituar e apresentar a quantização de energia.

Em primeiro lugar, a solução de Planck para o PRCN não se mostrou adequada para a discussão simplificada da discretização de energia, pois seu significado no PRCN era completamente diverso daquele que entendemos hoje. Os manuais didáticos não observam esse aspecto e atribuem como principal contribuição de Planck uma quantização com significação moderna. Também é importante observar que, conforme procuramos delinear no capítulo I, a principal contribuição de Planck não foi a quantização de energia, mas sim a constante $h$.

Em segundo lugar, a maneira como é realizada a introdução da noção de quantização nos manuais didáticos distorce a própria fisica, o fazer científico e a história da ciência. 
Com relação às distorções da física, encontramo-las inicialmente na simplificação da noção de corpo negro e sua equivalência com uma cavidade. Também as observamos no fato de que a quantização é introduzida tomando como referência o próprio escopo da física quântica, visto que os manuais analisados tomam como situações fisicamente equivalentes (sem explicações adequadas) a energia dos osciladores nas paredes da cavidade e a energia da radiação no seu interior. Entretanto, essa equivalência só é possível de ser derivada a partir da compreensão da física quântica, que paradoxalmente está sendo pretensamente introduzida.

Sobre as distorções do fazer científico, estas são notadas, principalmente, com relação à falta de descrição ou mesmo discussão sobre a atividade experimental. Também o trabalho de Planck ora é banalizado, pois não é mostrada a complexidade e o seu árduo trabalho, ora é supervalorizado, como se Planck tivesse feito tudo sozinho.

Já as distorções da história estão presentes nos relatos de maneira bastante acentuada. Os textos analisados, ao buscarem descrições simplistas e livres de conflitos, enfatizam a eqüipartição da energia, que não era completamente compreendida em 1900 e não foi utilizada por Planck (que pautou seu trabalho no conceito de entropia). Também a cronologia dos fatos muitas vezes foi alterada, ou mesmo omitida, nestes relatos.

Concluímos assim, pelos problemas expostos com relação a esses manuais didáticos, que o PRCN simplificado da forma que aparece não é útil. Acreditamos que seria mais proveitoso, nesse tipo de abordagem sintética, apresentar apenas uma discussão sobre a quantização de energia (com possivel histórico da evolução do conceito), ou então, resolver o PRCN usando a quantização sob a ótica da física moderna, por exemplo, com estatística de fótons. Julgamos que, se forem feitas escolhas justificadas por abordagens superficiais, estas deveriam apenas se preocupar em ensinar os conceitos da física, sem mesmo mencionar a história da ciência, pois, sem contextualização adequada e preocupação com o funcionamento da ciência, estes relatos têm apresentado muitos erros, além de permitirem ao leitor generalizações indesejáveis.

Também apresentamos neste trabalho uma análise de uma abordagem históricofilosófica do PRCN e sua solução por Planck que vai ao encontro dos nossos anseios pedagógicos. Essa abordagem é parte da disciplina "Evolução dos Conceitos da Física" do Instituto de Física da USP - São Paulo, quando ministrada pelo orientador desse trabalho. Nesta disciplina, além dos trabalhos propostos aos alunos e discussões em classe, as aulas são pautadas em notas de aula, que abordam o PRCN de uma maneira bastante ampla e com alguma riqueza de detalhes. 
Pela análise das notas de aulas e dos trabalhos e provas propostos, pudemos abstrair os objetivos da disciplina e detectar que nesta os problemas apontados nas abordagens dominantes foram minimizados ou mesmo anulados.

Notamos que as notas de aula pretendem ensinar a fisica através de sua história e de sua filosofia, aspectos que são muito importantes para que se possa apresentar a física de uma maneira realmente rica e plena. O conhecimento físico, separado da sua história e da sua filosofia, fica sujeito a simplificações que escondem as significações profundas dos seus conceitos.

As notas de aula também propõem e procuram estimular o debate e a reflexão sobre a própria educação científica, principalmente quando estimula os alunos a analisarem os manuais didáticos sobre o PRCN. Também o cuidado com a disponibilização de ampla bibliografia e a apresentação de textos originais nas notas de aula mostram a preocupação da disciplina com a cultura científica na formação de profissionais da ciência.

Como conclusão à contraposição da abordagem do PRCN da disciplina "Evolução dos Conceitos da Física" às abordagens dominantes analisadas, propomos uma ampliação da utilização desse conteúdo no ensino da física que vai ao encontro de nossa proposta pedagógica.

Almejamos um ensino da ciência que forme profissionais autônomos, críticos, reflexivos e que também os prepare para vislumbrar eventuais futuras crises e revoluções científicas. Conseqüentemente, a educação científica não deveria se preocupar em pretensamente trabalhar toda a fisica de maneira breve, mas sim atuar com uma melhor seleção, flexibilização, problematização e aprofundamento dos seus conteúdos.

Julgamos também que uma maneira de se atingir esses objetivos seria a inserção da história e filosofia da ciência no ensino da física, tanto para propiciar a compreensão do papel das grandes teorias que se sucederam quanto para a aprendizagem significativa dos conteúdos físicos específicos. Nesse caso a educação científica deveria buscar por estratégias e leituras que valorizem a cultura científica, como textos originais e não apenas se basear nos manuais didáticos, diminuindo assim seus efeitos limitadores e/ou nocivos.

Um exemplo de tema bastante profundo, importante e cuja fundamentação é essencial para a formação de profissionais em ciência seria a gravitação universal. Além de ser extremamente rico no que tange aos aspectos históricos e filosóficos, esse assunto possibilita o tratamento de praticamente toda a mecânica, além da relatividade. A disciplina "Gravitação" do IF-USP também ministrada pelo orientador desta dissertação é 
uma tentativa de discussão mais profunda sobre o tema, embora o fato de ser ministrada para alunos iniciantes restrinja a natureza da abordagem matemática e mesmo conceitual.

Outro exemplo pode ser abstraído deste trabalho de dissertação. $O$ estudo da radiação térmica, do $\mathrm{PRCN}$ e sua solução por Planck nos mostraram a riqueza e a profundidade do tema. Para compreender a física do PRCN é necessário o conhecimento de praticamente todos os ramos da física clássica: termodinâmica, eletromagnetismo e física estatística, além de noções da mecânica.

Dessa maneira, sugerimos que o PRCN seja utilizado com um propósito muito maior do que apenas introduzir a mecânica quântica. Esse assunto poderia ser usado em muitas outras disciplinas para se estudar a física clássica e exemplificar um funcionamento mais real da ciência, no qual os modelos científicos fundem os vários ramos da física. 


\section{VI - BIBLIOGRAFIA}

ALBUQUERQUE, Ivone Freire da Mota e. Entropia e a quantização da energia: cálculo termodinâmico de Planck. 1988. Dissertação (Mestrado em Ensino de Ciências) Instituto de Física e Faculdade de Educação, Universidade de São Paulo, São Paulo.

ASIMOV, Isaac. Asimov explica. Rio de Janeiro: Francisco Alves, 1990. p.83-84.

ARRUDA, Sergio M. Dificuldades no ensino do problema da radiação do corpo negro. In: REUNIÃO ANUAL DA SBPC, 44ª , 1992, São Paulo. Resumos. p. 563.

BASSALO, José Maria Filardo. Sobre a lei de Rayleigh-Jeans. Revista Brasileira de Ensino de Física, vol. 18, n. 1, p. 33-41, 1996.

CARR, Edward Hallet. Que é história? Rio de Janeiro: Paz e Terra, 1996.

CLINE, Barbara Lovett. Los creadores de la fisica. México: Fondo de Cultura Econômica, 1992.

DE BROGLIE, Louis. La grande découvert de Max Planck: la mystérieuse constant $h$. In: KOCKEL, B. et al. (org.). Max-Planck-Festschrift. Berlin: Veb Deutscher Verlag Der Wissenschaften, 1958. p 197-201.

DE BROGLIE, Maurice. Les Premiers Congress de Physique Solvay et L'orientation de la physique depuis 1911. Paris: Albin Michel, 1951.

DION, Sonia Maria. O diálogo com documentos originais da ciência em sala de aula: uma proposta. 1997. Tese (Doutorado em Educação) - Faculdade de Educação, Universidade de São Paulo, São Paulo.

DOUGAL, R. C. The presentation of the Plank radiation formula. Physics Education, vol. 11, n. 6, p.438-443, 1976.

EISBERG, Robert; RESNICK, Robert. Física Quântica. Rio de Janeiro: Campus, 1994.

FLEMING, Henrique. Max Planck e a idéia do quantum. In: HUSSEIN, Mahir S.; SALINAS, Silvio R. A. (org.). 100 anos de física quântica. São Paulo: Editora Livraria da Física, 2001, p. 1-12.

GAMOW, George. Treinta años que conmovieron la física. Buenos Aires: Editora Universitária de Buenos Aires, 1974.

GARBER, Elizabeth. Some reactions to Planck's law, 1900-1914. Studies in History and Philosophy of Science, vol. 7, n.2, p. 89-126, 1976.

GILBERT, Armando. Origens históricas da física moderna. Lisboa: Fundação C. Gulbenkian, 1982.

GUIMARÃES, P. S. Radiação de corpo negro. Revista Brasileira de Ensino de Física, vol. 21 , n. 2, p. 291-297, 1999. 

JAMMER, Max. The conceptual development of Quantum Mechanics. New York:
McGraw-Hill, 1966.

JEANS, James. Historia de la física. México: Fondo de Cultura Económica, 1953.

KRAGH, Helge. Max Planck: the reluctant revolutionary. Physics World, v.13, n.12, p.31-35, 2000.

KLEIN, M. J. Thermodinamics and quanta in Planck's work. Physics Today, vol. 19, n. 11, p. 23, 1966.

KANGRO, Hans (ed.). Planck's original papers in quantum physics. London: Taylor \& Francis, 1972.

KUHN, Thomas S. A estrutura das revoluções científicas. São Paulo: Perspectiva, 2000. . Qué son las revoluciones científicas? Barcelona: Paidós Ibérica, 1989.

. Black-body theory and the quantum discontinuity: 1894-1912. New York: Oxford University Press, 1978.

. A função do dogma na investigação científica. In: Deus, D. de. A crítica da ciência. Rio de Janeiro: Zahar Editores, 1977. p. 51-80.

LAKATOS, Imre. Historia de la ciencia y sus reconstrucciones racionales. Madrid: Tecnos, 1987.

LARANJEIRAS, Cássio Costa. O programa de pesquisa de Ludwig Boltzmann para a mecânica estatística. 2002. Tese de Doutorado - FFLCH, Universidade de São Paulo, São Paulo.

. Redimensionando o ensino de física numa perspectiva histórica. 1994.

Dissertação (Mestrado em Ensino de Ciências) - Instituto de Física e Faculdade de Educação, Universidade de São Paulo, São Paulo.

LEITE LOPES, José; ESCOUBÈS, Bruno. Sources et évolution de la physique quantique: textes fondateurs. Paris: Masson, 1994.

LEITE LOPES, José. Introdução à teoria atômica da matéria. Rio de janeiro: LT, 1959.

MARTINS, Roberto de Andrade. A natureza da quantização: o trabalho de Planck e suas interpretações até 1912. In: SIMPÓSIO COMEMORATIVO DO CENTENÁRIO DA CONSTANTE DE PLANCK, 2000, Unicamp - Campinas. Transparências apresentadas.

MCCAUGHAN, J. B. T. Jeans's role in the law of black-body radiation. Physics Education, vol. 15, n. 4, p. 255-260, 1980.

MEHRA, Jagdish; RECHENBERG, Helmut. The historical developmente of quantum theory. New York: Springer-Verlag, 1982. 
OSADA, Jun'ichi. Evolução das idéias da física. São Paulo: Edgard Blücher, 1972. PENROSE, Roger. Einstein's miraculous Year. Princeton: Princeton University Press, 1998.

PESSOA JR., Osvaldo. Quando a abordagem histórica deve ser usada no ensino de ciências? Ciência \& Ensino, n.1, p. 4-6, 1996

PLANCK, Max. The theory of heat radiation. New York: Dover Publications, 1959.

A scientific autobiography. In: Scientific autobiography and other Papers. London: Willians and Norgate, 1950. p. 13-51.

RICHTMYER, F. K. et al. Introduction to modern physics. New York: McGraw-Hill. 1955.

SEGRÈ, Emílio. Dos raios $\mathbf{X}$ aos quarks: físicos modernos e suas descobertas. Brasilia: Editora Universidade de Brasilia, 1987.

TIPLER, Paul A. Física moderna. Rio de Janeiro: Guanabara Dois, 1981.

TRIGG, G. L. The origin of the quantum concept. Crucial experiments in modern physics. New York: Van Nostrand Reinhold, 1971. p. 4-22.

ZANETIC, João. 2000: um século do nascimento da fisica quântica e seu ensino. In: VI

ENCONTRO DE PESQUISADORES EM ENSINO DE FÍSICA (EPEF), 2000,

Florianópolis.

. Alguns tópicos de "filosofia" da ciência: $1^{\text {a }}$ parte. 1999a. Notas de aula do curso de Evolução dos Conceitos da Física - IFUSP.

. Alguns tópicos de história da física: $2^{\mathrm{a}}$ parte. $1999 \mathrm{~b}$. Notas de aula do curso de

Evolução dos Conceitos da Física - IFUSP.

Física também é cultura. 1989. Tese (Doutorado em Educação) -Faculdade de

Educação, Universidade de São Paulo, São Paulo.

WHITAKER, M. A. B. History and quase-history in physics education - part 1. Physics

Education, vol. 14, p. 108-112, 1979a.

. History and quase-history in physics education - part 2. Physics Education, vol.

14, p. 239-242, 1979 b.

WHITTAKER, Edmund Taylor. A history of the theories of aether and electricty.

London: Thomas Nelson and Sons, 1953.

WRÓBleWSKI, A. K. Physics in 1900. Acta Physica Polonica B, vol. 31, n.2, p.179196, 2000. 


\section{Apêndice I - Derivação da lei de Kirchhoff}

Neste apêndice mostramos como Kirchhoff, através do exemplo de troca de radiação entre duas placas discutido na seção 1.1 do Capítulo $\mathrm{I}$, chegou a sua lei. Utilizamos o desenho abaixo para ilustrar o exemplo.
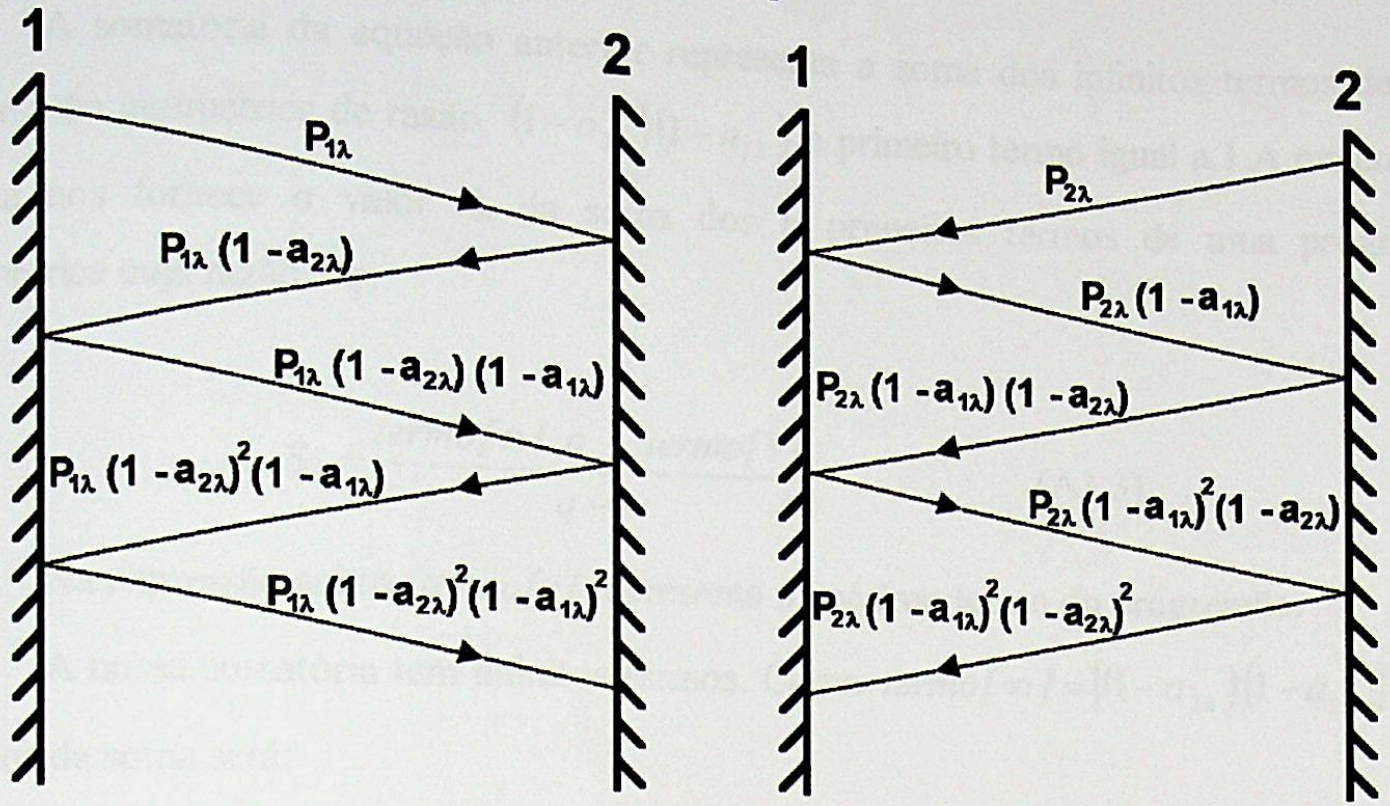

$\mathrm{Na}$ figura da esquerda mostramos uma onda que é emitida pela placa 1 com poder emissivo $P_{1 \lambda}$. Após ela interagir com a placa 2, uma fração $a_{2 \lambda}$ será absorvida, de modo que a onda refletida terá poder emissivo $P_{1 \lambda}\left(1-a_{2 \lambda}\right)$. Assim, a placa 1 absorverá um total de $P_{1 \lambda}\left(1-a_{2 \lambda}\right) a_{1 \lambda}$, enquanto $P_{1 \lambda}\left(1-a_{2 \lambda}\right)\left(1-a_{1 \lambda}\right)$ será refletido, reiniciando o processo. $\mathrm{O}$ total de energia absorvida por unidade de tempo pela placa 1 após infinitas reflexões é:

$$
\sum_{n=1}^{\infty} P_{1 \lambda} a_{1 \lambda}\left(1-a_{2 \lambda}\right)^{n}\left(1-a_{1 \lambda}\right)^{n-1}
$$

A figura do lado direito mostra uma seqüência semelhante de raios, mas com a onda inicial sendo emitida pela placa 2. Usando o mesmo raciocínio anterior, a potência total absorvida pela placa 1 é:

$$
\sum_{n=1}^{\infty} P_{2 \lambda} a_{1 \lambda}\left(1-a_{1 \lambda}\right)^{n-1}\left(1-a_{2 \lambda}\right)^{n-1}
$$

No equilibrio, a potência emitida deve ser igual à potência absorvida pela placa. Assim:

$$
P_{1 \lambda}=\sum_{n=1}^{\infty} P_{1 \lambda} a_{1 \lambda}\left(1-a_{2 \lambda}\right)^{n}\left(1-a_{1 \lambda}\right)^{n-1}+\sum_{n=1}^{\infty} P_{2 \lambda} a_{1 \lambda}\left(1-a_{1 \lambda}\right)^{n-1}\left(1-a_{2 \lambda}\right)^{n-1}
$$

Reescrevendo o lado direito da equação: 
123

$$
\begin{gathered}
P_{1 \lambda}=\left(1-a_{2 \lambda}\right) \sum_{n=1}^{\infty} P_{1 \lambda} a_{1 \lambda}\left(1-a_{2 \lambda}\right)^{n-1}\left(1-a_{1 \lambda}\right)^{n-1}+\sum_{n=1}^{\infty} P_{2 \lambda} a_{1 \lambda}\left(1-a_{1 \lambda}\right)^{n-1}\left(1-a_{2 \lambda}\right)^{n-1} \\
P_{1 \lambda}=\left[P_{1 \lambda} a_{1 \lambda}\left(1-a_{2 \lambda}\right)+P_{2 \lambda} a_{1 \lambda}\right] \sum_{n=1}^{\infty}\left(1-a_{2 \lambda}\right)^{n-1}\left(1-a_{1 \lambda}\right)^{n-1}
\end{gathered}
$$

A somatória da equação anterior representa a soma dos infinitos termos de uma progressão geométrica de razão $\left(1-a_{2 \lambda}\right)\left(1-a_{1 \lambda}\right)$ e primeiro termo igual a 1.A matemática básica nos fornece o valor $S_{n}$ da soma dos $n$ primeiros termos de uma progressão geométrica cuja razão é $q$ :

$$
S_{n}=\frac{\operatorname{termo}[n] q-\operatorname{termo}[1]}{q-1}
$$

Na expressão acima, termo $[n]$ representa o enésimo termo da progressão.

A nossa somatória tem infinitos termos. Como termo $[\infty]=\left[\left(1-a_{2 \lambda}\right)\left(1-a_{1 \lambda}\right)\right]^{\infty}=0$, o valor da soma será:

$$
S_{\infty}=\frac{-1}{\left(1-a_{2 \lambda}\right)\left(1-a_{1 \lambda}\right)-1}=\frac{-1}{a_{1 \lambda} a_{2 \lambda}-a_{1 \lambda}-a_{2 \lambda}}=\frac{1}{a_{1 \lambda}\left(1-a_{2 \lambda}\right)+a_{2 \lambda}}
$$

Voltando a equação (A1.2):

$$
P_{1 \lambda}=\frac{\left[P_{1 \lambda} a_{1 \lambda}\left(1-a_{2 \lambda}\right)+P_{2 \lambda} a_{1 \lambda}\right]}{a_{1 \lambda}\left(1-a_{2 \lambda}\right)+a_{2 \lambda}}
$$

Tal que

$$
\begin{gathered}
P_{1 \lambda} a_{1 \lambda}\left(1-a_{2 \lambda}\right)+P_{1 \lambda} a_{2 \lambda}=P_{1 \lambda} a_{1 \lambda}\left(1-a_{2 \lambda}\right)+P_{2 \lambda} a_{1 \lambda} \\
P_{1 \lambda} a_{2 \lambda}=P_{2 \lambda} a_{1 \lambda}
\end{gathered}
$$

Chegando assim à lei de Kirchhoff:

$$
\frac{P_{1 \lambda}}{a_{1 \lambda}}=\frac{P_{2 \lambda}}{a_{2 \lambda}}
$$




\section{Apêndice II - 0 desenvolvimento de Boltzmann} relação:

Pelo eletromagnetismo a luz exerce pressão $p$ sobre uma superficie opaca segundo a

$$
p=\frac{\mu}{3}
$$

sendo $\mu$ a densidade de energia da radiação.

Tomando como corpo negro uma cavidade opaca, a radiação no seu interior exerce pressão nas suas paredes. Escrevendo a Primeira Lei da Termodinâmica em sua forma diferencial:

$$
d Q=d U+p d V \quad \Rightarrow \quad T d S=d U+p d V
$$

com $U$ representando a energia total do sistema $(U=V \mu), V$ o seu volume, $T$ sua temperatura, $S$ sua entropia e $Q$ o calor resultante.

Podemos escrever a diferencial exata $d U$ como:

$$
d U=\left(\frac{\partial U}{\partial T}\right)_{V} d T+\left(\frac{\partial U}{\partial V}\right)_{T} d V
$$

com o subscrito indicando que tal grandeza é mantida constante na derivada.

Assim,

$$
d S=\frac{1}{T}\left(\left(\frac{\partial U}{\partial T}\right)_{V} d T+\left(\frac{\partial U}{\partial V}\right)_{T} d V\right)+\frac{p}{T} d V=\frac{1}{T}\left(V \frac{d \mu}{d T} d T+\mu d V\right)+\frac{p}{T} d V
$$

$\mathrm{Na}$ última equação utilizamos uma derivada total (e não parcial) de $\mu$ em relação a $T$, pois a densidade de energia não depende do volume $V$. Pela equação (A2.1) temos:

$$
d S=\frac{V}{T} \frac{d \mu}{d T} d T+\frac{4}{3} \frac{\mu}{T} d V
$$

Como

$$
d S=\left(\frac{\partial S}{\partial T}\right)_{V} d T+\left(\frac{\partial S}{\partial V}\right)_{T} d V
$$

Então, por comparação:

$$
\left(\frac{\partial S}{\partial T}\right)_{V}=\frac{V}{T} \frac{d \mu}{d T} \quad \text { e } \quad\left(\frac{\partial S}{\partial V}\right)_{T}=\frac{4}{3} \frac{\mu}{T}
$$


Como a quantidade $S$ é função do macroestado do sistema (de modo que $d S$ é uma diferenciação $^{120}$. Isto é:

Desse modo:

$$
\left(\frac{\partial}{\partial V}\right)_{T}\left(\frac{\partial S}{\partial T}\right)_{V}=\left(\frac{\partial}{\partial T}\right)_{V}\left(\frac{\partial S}{\partial V}\right)_{T} \Leftrightarrow \frac{\partial^{2} S}{\partial V \partial T}=\frac{\partial^{2} S}{\partial T \partial V}
$$

$$
\begin{gathered}
\frac{\partial^{2} S}{\partial V \partial T}=\frac{1}{T} \frac{d \mu}{d T} \quad \text { e } \quad \frac{\partial^{2} S}{\partial T \partial V}=-\frac{4}{3} \frac{\mu}{T^{2}}+\frac{4}{3} \frac{1}{T} \frac{d \mu}{d T} \\
\Rightarrow \frac{1}{T} \frac{d \mu}{d T}=-\frac{4}{3} \frac{\mu}{T^{2}}+\frac{4}{3} \frac{1}{T} \frac{d \mu}{d T} \\
\Rightarrow \frac{d \mu}{d T}=4 \frac{\mu}{T} \quad \text { (A2.7) }
\end{gathered}
$$

Integrando essa equação diferencial

$$
\begin{gathered}
\int \frac{d \mu}{\mu}=\int 4 \frac{d T}{T} \\
\ln \mu=4 \ln T+c t e \\
\ln \mu=\ln T^{4}+c t e \\
e^{\ln \mu}=e^{\ln T^{4}+c l e} \\
\mu=T^{4} \cdot e^{c t e}
\end{gathered}
$$

E sendo $\kappa$ uma constante de proporcionalidade:

$$
\mu=\kappa T^{4}
$$

É interessante ainda encontrar como que a densidade de energia $\mu$ se relaciona com a energia emitida pela superfície da cavidade. Para isso, utilizamos o procedimento de Ritchmyer (1955, p.108-110).

Se tivermos várias ondas de radiação (com densidade de energia $\mu$ ) dirigindo-se todas na mesma direção, o fluxo $\phi$ (energia por unidade de tempo por unidade de área) que atravessa uma superfície perpendicular a essa direção é:

$$
\phi=c \mu
$$

sendo $c$ a velocidade das ondas (no caso, a velocidade da luz).

${ }^{120}$ REIF, Federick Fundamentals of statistical and thermal physics. Singapore: McGraw-Hill, 1985. p.154. 
Já se o feixe atinge a superficie formando um ângulo $\theta$ com sua normal, o fluxo será menor, já que as ondas atingirão uma área maior da superficie. Neste caso, o fluxo será:

$$
\phi=c \mu \cos \theta
$$

Tomamos agora uma cavidade de corpo negro (ou seja, a radiação no seu interior é homogênea). Consideraremos as ondas que atingem o ponto $O$ da superficie da cavidade indicada na Figura AII1. Construindo uma superfície hemisférica (de raio unitário) ao redor deste ponto, as ondas podem atingir $O$ vindo de várias direções, ou seja, vindo de vários pontos do hemisfério.

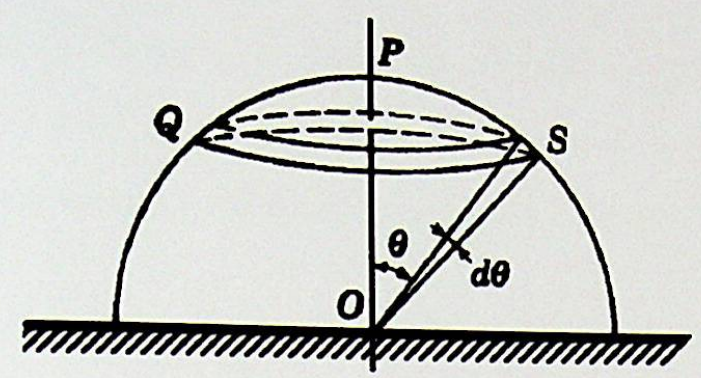

Fig.AII1: Construção geométrica para cálculo do fluxo de radiação incidente na superfície. ${ }^{121}$

Pelo raciocínio anterior, quanto menor o ângulo $\theta$ da figura, maior será o fluxo de energia que atravessa $O$ na superficie. Por outro lado, menor será a área do anel ao redor do hemisfério cuja radiação incide em $O$ com ângulo entre $\theta$ e $\theta+d \theta$. Pela figura vemos que essa área ${ }^{122}$ é igual a $2 \pi \operatorname{sen} \theta d \theta$. Ou seja, o fluxo que atinge $O$ através da superficie, vindo de um anel definido pelo ângulos $\theta$ e $\theta+d \theta$, é proporcional a $\cos \theta \operatorname{sen} \theta$.

Como a radiação é homogênea dentro da câmara, enquanto há um feixe se dirigindo ao ponto $O$ existe outro na direção oposta. Assim, apenas metade das ondas que atravessam a superfície hemisférica atingem ao ponto $O$. Isto equivale a dizer que a densidade de energia das ondas que se propagam em direção ao ponto $O$ é na verdade $\frac{\mu}{2}$. Portanto, para encontrar o fluxo total vindo do hemisfério que atinge $O$, devemos calcular a seguinte integral:

$$
\phi=\int_{0}^{\pi / 2} c \frac{\mu}{2} \cos \theta \operatorname{sen} \theta d \theta
$$

${ }^{121}$ Fonte: Richtmyer (1955), p. 109. 
De onde encontramos:

$$
\phi=\frac{c}{4} \mu
$$

Como as paredes do corpo estão em equilíbrio, o fluxo de radiação que atinge as paredes deve ser igual à radiância $R$ da superfície. Assim, pelas equações (A2.8) e (A2.10):

$$
R=\sigma T^{4}
$$


Apêndice III - Estudo de corpo negro

\section{um oscilador harmônico nas paredes de um}

Neste apêndice pretendemos encontrar a relação entre a energia média dos osciladores e a densidade de energia no interior da cavidade de um corpo negro. Vamos iniciar o estudo do problema com um modelo simplificado, o oscilador harmônico simples, que depois será aprimorado nas seções seguintes.

\section{Oscilador Harmônico simples}

Seja um oscilador de carga $q$ e massa $m$ oscilando numa direção qualquer com constante de mola $k$. Tomando esta direção como o eixo $x$, com a origem no ponto de energia potencial nula, escrevemos o momento de dipolo $f$ como:

$$
f=q x
$$

A energia $U$ do oscilador numa dada posição é dada por:

$$
U=\frac{1}{2} m \dot{x}^{2}+\frac{1}{2} k x^{2}
$$

sendo o primeiro termo da direita a energia cinética e o segundo a energia potencial do oscilador. O ponto acima da variável indica derivada em relação ao tempo.

Escrevendo $K=k / q^{2}$ e $L=m / q^{2}$ :

$$
U=\frac{1}{2} L \dot{f}^{2}+\frac{1}{2} K f^{2}
$$

A equação de força pode ser obtida diferenciando a equação acima:

$$
\frac{d}{d t} U=\frac{d}{d t}\left(\frac{1}{2} L \dot{f}^{2}+\frac{1}{2} K f^{2}\right) \Rightarrow L \ddot{f}+K f=0
$$

Esta equação tem como solução uma função oscilatória. Escolhendo $f=A \cos \omega t$ : 


$$
-\omega^{2} L A \cos \omega t+K A \cos \omega t=0
$$

Assim encontramos a freqüência natural de oscilação:

$$
\omega=\sqrt{\frac{K}{L}} \Rightarrow \nu=\frac{1}{2 \pi} \sqrt{\frac{K}{L}}
$$

A constante $A$ representa a amplitude de oscilação do oscilador. Quando $x=A$, a energia cinética é nula, portanto:

$$
U=\frac{1}{2} K A^{2} \Rightarrow A^{2}=\frac{2 U}{K}
$$

em que $U$ é a energia do oscilador.

Contudo, essa solução não é exata, viso que tal oscilador irá perder energia por radiação. Da teoria do eletromagnetismo uma carga oscilando (sendo assim acelerada) emite radiação com potência $P$ dada pela equação ${ }^{123}$ :

$$
P=\frac{2}{3} \frac{\ddot{f}^{2}}{c^{3}}
$$

Se considerarmos que a perda de energia não é muito grande, de modo que o movimento continua sendo descrito pela solução anterior para $f$ :

$$
P=\frac{2}{3 c^{3}} A^{2} \omega^{4} \cos ^{2} \omega t
$$

Assim, a energia perdida em um período de oscilação $T(=1 / v)$ é:

$$
\Delta U=-\int_{0}^{T} P d t=-\int_{0}^{T} \frac{2}{3 c^{3}} A^{2} \omega^{4} \cos ^{2} \omega t d t=-\frac{2}{3 c^{3}} A^{2} \omega^{3} \int_{0}^{\omega T} \cos ^{2} \omega t d(\omega t)
$$




$$
\Delta U=-\frac{2}{3 c^{3}} A^{2} \omega^{3}\left(\frac{\omega T+\cos \omega T \operatorname{sen} \omega T}{2}\right)=-\frac{1}{3 c^{3}} A^{2} \omega^{4} T
$$

visto que $\omega T=2 \pi \Rightarrow \operatorname{sen} \omega T=0$

Substituindo os valores para $A, \omega$ e $T$ :

$$
\Delta U=-\frac{1}{3 c^{3}} \frac{2 U}{K}(2 \pi v)^{4} \frac{1}{v} \Rightarrow \Delta U=-\frac{32 \pi^{4} v^{3} U}{3 c^{3} K}
$$

Dessa forma, para obtermos uma descrição mais precisa do problema, iremos substituir o oscilador harmônico simples, por um amortecido, de maneira que a sua perda de energia seja dada pela expressão anterior.

\section{Oscilador Harmônico Amortecido}

Como estudamos nos livros de Mecânica Geral, por exemplo Symon (1986, p.67), podemos relacionar a perda de energia de um oscilador com um amortecimento, que pode ser considerado adicionando um termo proporcional à derivada primeira na equação de força. Uma forma conveniente de escrevê-la é:

$$
L \ddot{f}+\frac{\sigma}{\pi} \sqrt{K L} \dot{f}+K f=0
$$

Ou ainda em termos da freqüência de oscilação do oscilador não amortecido:

$$
\ddot{f}+\frac{\sigma}{\pi} \sqrt{\frac{K}{L}} \dot{f}+\frac{K}{L} f=0 \Rightarrow \ddot{f}+2 v \sigma \dot{f}+4 \pi^{2} v^{2} f=0
$$

No texto de $\operatorname{Symon}^{124}$, vemos que para um oscilador deste tipo a perda de energia é expressa por:

${ }^{123}$ HEALD, Mark A ; MARION, Jerry B. Classical electromagnetic radiation. New York: Saunders

${ }^{124}$ SYMON, Keith R. Mecânica. Rio de Janeiro: Campus, 1986. p.69. 


$$
\frac{1}{U} \frac{d U}{d t}=-2 v \sigma
$$

Assim, substituímos a perda de energia durante um período de oscilação $(\Delta t=1 / v)$ calculado na equação A3.7 na expressão anterior:

$$
\begin{gathered}
\frac{1}{U} \frac{\Delta U}{\Delta t}=-2 v \sigma \Rightarrow-\frac{1}{U} \frac{32 \pi^{4} v^{3} U}{3 c^{3} K} v=-2 v \sigma \\
\sigma=\frac{16 \pi^{4} v^{3} U}{3 c^{3} K}
\end{gathered}
$$

O valor de $\sigma$ deve ser pequeno para que o oscilador não perca energia considerável durante um período de oscilação, visto que a expressão para $\Delta U$ foi obtida no caso do oscilador harmônico simples, (no qual não há perda de energia).

Contudo, o oscilador que desejamos estudar não é ainda exatamente este. Como existe radiação no interior da cavidade, o sistema será um oscilador forçado, descrito na próxima seção.

\section{Oscilador Harmônico Forçado}

Adicionando na equação A3.8 mais um termo de força, representado pelo campo $Z^{125}$ obteremos:

$$
L \ddot{f}+\frac{\sigma}{\pi} \sqrt{K L} \dot{f}+K f=Z
$$

Ou em termos de $v$.

$$
\ddot{f}+2 v \sigma \dot{f}+4 \pi^{2} v^{2} f=\frac{3 c^{3} \sigma}{4 \pi^{2} v} Z
$$

${ }^{125} \mathrm{O}$ campo $Z$ será uma componente do campo elétrico $\left(E_{x}\right)$. O campo magnético não entra nessa equação rasto que a força magnética é perpendicular ao deslocamento. 
No texto de $A r f k e n^{126}$, vemos que qualquer função pode ser representada por uma série de Fourier, isto é, por uma série de senos e cossenos, com freqüências $v^{\prime}, 2 v^{\prime}, 3 v^{\prime}$,etc. Podemos ainda representar qualquer função por uma série usando apenas cossenos, com a adição de uma fase apropriada $\theta_{n}$ em cada termo. Usamos tal série para descrever $Z$ (com os termos $C_{n}$ constantes):

$$
Z=\sum_{n=1}^{\infty} C_{n} \cos \left(\frac{2 \pi n}{T^{\prime}} t+\theta_{n}\right)
$$

Para escrever $f$, é mais conveniente manter os senos e cossenos da série (com $A_{n}$ e $B_{n}$ constantes para cada termo da somatória):

$$
f=\sum_{n=1}^{\infty} A_{n} \cos \left(\frac{2 \pi n}{T^{\prime}} t+\theta_{n}\right)+B_{n} \operatorname{sen}\left(\frac{2 \pi n}{T^{\prime}} t+\theta_{n}\right)
$$

Em cada uma destas expressões, $n$ varia de 1 a infinito, $\operatorname{com} T^{\prime}=1 / v^{\prime}$.

Para facilitar a notação, denominamos $\phi_{n}$ o argumento das funções sen e cos das expansões anteriores. Além disso, escrevemos $\omega^{`}=2 \pi / T$. Substituindo $f$ e $Z$ na equação de força:

$$
\begin{gathered}
-\omega^{` 2} n^{2}\left(A_{n} \cos \phi_{n}+B_{n} \operatorname{sen} \phi_{n}\right)+2 \sigma v n \omega^{`}\left(-A_{n} \operatorname{sen} \phi_{n}+B_{n} \cos n \phi_{n}\right)+ \\
+4 \pi^{2} v^{2}\left(A_{n} \cos \phi_{n}+B_{n} \operatorname{sen} \phi_{n}\right)=\frac{3 c^{3} \sigma}{4 \pi^{2} v} C_{n} \cos \phi_{n}
\end{gathered}
$$

Para essa equação ter solução para qualquer tempo $t$, ou seja, para qualquer valor de $\phi_{n}$, os termos em sen e cos devem ser iguais dos dois lados da igualdade. Assim

$$
A_{n}\left(-n^{2} \omega^{-2}+4 \pi^{2} v^{2}\right)+B_{n} 2 \sigma v n \omega^{`}=\frac{3 c^{3} \sigma}{4 \pi^{2} v} C_{n}
$$

e

${ }^{126}$ ARFKEN, George B.; WEBER, Hans J. Mathematical methods for physicists. San Diego: Academic Press, 1995. p.808. 
133

$$
B_{n}\left(-n^{2} \omega^{\prime 2}+4 \pi^{2} v^{2}\right)-A_{n} 2 \sigma v n \omega^{`}=0
$$

Escrevendo

$$
\frac{4 \pi^{2} v^{2}-n^{2} \omega^{\prime 2}}{2 \sigma v n \omega^{`}}=\frac{\pi\left(v^{2}-n^{2} / T^{` 2}\right)}{\sigma v n / T^{`}}=\cot \gamma_{n}^{127}
$$

Temos da segunda relação:

$$
\frac{A_{n}}{B_{n}}=\cot \gamma_{n}
$$

Da primeira relação:

$$
A_{n}\left(-n^{2} \omega^{\prime 2}+4 \pi^{2} v^{2}\right)+A_{n} 2 \sigma v n \omega^{`} \operatorname{tg} \gamma_{n}=\frac{3 c^{3} \sigma}{4 \pi^{2} v} C_{n}
$$

$$
\Rightarrow A_{n}\left(\cot \gamma_{n}+\operatorname{tg} \gamma_{n}\right)=\frac{3 c^{3} \sigma}{4 \pi^{2} v} \frac{C_{n}}{2 \sigma v n \omega^{\prime}} \Rightarrow A_{n}=\frac{3 c^{3} C_{n} \cos \gamma_{n} \operatorname{sen} \gamma_{n}}{8 \pi^{2} v^{2} n \omega^{`}} \text { (A3.15) }
$$

no qual utilizamos: $\cot \gamma_{n}+\operatorname{tg} \gamma_{n}=\frac{\cos \gamma_{n}}{\operatorname{sen} \gamma_{n}}+\frac{\operatorname{sen} \gamma_{n}}{\cos \gamma_{n}}=\frac{\cos ^{2} \gamma_{n}+\operatorname{sen}^{2} \gamma_{n}}{\cos \gamma_{n} \operatorname{sen} \gamma_{n}}=\frac{1}{\cos \gamma_{n} \operatorname{sen} \gamma_{n}}$

Assim, solução para $f$ fica:

$$
\begin{gathered}
f=\sum_{n=1}^{\infty} \frac{3 c^{3} C_{n}}{8 \pi^{2} v^{2} n \omega^{\prime}}\left(\operatorname{sen} \gamma_{n} \cos \gamma_{n} \cos \phi_{n}+\operatorname{sen}^{2} \gamma_{n} \operatorname{sen} \phi_{n}\right)=\sum_{n=1}^{\infty} \frac{3 c^{3} C_{n} \operatorname{sen} \gamma_{n}}{8 \pi^{2} v^{2} n \omega^{\prime}} \cos \left(\phi_{n}-\gamma_{n}\right) \\
f=\frac{3 c^{3}}{16 \pi^{3} v^{2}} \sum_{n=1}^{\infty} \frac{C_{n} T^{v}}{n} \operatorname{sen} \gamma_{n} \cos \left(\frac{2 \pi n}{T^{v}} t+\theta_{n}-\gamma_{n}\right)
\end{gathered}
$$


no qual utilizamos a relação: $\cos \gamma_{n} \cos \phi_{n}+\operatorname{sen} \gamma_{n} \operatorname{sen} \phi_{n}=\cos \left(\phi_{n}-\gamma_{n}\right)$

Como $\sigma$ é pequeno, o valor de cot $\gamma_{n}$ será em geral grande, de modo que sen $\gamma_{n}$ será pequeno, pouco contribuindo então para $f$. Isto só não acontece se $\underline{v \approx n / T^{\prime}=n v^{\prime}}$ (ver expressão de $\cot \gamma_{n}$ ). Assim, apenas os termos $\operatorname{com} n \approx v / v^{\prime}$ precisam ser considerados na expansão de $f$. Podemos reescreve-la como:

$$
f=\frac{3 c^{3}}{16 \pi^{3} v^{3}} \sum C_{n} \operatorname{sen} \gamma_{n} \cos \left(\frac{2 \pi n}{T^{*}} t+\theta_{n}-\gamma_{n}\right)
$$

A expressão para cot $\gamma_{n}$ também pode ser reescrita para esta situação. Escrevendo $v-n / T^{\prime} .=w$, temos:

$$
\cot \gamma_{n} \cong \frac{\pi}{\sigma v^{2}}\left(v^{2}-(v-w)^{2}\right)=\frac{\pi}{\sigma v^{2}}\left(2 v w-w^{2}\right)
$$

Como $w \approx 0$ :

$$
\cot \gamma_{n} \cong \frac{2 \pi}{\sigma v}\left(v-n / T^{\prime}\right)
$$

Uma vez encontrada a expressão para o momento de dipolo $f$, podemos encontrar a energia média do oscilador com freqüência natural de oscilação $v$ :

$$
U_{v}=K \overline{f^{2}}=\frac{16 \pi^{4} v^{3}}{3 c^{3} \sigma} \overline{f^{2}}
$$

Onde a barra indica o valor médio em uma oscilação:

$$
\overline{f^{2}}=\frac{1}{T^{\top}} \int_{0}^{T^{\prime}} f^{2} d t
$$

Então: 


$$
\begin{gathered}
U_{v}=\frac{16 \pi^{4} v^{3}}{3 c^{3} \sigma}\left(\frac{3 c^{3}}{16 \pi^{3} v^{3}}\right)^{2} \times \\
\times \frac{1}{T^{v}} \int_{0}^{T^{\prime}} \sum_{n} \sum_{m} C_{n} C_{m} \operatorname{sen} \gamma_{n} \operatorname{sen} \gamma_{m} \cos \left(\frac{2 \pi n}{T^{\prime}} t-\theta_{n}-\gamma_{n}\right) \cos \left(\frac{2 \pi m}{T^{\prime}} t-\theta_{m}-\gamma_{m}\right)
\end{gathered}
$$

Mas: $\int_{0}^{T^{\prime}} \cos \left(\frac{2 \pi m}{T^{\vee}} t\right) \cos \left(\frac{2 \pi n}{T^{\vee}} t\right)=\frac{T^{V}}{2} \delta_{n m}$ para $n=m \neq 0, \operatorname{com} \delta_{n \mathrm{~m}}$ sendo a função

Delta de Kronecker ${ }^{128}$. Assim:

$$
U_{v}=\frac{3 c^{3}}{32 \pi^{2} \sigma v^{3}} \sum C_{n}{ }^{2} \operatorname{sen}^{2} \gamma_{n}
$$

Chamando $J=\overline{Z^{2}}$ e utilizando o mesmo procedimento anterior para média:

$$
J=\frac{1}{2} \sum C_{n}^{2}
$$

O valor de $J$ é importante, pois ele é proporcional a densidade de energia $\mu$ no interior da cavidade. Novamente pelo eletromagnetismo ${ }^{129}$, a expressão para $\mu$ é:

$$
\mu=\frac{1}{8 \pi}\left(\overline{E^{2}}+\overline{H^{2}}\right)
$$

com $E$ e $H$ representando os campos elétrico e magnético respectivamente.

Como o campo é homogêneo $E_{x}=E_{y}=E_{z}$. Além disso, no vácuo, as componentes do campo elétrico são iguais as do campo magnético ${ }^{130}$.Portanto:

$$
\mu=\frac{1}{8 \pi} 6 \overline{Z^{2}}=\frac{3}{4 \pi} J
$$

\footnotetext{
${ }^{128}$ ARFKEN (1995), p.11

${ }^{129}$ HEALD \& MARION (1995), p. 145

${ }^{130}$ Ibidem p. 173.
} 
Podemos decompor a densidade de energia $\mu$ em termos dependentes da freqüência $\psi$ (utilizamos essa letra para não confundirmos com as freqüências $v$, freqüência natural, e $\checkmark$, utilizada na expansão de $f$ :

$$
\mu=\int_{0}^{\infty} \mu_{\psi} d \psi \quad \text { ou } \quad J=\int_{0}^{\infty} J_{\psi} d \psi \quad \text { com } \quad \mu_{\psi}=\frac{3}{4 \pi} J_{\psi}
$$

Agora, relacionamos as componentes de freqüência de $J$ com as de $U$ através da relação:

$$
J_{\psi}=k_{\psi} U_{\psi}
$$

$\operatorname{com} k_{\psi}$ função de $\psi$.

Lembramos mais uma vez que nesse apêndice desejamos encontrar a relação entre a energia média dos osciladores e a densidade de energia no interior da cavidade de um corpo negro para uma dada freqüência. Ou seja, a relação entre $U_{\psi}$ e $\mu_{\psi}$. Resta-nos assim calcular o valor de $k_{\psi}$.

Comparando as duas expressões para $J$ :

$$
\frac{1}{2} \sum C_{n}{ }^{2}=\frac{3 c^{3}}{32 \pi^{2}} \int_{0}^{\infty} \frac{k_{\psi}}{\sigma \psi^{3}} \sum C_{n}^{2} \operatorname{sen}^{2} \gamma_{n} d \psi
$$

Trocando a ordem da somatória e da integral:

$$
1=\frac{3 c^{3}}{16 \pi^{2}} \int_{0}^{\infty} \frac{k_{\psi}}{\sigma \psi^{3}} \operatorname{sen}^{2} \gamma_{n} d \psi
$$

Como vimos que os termos que precisamos levar em conta são aqueles em que $\psi \approx v \approx n / T^{\prime}$, portanto:

$$
1=\frac{3 c^{3}}{16 \pi^{2}} \frac{k_{v}}{\sigma v^{3}} \int_{0}^{\infty} \operatorname{sen}^{2} \gamma_{n} d \psi
$$


Mas: $\operatorname{sen}^{2} \gamma_{n}=\left(1+\cot ^{2} \gamma_{n}\right)^{-1}$ :

$$
\int_{0}^{\infty} \operatorname{sen}^{2} \gamma_{n} d \psi=\int_{0}^{\infty}\left(1+\cot ^{2} \gamma_{n}\right)^{-1} d \psi=\int_{0}^{\infty}\left(1+\frac{4 \pi^{2}(\psi-v)^{2}}{\sigma^{2} v^{2}}\right)^{-1} d \psi
$$

Fazendo uma troca de variáveis:

$$
\frac{2 \pi(\psi-v)}{\sigma v}=\operatorname{tg} \chi \Rightarrow \psi=\frac{\sigma v}{2 \pi} \operatorname{tg} \chi+v \Rightarrow d \psi=\frac{\sigma v}{2 \pi} \frac{d \chi}{\cos ^{2} \chi}
$$

Para os novos limites de integração:

$$
\begin{gathered}
\psi=\infty \Rightarrow \chi=\frac{\pi}{2} \\
\psi=0 \Rightarrow \operatorname{tg} \chi=-\frac{2 \pi}{\sigma}
\end{gathered}
$$

Como $\sigma$ é pequeno, $\operatorname{tg} \chi$ é grande, de modo que

$$
\begin{gathered}
\psi=0 \Rightarrow \chi \approx-\frac{\pi}{2} \\
\int_{0}^{\infty} \operatorname{sen}^{2} \gamma_{n} d \psi=\frac{\sigma v}{2 \pi} \int_{-\pi / 2}^{\pi / 2} \frac{1}{1+\operatorname{tg}^{2} \chi} \frac{d \chi}{\cos ^{2} \chi}=\frac{\sigma v}{2 \pi} \int_{-\pi / 2}^{\pi / 2} d \chi=\frac{\sigma v}{2}
\end{gathered}
$$

Portanto:

$$
1=\frac{3 c^{3}}{16 \pi^{2}} \frac{k_{v}}{\sigma v^{3}} \frac{\sigma v}{2} \Rightarrow k_{v}=\frac{32 \pi^{2} v^{2}}{3 c^{3}}
$$




$$
J_{v}=\frac{32 \pi^{2} v^{2}}{3 c^{3}} U_{v}
$$

Como $\mu_{v}=\frac{3}{4 \pi} J_{v}$, chegamos na relação entre a energia média dos osciladores e a densidade de energia do campo de radiação para uma freqüência $v$.

$$
\mu_{v}=\frac{8 \pi v^{2}}{c^{3}} U_{v}
$$




\section{Apêndice IV - Análise Combinatória}

Queremos calcular o número de modos em que $P$ quanta de energia podem ser divididos em $N$ osciladores.

Sem o uso de fórmulas prontas da análise combinatorial, podemos fazer o seguinte raciocínio: imaginemos inicialmente que os quanta de energia sejam elementos distinguíveis, rotulando cada um deles por $q_{i}\left(q_{1 \ldots} q_{P}\right)$. O primeiro quanta de energia pode ser colocado em qualquer oscilador. Existem $N$ modos de se fazer isso. Na figura abaixo vemos um exemplo no qual este quanta é colocado no oscilador número 2.

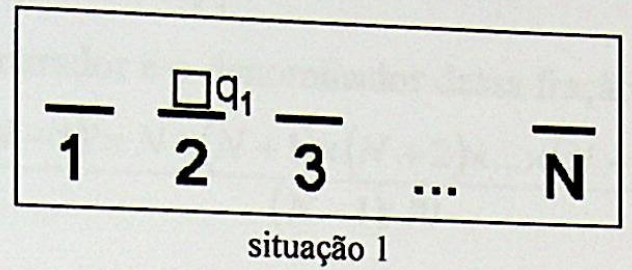

Para colocar o quanta $q_{2}$, podemos escolher qualquer um dos $N-1$ osciladores "vazios" (situação 2), ou ainda escolher o oscilador 2 novamente. Neste último, contudo, existem 2 maneiras possíveis, colocando-o antes ou depois de $q_{1}$ (situações $3 a$ e $3 b$ ).

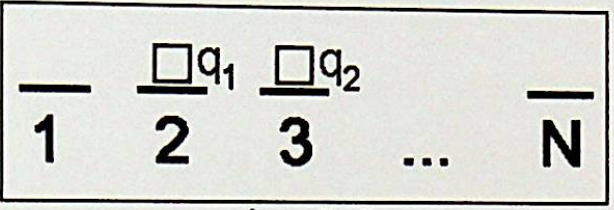

situação 2

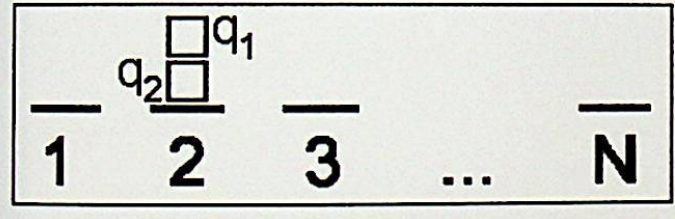

situação $3 a$

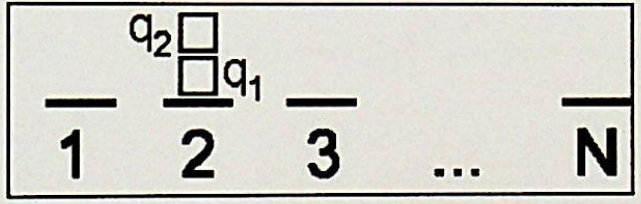

situação $3 b$

Dessa forma, existem $(N-1)+2$ maneiras de colocar o quanta $q_{2}$ nos osciladores, ou seja $N+1$ possibilidades.

Para colocar $q_{3}$, temos que analisar a maneira como $q_{2}$ foi disposto. Na situação 2 , $q_{3}$ pode ser disposto nos $N$-2 osciladores "vazios" ou nos outros dois "ocupados". Em cada um deles, pelo raciocínio anterior, o quanta pode ser colocado de 2 modos, de forma que $o$ número de possibilidades de colocar $q_{3}$ nesse caso é $N+2$.

$\mathrm{Na}$ situação 3, além de posicionar $q_{3}$ nos $N-1$ osciladores "vazios", podemos colocá-lo de três maneiras no oscilador 2 (antes de $q_{1}$, entre $q_{1}$ e $q_{2}$ e após $q_{2}$ ).

Vemos então que em ambos casos existem $N+2$ modos de dispor $q_{3}$. 
140

Continuando o raciocínio, o quanta $q_{4}$ poderá ser disposto de $N+3$ modos, não importando a disposição dos quanta anteriores. Assim, o último quanta $q_{P}$ poderá ser disposto de $N+P-1$ modos.

Portanto, o número total de modos de arranjar todos os quanta será:

$$
N \times(N+1) \times(N+2) \times \ldots \times(N+P-1)
$$

Entretanto, fisicamente, os quanta são indistinguiveis e a permutação entre dois deles não altera o sistema físico. Como existem $P$ ! maneiras de permutar os quanta, 0 número de modos $(W)$ de distribuir os $P$ quanta entre os $N$ osciladores é dado por:

$$
W=\frac{N \times(N+1) \times(N+2) \times \ldots \times(N+P-1)}{P !}
$$

Multiplicando o numerador e o denominador dessa fração por $(N-1)$ !, temos:

$$
W=\frac{(N-1) ! \times N \times(N+1) \times(N+2) \times \ldots \times(N+P-1)}{(N-1) ! P !}
$$

De modo que:

$$
W=\frac{(N+P-1) !}{(N-1) ! P !}
$$




\section{APÊNDICE V - Atividade de estudo e Aplicação}

\section{INSTITUTO DE FÍSICA/UNIVERSIDADE DE SÃO PAULO \\ FMT 405 - Evolução dos Conceitos da Física 06-07/junho/2000 \\ Atividade de estudo e aplicação}

$\mathrm{Na}$ aula de hoje e nas próximas estaremos tratando de um exemplo de "história internalista" da física explorando o tema "radiação do corpo negro", dos antecedentes históricos até a solução apresentada por Max Planck. Nessa tarefa teremos oportunidade de abordar inúmeras citações de textos originais e/ou históricos da física do século XIX, incluindo a íntegra do artigo de Planck, apresentado em Berlin no dia 19/10/1900, que apresentava uma expressão para a função de distribuição de radiação do corpo negro que se ajustava muito bem com as curvas experimentais de emissão então conhecidas. Exploraremos também boa parte do artigo de Planck, apresentado no dia 14/12/1900, onde ele propunha uma interpretação teórica para seu resultado anterior que incluía, pela primeira vez na história da fisica, a hipótese da quantização da energia. Era o nascimento da fisica quântica.

É minha intenção não apenas apresentar um exercício de história da fisica, mas também aproveitar a oportunidade para analisar a apresentação dessa origem da fisica quântica nos livros universitários voltados para a introdução da física moderna e que vocês utilizaram no curso aqui no IFUSP. Desejo também estabelecer uma ligação analítica entre essa história da radiação do corpo negro e as diversas teorias epistemológicas apresentadas nesta disciplina.

Assim proponho que vocês releiam com atenção, anotando todos os detalhes significativos, a apresentação da radiação do corpo negro nesses textos, procurando responder questões do tipo:

1. Quais as principais diferenças entre a apresentação desse tema em "Evolução" e nos textos consultados? Discuta.

2. O que você conclui da utilização do conceito de entropia por Planck?

3. Escolha uma das propostas epistemológicas apresentadas e procure associar seus elementos constitutivos a diferentes passagens da explicação da radiação do corpo negro de Wien a Planck. 
APÊNDICE VI - Trabalhos e avaliações

\section{INSTITUTO DE FÍSICA/UNIVERSIDADE DE SÃO PAULO \\ FMT 405} Evolução dos Conceitos da Física $2^{\circ}$ Trabalho $[T(7,8,9)]^{131}$

06 e 07/julho/2000

1. i. Destaque e comente pelo menos três resultados que podem ser extraídos da análise da forma das curvas de emissão do corpo negro e que levaram vários físicos do final do século XIX a estudarem esse fenômeno com afinco. ii. Comente as diferentes análises teóricas utilizadas para encontrar uma função de distribuição para a radiação do corpo negro. Destaque particularmente os trabalhos que vão até a publicação do artigo de Planck de outubro de 1900.

2. i. Comparando o artigo de Max Planck de 14 de dezembro de 1900 com o artigo de 19 de outubro do mesmo ano, comente pelo menos duas contribuições físicas importantes que ele acrescentou no segundo artigo. ii. Em 1905, Einstein, aproveitando a característica discreta de energia sugerida por Planck, introduzia seu "quantum de ação" para formular uma explicação do efeito fotoelétrico. Como Planck reagiu nos anos seguintes às duas concepções quânticas surgidas?

3. i. Compare a apresentação do estudo da radiação do corpo negro do texto de "Evolução" com o tratamento de algum livro didático que você tenha estudado. Pontue as diferenças e semelhanças. ii. Escolha uma das propostas epistemológicas estudadas exemplificando suas principais concepções com o estudo da radiação do corpo negro.

\footnotetext{
${ }^{131}$ Esse trabalho continha mais uma questão que foi omitida por não tratar sobre o PRCN.
} 


\section{INSTITUTO DE FÍSICA/UNIVERSIDADE DE SÃO PAULO FMT 405 - EVOLUÇÃO DOS CONCEITOS DA FÍSICA $2^{\mathrm{a}}$ avaliação/diurno - 04 de agosto $2000^{132}$}

$2^{\text {a }}$ questão: i. No estudo da radiação do corpo negro foram importantes as seguintes contribuições experimentais e/ou teóricas: 1. lei de Kirchhoff da radiação térmica; 2. relação entre a radiância total e a temperatura absoluta; 3. teorema da equipartição de energia; 4. Forma das curvas de emissão de radiação, entre outras. Destaque e comente duas dessas contribuições.

ii. Comente diferentes análises teóricas utilizadas para encontrar uma função de distribuição para a radiação do corpo negro. Destaque particularmente os trabalhos que vão até a publicação do artigo de Planck de dezembro de 1900.

$3^{\text {a }}$ questão: i. Compare a apresentação do estudo da radiação do corpo das aulas de "Evolução" com o tratamento de algum livro didático que você tenha estudado. Pontue as diferenças e semelhanças.

ii. Escolha uma das propostas epistemológicas estudadas (Bacon, Popper, Kuhn, Feyerabend e Bachelard) exemplificando suas principais concepções com o estudo da radiação do corpo negro.

\section{INSTITUTO DE FÍSICA/UNIVERSIDADE DE SÃO PAULO FMT 405 - EVOLUÇÃO DOS CONCEITOS DA FÍSICA}

\section{Avaliação substitutiva - agosto 2000}

$2^{\text {a }}$ questão: i. Em geral os textos didáticos de física moderna, para simplificar a apresentação da lei da radiação de Planck, dizem que ele a obteve por interpolação da lei de Wien com a lei de Rayleigh-Jeans. Comente esse procedimento didático, com base no artigo de Planck de 19/10/1900 no qual ele formula a sua lei.

ii. Planck dedicou oito semanas de intenso trabalho no intento de transformar o feliz "chute" de seu artigo de outubro em algo que tivesse significação física. $O$ resultado foi publicado no artigo de 19/12/1900, que é considerado o marco do nascimento da teoria quântica. Comente o que Planck apresenta nesse seu artigo.

${ }^{132}$ A primeira questão da prova foi omitida pois não se relacionava ao nosso objeto de estudo. A prova continha três questões, mas era pedido ao aluno a resolução de apenas duas questões quaisquer. 0 mesmo vale para a prova substitutiva. 